\title{
Movilidad de ingresos de corto plazo en América Latina 2002-2015
}

Martin Trombetta

Tesis Doctoral

Doctorado en Economía

Facultad de Ciencias Económicas

Universidad Nacional de La Plata

Director de Tesis: Dra. Roxana Maurizio 


\section{Agradecimientos}

A mis padres, que me inculcaron desde corta edad la pasión por la formación y el conocimiento científico.

A Susana Pesis, Carlos Bermani, Fernando Farji, Ariel Slipak y Susana Hernández, con quienes di mis primeros pasos en el mundo de la docencia universitaria, que al día de hoy me apasiona y maravilla tanto como el primer día.

A Juana Brufman y a la memoria de Heriberto Urbisaia, con quienes comencé a descubrir el mundo de la investigación científica.

A Martín González Rozada, director de tesis de maestría y maestro en el arte de la investigación aplicada en temas sociales.

A Roxana Maurizio y Luis Beccaria, directores ambos de este trabajo de tesis doctoral y de mi trabajo como becario en el Área de Economía de la Universidad Nacional de General Sarmiento.

A Guido Porto, Julio César Neffa y Pedro Moncarz, jurados de esta tesis doctoral, por sus evaluaciones, críticas y comentarios, indispensables para seguir creciendo como profesional.

A Leonardo Gasparini, Mariana Marchionni, Walter Cont, Christian Ruzzier y Walter Sosa Escudero, por sus comentarios, críticas, aportes y por incentivarme siempre a llevar adelante este trabajo.

A Manuel Espro, Gustavo Vázquez, Francisca Pereyra, Ariela Micha, Stefanía Silva, Ana Laura Fernández, Ana Paula Monsalvo y Sonia Filipetto, compañeros de trabajo del Área de Economía, parte fundamental de todo este proceso.

A Joaquín Farina y Antonio Rosselló, colegas y compañeros de lucha.

A Pablo Barreto, Facundo Pietra, Andrés Gibson, Federico López Brusau, Diego Flexer, Ignacio Ibarra, Frances Gaska, Walter Bettinelli, Guido Lapajufker y Juan Manuel Pico, por los grandes años de lucha en la Facultad de Ciencias Económicas de la Universidad de Buenos Aires.

A Matías Escudero, Gabriela Cugat, Marcos Dinerstein, Juan Martín Morón, Samuel Kaplan y demás compañeros de la Maestría en Economía de la Universidad Torcuato Di Tella, donde todos empezamos un gran camino profesional y personal.

A Leonardo Mastronardi, Alejandro Calabria, Sergio Rottenschweiler, Alexis Pirchio y demás compañeros del Departamento de Economía de la Universidad Argentina de la Empresa, donde soy feliz de ser profesor.

A Fernando Delbianco, María María Ibáñez Martín, Pablo Monterrubianesi, María Celeste Chaz Sardi, Mara Rojas, Rodrigo Pérez Artica, Valentina Viego, Gustavo Burachik y demás amigos del Departamento de Economía de la Universidad Nacional del Sur. 
A Cecilia Velázquez, Andrés César, Jorge Puig, Alina Machado, Lucía Echeverría, Cecilia Parada, Diego Campoy, Analía Calero y demás compañeros del doctorado, con quienes compartimos todo lo que esta experiencia significa a lo largo de los años.

A los grandes amigos que me ha dado esta profesión: Nicolás Ajzenman, Leandro Mora Alfonsín, Ariel Setton, Martín Kalos, Daniel Schteingart, Federico González Rouco, Gonzalo Rondinone, Leandro Laguía, Isabel Sicardi, Marina Alonso, Guido Ianni, Leandro Benítez. Todos ellos me acompañaron de diversas maneras en esta travesía.

A los amigos de toda la vida: José, Pablo, Pato, Emi, Lean, Emi, Pelufo, Martín, Lean, Franco, Pipo, Juan, Salta, Seba. Por bancarme siempre en todas.

Y a Patsy, por todo. 


\section{Índice}

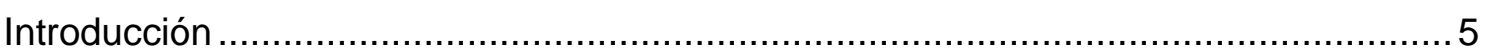

Capítulo 1: Movilidad de ingresos y desigualdad en Argentina en los 2000 ...............26

Capítulo 2: Inestabilidad de ingresos en América Latina en los $2000 \ldots \ldots \ldots \ldots \ldots \ldots \ldots \ldots . . . . . . . . . . .50$

Capítulo 3: Movilidad de ingresos y movimientos demográficos en América Latina .... 75 


\section{Introducción}

El análisis de la movilidad de ingresos ha capturado el interés de una parte creciente de la literatura económica a partir de las últimas décadas del siglo XX. Inicialmente, se trató de una extensión del marco de análisis de la distribución personal del ingreso basado en el trabajo con encuestas de hogares; a medida que surgieron encuestas con estructura de panel, es decir, aquellas que relevan a un determinado conjunto de individuos en varias ocasiones a lo largo del tiempo ${ }^{1}$, se dio paso al análisis de los cambios en sus ingresos en el tiempo.

Actualmente, el estudio de la movilidad de ingresos se ha constituido como una línea de investigación relativamente independiente, cuya idea fundadora es que el análisis de información de tipo dinámico permite arribar a conclusiones novedosas que enriquecen profundamente el análisis de fuentes de tipo estático. Resulta claro que el bienestar de los individuos no depende exclusivamente de su ingreso corriente sino del flujo de ingresos que percibirán en el futuro. Mientras que el trabajo con bases de datos de tipo corte transversal solo ilustra la "fotografía" de un momento particular del tiempo, el análisis de datos de panel permite evaluar la evolución de las variables de interés en el tiempo y de este modo ofrece una caracterización mucho más precisa de las condiciones de vida de los individuos que los análisis tradicionales.

Sin embargo, un rasgo característico de esta literatura es que actualmente carece de un marco de análisis unificado, sea en términos teóricos o empíricos. Una cita popular de Fields y Ok (1999b) indica que "existe, de hecho, una considerable literatura sobre cómo medir movilidad de ingresos. Pero, a diferencia de las teorías de medición de desigualdad de ingresos y pobreza económica, la literatura sobre movilidad no provee un discurso unificado de análisis. Esto puede deberse a que la propia noción de movilidad de ingresos no está bien definida; distintos estudios se concentran en distintos aspectos de este fenómeno multifacético. En todo caso, parece claro que un considerable grado de confusión confronta a los recién llegados al campo". En efecto, una amplia literatura sobre medidas teóricas variadas convive con una aún más extensa literatura aplicada donde la metodología y la estrategia de medición varían sensiblemente de un trabajo al otro.

En esta introducción, trazamos las líneas generales de trabajo para el resto de la tesis doctoral. El objetivo general es repasar los distintos abordajes teóricos y metodo-

\footnotetext{
${ }^{1}$ La encuesta más antigua de este tipo (y, por lo tanto, la más utilizada en la literatura) es la Panel Study of Income Dynamics, realizada por la Universidad de Michigan en Estados Unidos desde 1968. La British Panel Household Survey realizada por la Universidad de Essex en Gran Bretaña desde 1991 también ha recibido considerable atención.
} 
lógicos existentes con el fin de enmarcar nuestro trabajo en la literatura especializada. La sección 1 discute el concepto de movilidad de ingresos, su origen en la literatura y las distintas definiciones e interpretaciones que este ha recibido. La sección 2 repasa las distintas medidas de movilidad existentes, divididas en dos enfoques generales. La sección 3 analiza las características particulares de América Latina en los 2000 y de la información estadística disponible para delimitar las posibilidades de este estudio. Finalmente, la sección 4 traza una hoja de ruta para los capítulos restantes.

\section{Movilidad de ingresos: definiciones e interpretaciones}

Una de las referencias más antiguas y célebres a la importancia de la movilidad de ingresos se debe a Friedman (1962): "Considérese dos sociedades que tienen la misma distribución del ingreso anual. En una existe gran movilidad y cambio de manera que la posición de familias particulares en la jerarquía de ingresos varía de año a año. En la otra, existe gran rigidez de manera que cada familia se mantiene en la misma posición año tras año. Claramente, en cualquier sentido relevante, la segunda sería la sociedad más desigual”. Otra referencia clásica, aunque más reciente, se encuentra en Krugman (1992): "Si la movilidad de ingresos fuera muy alta, el grado de desigualdad en cualquier año dado sería poco importante ya que la distribución del ingreso intertemporal sería muy equitativa".

Ambas ideas preliminares sobre movilidad de ingresos la conciben como un proceso de reducción intertemporal de desigualdades. Gardiner y Hills (1999) sintetizan esta noción en la metáfora de la "lotería celestial", de acuerdo a la siguiente lógica: "Cada año un bolillero celestial de determinación del ingreso es girado y, dependiendo de los números que salen, cada uno de nosotros deviene aleatoriamente en beneficiario de planes sociales o en multimillonario. Al año siguiente, la suerte se echa nuevamente. En este tipo de mundo, una gran "pobreza" sería un fenómeno excepcional. De ser así, quizás no debamos preocuparnos tanto por el aumento en la desigualdad. La diferencia entre ganadores y perdedores puede haber crecido, pero dado que todos tenemos la misma probabilidad de ser ganadores o perdedores, no importa mucho. En particular, siempre que ahorremos o nos aseguremos en los buenos tiempos, podemos lidiar con los malos a menos que seamos particularmente desafortunados".

En efecto, esta concepción de la movilidad de ingresos recorre buena parte de la literatura, incluyendo trabajos clásicos como Atkinson, Bourguinon y Morrison (1988) y Shorrocks (1978b). Sin embargo, otras varias definiciones o interpretaciones del fenómeno han sido propuestas y han recibido considerable atención en otros trabajos. La variada gama de aportes condujo a una literatura amplia y poco sistemática, lo que 
motivó la escritura de algunos surveys. El más clásico posiblemente corresponda a Fields y Ok (1999b), aunque más recientemente encontramos también los aportes de Ayala y Sastre (2008) y, en particular, Jantti y Jenkins (2015). En todos ellos se repasa tanto las cuestiones teóricas como las estrategias de medición disponibles para abordar la movilidad de ingresos.

Existe un consenso amplio en torno a la idea de que la movilidad de ingresos es intrínsecamente un concepto multifacético que incluye más de una dimensión posible. En otro trabajo clásico y ampliamente citado, Fields (2006) distingue 6 aspectos distintos de la movilidad de ingresos: independencia temporal, movimiento posicional, movimiento de participaciones, flujo de ingresos (también llamado "inestabilidad"), movimiento direccional e igualación de los ingresos de largo plazo. El autor presenta una medida específica para cada concepto de movilidad, completando así la idea de que cada concepto de movilidad amerita un tratamiento diferente.

Algunos de los conceptos de movilidad propuestos por Fields están vinculados a la distribución del ingreso mientras que otros no. Dado que esta distinción es frecuente, la literatura habitualmente distingue entre movilidad absoluta (aquella que no necesariamente implica cambios en la distribución del ingreso) y movilidad de orden (aqueIla que consiste precisamente en cambios distributivos). De este modo, el crecimiento económico necesariamente implica movilidad absoluta aunque no necesariamente de orden; en cambio, transferencias de ingresos de ricos a pobres motivadas por políticas públicas implican movilidad de orden potencialmente grande aun si en términos de movilidad absoluta son reducidas.

Una idea frecuentemente empleada en este contexto es la metáfora del hotel de Schumpeter $(1955)^{2}$. En esta analogía, se asume que la distribución del ingreso puede equipararse a la distribución de habitaciones en un hotel. Cada piso en el hotel representa una jerarquía social y los individuos ocupan habitaciones en cada una de ellas. Se dice que existe movilidad de intercambio cuando individuos que ocupan habitaciones en pisos bajos cambian lugares con los que ocupan habitaciones en pisos altos, ceteris paribus la estructura del hotel. En cambio, se llama movilidad estructural al cambio en la estructura del hotel, es decir, en la cantidad de habitaciones en cada piso. Van Kerm (2004) agrega que esta última también puede descomponerse en un "efecto crecimiento" y un "efecto dispersión" y propone una metodología para realizar esa descomposición en la práctica.

\footnotetext{
${ }^{2}$ Citada, por ejemplo, en Fields (2006).
} 
Otra idea relevante asociada a esta concepción de la movilidad de ingresos es la noción de convergencia de ingresos. Existe convergencia en los ingresos si las diferencias iniciales de ingresos entre individuos se reducen a lo largo del tiempo. En otras palabras, la velocidad de convergencia de una sociedad es una medida del ritmo al cual se reducen las desigualdades iniciales existentes en ella. Desde esta perspectiva, sociedades con mayor movilidad de ingresos deberían presentar velocidades de convergencia mayores y viceversa. La existencia de convergencia y su velocidad han sido analizadas en numerosos trabajos empíricos, entre los que destacan Antman y McKenzie (2007), Cuesta, Ñopo y Pizzolitto (2011), Fields et al. (2003a) y Fields et al. (2015).

La popular visión de la movilidad de ingresos como proceso de reducción intertemporal de las desigualdades ha respaldado una valoración positiva de la misma en términos normativos. Sin embargo, queda claro en la distinción realizada por Fields que no todos los aspectos mencionados de la movilidad de ingresos son socialmente deseables. En particular, la idea de "flujo de ingresos" hace referencia a la existencia de fluctuaciones temporales en el sendero de los ingresos recibidos por los individuos (independientemente de todo lo demás). Existe consenso en la literatura en que los agentes sienten aversión por este tipo de fluctuaciones, es decir, que disfrutarían de mayor bienestar si recibieran un flujo temporal suave de ingreso en lugar de uno volátil (para un mismo nivel de ingreso medio descontado) ${ }^{3}$. Esto conduce a la conclusión de que la movilidad de ingresos tiene un componente negativo que puede en principio ser mayor o menor que su efecto positivo.

El problema de la variabilidad de ingresos en el tiempo ha recibido considerable atención en las últimas dos décadas. Aquí el grado de heterogeneidad es aún mayor ya que ni siquiera existe consenso en cómo denominar a este problema particular. Algunos autores emulan a Fields y utilizan el término "inestabilidad de ingresos" (por ejemplo, Aristei y Perugini (2015), Bartels y Bonke (2015), Cameron y Tracy (1998), Dynarski y Gruber (1997), Haider (2001), Moffit y Gottschalk (2012), Rohde, Tang y Rao (2014) y Stevens (2001)). Otros hablan de "volatilidad de ingresos" o "inseguridad de ingresos" (Cappellari y Jenkins (2014), Cantó y Ruiz (2015), Celik et al. (2012), Dahl, DeLeire y Schwabish (2011), Dynan, Elmendorf y Sichel (2012), Hacker et al.

\footnotetext{
${ }^{3}$ Esta idea guarda similitud con la noción tradicional de aversión al riesgo. Un agente averso al riesgo es aquel que prefiere un determinado nivel de ingreso cierto a una lotería que asigna probabilidades positivas a ingresos mayores pero también a ingresos menores y que otorga idéntico valor esperado. De igual modo, un agente averso a la fluctuación intertemporal del ingreso es aquel que prefiere recibir una suma fija en cada período en lugar de un flujo que otorga idéntico valor esperado pero con varianza positiva.
} 
(2014), Hardy y Ziliak (2014), Shin y Solon (2011), Sologon y Donoghue (2014), Ziliak, Hardy y Bollinger (2011)). Finalmente, el concepto de "riesgo de ingresos" también ha sido mencionado (Nichols y Rehm (2014)).

Haider (2001) señala que la inestabilidad de ingresos podría ser neutral en términos de bienestar si existieran mercados perfectos de crédito a los que los agentes pudieran recurrir cuando su ingreso se reduce bruscamente. Sin embargo, el autor agrega que este supuesto es poco realista y que, en la práctica, la existencia de restricciones de liquidez explica el carácter socialmente negativo de la inestabilidad de ingresos. Por otra parte, Hacker et al. (2014) agregan otros factores: el sesgo cognitivo conocido como "aversión a las pérdidas" (que vuelve a los agentes más sensibles a cambios negativos que a cambios positivos); la dificultad de los agentes para prever contingencias negativas y, finalmente, los mercados incompletos de seguros, que limitan la capacidad de asegurarse contra dichas contingencias. La Organización Internacional del Trabajo (OIT) incluye la "seguridad de ingresos" como un componente de la noción más general de "seguridad vinculada al trabajo" y la define como "un adecuado ingreso corriente, percibido y esperado, ya sea en forma de salario o de seguridad social y otros beneficios"4.

Diversos trabajos han intentado proveer un marco teórico general a partir del cual analizar la movilidad de ingresos y su vinculación con el bienestar social. Una de las referencias seminales más antiguas corresponde a un trabajo no publicado de Kanbur y Stiglitz (1986), que introduce la movilidad intergeneracional de ingresos en un modelo de dinastías cuya evolución en el tiempo se asume caracterizada por matrices de transición entre estados (donde cada estado podría representar un nivel absoluto o relativo de ingresos). Los autores muestran que si se utilizan matrices de transición de cuantiles de ingresos, se asume que la economía se encuentra en estado estacionario y que la función de bienestar social es aditivamente separable en el tiempo y entre agentes, entonces la movilidad de ingresos resulta neutral para el bienestar social (un resultado similar al alcanzado por Atkinson y Bourguignon (1982) al trabajar con distribuciones de ingreso multidimensionales). En otras palabras, el interés por la movilidad de ingresos debe partir de la violación de alguno de esos supuestos. En particular, el supuesto de aversión a la fluctuación intertemporal del ingreso indica que el bienestar social debe ser una función cóncava del vector de ingresos recibido.

Otros autores han ensayado enfoques alternativos. Por ejemplo, Benabou y Ok (2001) han trabajado sobre lo que podemos llamar la "analogía fiscal", es decir, la idea

\footnotetext{
${ }^{4}$ Citado en Sologon y Donoghue (2014).
} 
de que la movilidad puede ser concebida como un proceso de transformación entre distribuciones marginales (estáticas) del ingreso y como tal, puede ser analizada en términos de progresividad y regresividad, como se estila con las políticas fiscales (que también transforman un vector de ingreso bruto en otro vector de ingreso neto). Aunque algunos autores la consideran atractiva, esta visión del problema ha recibido ciertas críticas, por ejemplo en Fields (2010).

En definitiva, resulta claro que no contamos con una definición única de movilidad de ingresos y, naturalmente, esto conduce a diversas valoraciones normativas del fenómeno no necesariamente excluyentes entre sí. En la sección siguiente analizamos las diversas medidas empíricas que se han propuesto y utilizado en la literatura y discutimos su vínculo con los elementos analizados hasta aquí.

\section{Medición de la movilidad}

La mayoría de las medidas de movilidad propuestas en la literatura se diferencian en dos dimensiones fundamentales. En primer lugar, difieren en el elemento que utilizan para describir el movimiento observado: mientras algunas medidas parten de los vectores de ingresos individuales observados en cada período, otras optan por caracterizar el movimiento a partir de una matriz de transición de cuantiles construida a partir de esos vectores (lo que a veces se denomina "enfoque markoviano") ${ }^{5}$. Por otro lado, no existe una única forma de proceder a la hora de construir la medida a utilizar. En líneas generales, los trabajos se dividen entre aquellos que realizan un desarrollo axiomático (es decir, definen un conjunto de axiomas que debe satisfacer una "buena medida" y luego caracterizan la clase de medidas que verifica esos axiomas) y los que apelan a un enfoque welfarista (eligen una función de bienestar social y luego caracterizan medidas de movilidad compatibles con esa función) ${ }^{6}$.

A su vez, la movilidad capturada por cada medida puede ser absoluta, de orden o alguna combinación de ambas. Por otra parte, algunos autores, al definir medidas, prefieren recurrir a la analogía del hotel de Schumpeter y distinguir movilidad estructu-

\footnotetext{
${ }^{5}$ En algunos trabajos, tanto teóricos como empíricos, se admite el uso de matrices de transición entre estados que no necesariamente representan cuantiles de distribuciones de ingresos sino que pueden corresponder a "niveles de ingresos", "clases sociales" u otras categorías similares, en línea con la literatura sociológica clásica centrada en la movilidad social (véase, por ejemplo, Ginsberg (1929) o Praiss (1955)). En esos casos, las matrices utilizadas deben ser estocásticas, mientras que las matrices de transición de cuantiles deben ser biestocásticas, condición más restrictiva. Sin embargo, esta distinción no resulta central para el desarrollo de medidas de movilidad de modo que la ignoraremos.

${ }^{6}$ Tsui (2009) muestra que, independientemente de que se adopte un enfoque axiomático o welfarista, el trabajo con matrices de transición o con vectores de ingresos conduce a idénticas conclusiones bajo ciertas condiciones
} 
ral de movilidad de intercambio. En definitiva, la variedad existente es considerable. A continuación repasamos brevemente los aportes principales y destacamos algunas de sus características. Para un análisis más detallado de muchas de las medidas mencionadas, se puede consultar Jantti y Jenkins (2015).

\subsection{El enfoque axiomático}

La primera formulación axiomática de una medida de movilidad de ingresos se debe a Shorrocks (1978), que formula 4 axiomas intuitivos sobre matrices de transición (un axioma de normalización, uno de monotonicidad y dos que definen casos extremos). Esta axiomática inicial resulta inconsistente debido a lo que es esencialmente un problema conceptual: no resulta claro si el caso de independencia del origen (mismo vector de probabilidades a los estados finales independientemente del estado inicial) debe ser considerado más o menos "móvil" que el de reversión total (cada agente transita con certeza hacia un estado inverso a aquel del cual partió).

Tanto la independencia del origen como la reversión total representan casos extremos de movilidad, solo que el concepto de movilidad es distinto en cada caso. El problema de esta axiomática inicial es que no permite diferenciar un concepto del otro, por ende conduce a una inconsistencia. Sin embargo, Shorrocks nota que esta puede ser evitada si se excluyen del análisis matrices de transición "extremas" ya que, en general, ambos conceptos de movilidad coinciden: mayor independencia del origen implica mayor reversión para las matrices "empíricamente relevantes". En consecuencia, la solución que el autor propone consiste en reducir el conjunto de matrices de transición posibles, eliminando aquellas que representan "casos extremos". Así define lo que actualmente conocemos como el índice de una traza, para una matriz de transición $P$ entre $n$ cuantiles:

$$
\widehat{M}(P)=\frac{n-\operatorname{tr}(P)}{n-1}
$$

Este indicador ha recibido considerable uso en la literatura, tanto en contextos intrageneracionales como intergeneracionales. Se trata de una medida de movilidad de orden en la medida en que solo permite analizar cambios en la distribución del ingreso (rasgo que caracteriza a todas las medidas que se basan en matrices de transición).

Más recientemente, Fields y Ok se han destacado por desarrollar dos axiomáticas distintas, cada una de las cuales da origen a una medida particular de amplio uso. La primera axiomática corresponde a Fields y Ok (1996) y su característica fundamental es que incluye un axioma de invariancia a traslaciones. Esto conduce a una medida 
de movilidad construida a partir de variaciones absolutas en los niveles de ingreso individual, que además satisface ciertos requisitos de consistencia y descomponibilidad. Siendo $y_{1}$ e $y_{2}$ los vectores de ingresos en los períodos inicial y final respectivamente y $n$ el tamaño de la población, la medida obtenida viene dada por:

$$
d\left(y_{1}, y_{2}\right)=\frac{1}{n} \sum_{i=1}^{n}\left|y_{2 i}-y_{1 i}\right|
$$

Mitra y Ok (1998) extienden esta medida y muestran que es compatible con un ordenamiento parcial de pares de vectores de ingresos, implementable empíricamente a partir de una regla de cálculo simple. Dardanoni (1993) y D'Agostino y Dardanoni (2009) realizan un desarrollo similar y también proponen una medida de movilidad compatible con un ordenamiento parcial pero utilizando matrices de transición (y con ciertas diferencias conceptuales en los axiomas formulados).

A pesar de la relevancia de esta medida, el trabajo con variaciones absolutas de ingresos individuales ha recibido cierta crítica en la literatura. Posiblemente en virtud de estas críticas es que los autores desarrollan una segunda axiomática en Fields y Ok (1999a), donde el axioma de invariancia a traslaciones es reemplazado por uno de invariancia a la escala, lo que conduce a una medida de movilidad basada en la agregación de cambios relativos en los niveles de ingreso individual. Asimismo se incluyen nuevamente condiciones de consistencia y descomponibilidad. Esto ha dado lugar a una de las medidas de uso más general en la literatura:

$$
m\left(y_{1}, y_{2}\right)=\frac{1}{n} \sum_{i=1}^{n}\left|\ln y_{2 i}-\ln y_{1 i}\right|
$$

La popularidad de este indicador se debe a varias virtudes. En primer lugar, la concepción de la movilidad absoluta como la agregación de los cambios proporcionales en ingresos experimentados por individuos $u$ hogares ha resultado bastante convincente para muchos investigadores. En segundo lugar, porque aparece como una medida natural para captar el tamaño de la inestabilidad de los ingresos en ventanas temporales cortas. Finalmente, porque los autores muestran que es posible descomponer $m$ en un "efecto crecimiento" (aumento del ingreso medio en el tiempo) y un "efecto transferencia" (cambios distributivos entre individuos para un ingreso medio dado), que permite ahondar en la caracterización de la movilidad observada al separar dos de sus facetas más relevantes. 
También encontramos en la literatura otras formulaciones axiomáticas relevantes, aunque su uso no sea tan amplio. Cowell (1985) propone una axiomática para medidas de cambios en distribuciones del ingreso e indica que la movilidad de ingresos puede ser estudiada en este marco. Nuevamente se arriba a una medida de movilidad absoluta construida a partir de cambios en niveles de ingreso individual en cada momento del tiempo. Cowell y Flachaire (2011) generalizan estos aportes para llegar a una medida axiomática de movilidad entre estados que resulta algo más flexible, por ejemplo porque puede ser aplicada tanto sobre vectores de ingresos como sobre matrices de transición.

Algunas medidas capturan una definición más acotada o específica de movilidad de ingresos. Schluter y Van de Gaer (2011) desarrollan una axiomática para medidas de movilidad estructural ascendente construidas a partir de vectores de ingresos. Los autores muestran que muchas de las medidas existentes en la literatura (por ejemplo, las de Fields y Ok) satisfacen algunos de los axiomas elegidos pero no otros y proponen una medida propia que satisface todos.

Por último, Bossert y D’Ambrosio (2013) proponen una axiomática para la medición de la inseguridad económica, concepto que no es exactamente equivalente a inseguridad de ingresos (ni a otros conceptos de movilidad de ingresos) aunque guarda cierta similitud. El objeto del que parte este trabajo es el flujo de riqueza de un individuo, el cual puede equipararse a un flujo de ingreso siempre que se provea (o se acepte una convención sobre) un valor inicial. Por lo tanto, la medida que proveen los autores puede ser aplicada de manera directa al análisis de la movilidad de ingresos entendida como inseguridad.

\subsection{El enfoque de bienestar}

La economía del bienestar provee un marco de análisis donde la medición de la movilidad de ingresos puede ser abordada de manera natural. El enfoque consiste en definir una función de bienestar social que surge de agregar niveles individuales de utilidad (lo que implica necesariamente una visión de la utilidad que no sea puramente ordinal). A continuación, la movilidad puede ser introducida de diversas maneras; en general, si la función de bienestar social depende de los flujos de ingresos de los agentes, el grado de movilidad necesariamente afectará el bienestar social, aunque no es evidente a priori que esta relación deba ser monótona. Mayor movilidad podría conducir a mayor o menor bienestar dependiendo del punto de partida o bien de lo que se entienda por mayor movilidad. 
Las funciones de bienestar social no son incompatibles con resultados obtenidos a partir de desarrollos axiomáticos. Por ejemplo, la medida de Fields y Ok (1999a) puede ser interpretada como una medida welfarista de bienestar si se asume que la función logaritmo representa las preferencias de los agentes. Sin embargo, otros autores han preferido otros abordajes para alcanzar medidas de movilidad de ingresos a partir de funciones de bienestar social. A continuación repasamos los principales aportes.

King (1983) propone una estrategia para construir un índice de movilidad basado en un aporte original de Atkinson (1970), un texto pionero en la literatura sobre desigualdad. En ese trabajo, Atkinson propone un índice para medir la desigualdad de una distribución del ingreso que consiste en calcular el nivel de ingreso equitativamente distribuido que proveería el mismo nivel de bienestar social que la actual distribución. Si asumimos, como es habitual, que la desigualdad reduce el bienestar social, entonces este nivel de ingreso equitativo será inferior a la media de la distribución considerada. El ratio entre el ingreso equitativo y la media de la distribución puede ser utilizado para calcular cuál es el nivel de ingreso que la sociedad requeriría para alcanzar el mismo nivel de bienestar, suponiendo que las desigualdades distributivas fueran eliminadas. King propone una adaptación de este procedimiento al problema específico de la movilidad de ingresos, en base a la idea de la movilidad concebida como una forma de desigualdad intertemporal.

Para vectores de ingresos $\left(y_{1}, y_{2}\right)$, King define $z_{i}$ como el ingreso que el i-ésimo agente obtendría en el período final si su posición en la distribución no se alterara. Entonces la función de bienestar social $W$ puede escribirse $W\left(y_{1}, y_{2}\right)=w\left(y_{1}, s\right)$ donde $s$ es tal que:

$$
s_{i}=\frac{\left|z_{i}-y_{i}\right|}{\mu\left(y_{2}\right)}
$$

Analizando solo la movilidad de orden, el nivel mínimo de movilidad se alcanza cuando $s=(0, \ldots, 0)$. En ese caso, se define el valor $\theta\left(y_{1}, y_{2}\right)$ que satisface $w\left(\theta\left(y_{1}, y_{2}\right) y_{1},(0, \ldots, 0)\right)=w\left(y_{1}, s\right)$. En palabras, $\theta\left(y_{1}, y_{2}\right)$ es el factor de escala del ingreso futuro que produciría el mismo nivel de bienestar suponiendo que no hubiera cambios de orden en la distribución. Bajo supuestos habituales, es claro que $\theta\left(y_{1}, y_{2}\right) \geq 1$. En consecuencia, King elabora un índice de movilidad, en analogía al índice de Atkinson de desigualdad: 


$$
M\left(y_{1}, y_{2}\right)=1-\frac{1}{\theta\left(y_{1}, y_{2}\right)}
$$

$M\left(y_{1}, y_{2}\right)$ mide la fracción de ingreso futuro que la sociedad estaría dispuesta a sacrificar para obtener el nivel de movilidad actual, vis-à-vis un escenario de absoluta inmovilidad. Este índice provee entonces una medida sencilla de interpretar, aunque es propicio insistir en que solo captura la movilidad de orden.

El paso final consiste en elegir una función de bienestar social, lo que naturalmente implica introducir supuestos normativos. King utiliza una forma funcional particular, mientras que Chakravarty (1984) propone algunas alternativas. Por su parte, Chakravarty, Dutta y Weymark (1985) analizan un camino similar aunque con una diferencia significativa en la definición de plena inmovilidad: mientras que en el índice de King este escenario corresponde a la no modificación de la posición de cada individuo en la distribución, Chakravarty, Dutta y Weymark consideran como la situación de mínima movilidad aquella donde la proporción del ingreso total que corresponde a cada individuo se mantiene constante en el tiempo. Esto conduce a un índice diferente pero de interpretación similar.

En un trabajo muy relevante, Shorrocks (1978b) propone una medida de movilidad de ingresos que ha resultado muy popular en la literatura empírica. Partiendo de la noción de movilidad como un proceso de reducción intertemporal de las desigualdades, Shorrocks propone comparar la desigualdad observada en un momento del tiempo con la desigualdad promedio a lo largo de una ventana temporal dada. Esta medida puede calcularse sobre una ventana temporal de cualquier duración, de modo tal que para vectores de ingresos $\left(y_{1}, \ldots, y_{T}\right)$ y una medida de desigualdad $I$ (habitualmente, el índice de Gini o el de Theil), la expresión viene dada por:

$$
M=1-\frac{I(\bar{y})}{\sum_{t=1}^{T} w_{t} I\left(y_{t}\right)}
$$

Donde $\bar{y}$ es el vector de ingreso promedio temporal de cada individuo y $w_{t}=$ $\mu\left(y_{t}\right) / \mu(\bar{y})$. A pesar de no estar derivado explícitamente de una función de bienestar social, Shorrocks da a este índice una interpretación welfarista y lo utiliza para calcular la ganancia de bienestar generada por la movilidad, en términos de reducción de la desigualdad. También es posible vincular esta metodología al enfoque axiomático: 
cualquier conjunto de axiomas que justifique la interpretación normativa de la medida de desigualdad $I$ habilita la misma interpretación para la medida de Shorrocks ${ }^{7}$.

Se puede argumentar que el índice de Shorrocks toma como referencia una economía de agentes idénticos, sin shocks idiosincráticos individuales que afecten el proceso de ingresos de cada individuo. En ausencia de este tipo de incertidumbre, la movilidad de ingresos necesariamente debería eliminar cualquier desigualdad inicial en una ventana temporal suficientemente larga. En cambio, otras formulaciones toman como referencia (explícita o implícitamente) la igualación de oportunidades, que no necesariamente implica que los resultados (los ingresos efectivamente observados) deban igualarse.

El índice de Shorrocks ha recibido considerable atención en la literatura empírica por tratarse de una medida de sencillo cálculo e interpretación. Dado que no requiere explicitar una función de bienestar social, pero es compatible con la mayoría de las usadas en la práctica, resulta una herramienta particularmente versátil. Sin embargo, la concepción de movilidad que respalda este índice no es muy popular en términos normativos. La igualación de oportunidades suele ser un objetivo más valorado que la igualación de resultados. También es importante señalar que el índice de Shorrocks no toma en cuenta pérdidas de bienestar originadas en la inestabilidad del flujo de ingresos o bien en el riesgo sobre el ingreso futuro (ya que, como explicamos, el índice se basa en una economía donde no existe incertidumbre a nivel individual). Estas consideraciones son abordadas explícitamente por trabajos posteriores. Maasoumi y Zandvakili (1986) aportan una leve generalización del índice, sin afectar su esencia.

Por un lado, en la analogía fiscal de Benabou y Ok (2001) se acepta que todo patrón de movilidad que sea equiparable a una redistribución ("fiscal") progresiva de los ingresos resulta positiva. Sin embargo, puesto que los autores contemplan la existencia de shocks idiosincráticos individuales sobre los ingresos, lo relevante no serán los ingresos finales ("resultados"), sino los ingresos esperados del segundo período condicionados a los observados en el primero ("oportunidades"). De este modo, existe "progresividad" o igualación de oportunidades en el proceso de movilidad si la distribución de los ingresos esperados futuros es más equitativa (en sentido de Lorenz) que la distribución de los ingresos actuales observados. Los autores proveen diversos criterios en base a los cuales es posible construir un ordenamiento parcial de economías en base a su nivel de "progresividad".

\footnotetext{
${ }^{7}$ Idea a la que apelan Yitzhaki y Wodon (2005) en su construcción del índice de Gini de movilidad.
} 
Por otra parte, Gottschalk y Spolaore (2002) proveen un marco de análisis donde la función de bienestar social incorpora explícitamente la pérdida de utilidad experimentada por los agentes debido a las fluctuaciones en su ingreso y también a la incertidumbre. La función de bienestar social que los autores proponen depende de tres parámetros que indican, respectivamente: el grado de aversión a la desigualdad intertemporal, el grado de aversión a las fluctuaciones en el ingreso y el grado de aversión al riesgo. La ventaja fundamental de este enfoque es que permite desentrañar estos tres aspectos de la movilidad de ingresos, cada uno de los cuales puede recibir una valoración normativa diferente. En cambio, su principal limitación es que los autores no indican cómo determinar valores razonables para los parámetros, aunque sí prueban condiciones bajo las cuales mayor movilidad de ingresos redunda en mayor bienestar social y viceversa.

Un último aporte relevante es el de Markandya (1984), que desarrolla medidas de movilidad estructural y movilidad de intercambio en base a matrices de transición asumiendo utilidad de tipo CES.

\section{América Latina en los 2000: qué podemos inferir de los datos}

De acuerdo con lo analizado en las secciones anteriores, resulta claro que no existe una definición teórica de movilidad de ingresos que sea universalmente aceptada ni una metodología de medición que pueda ser considerada general. A esta heterogeneidad a nivel teórico hay que sumar un problema de implementación: son aún pocos los países que cuentan con encuestas longitudinales que releven a los mismos hogares durante ventanas temporales largas. Esto explica por qué el grueso de la literatura empírica se ha centrado en un grupo reducido de países (Estados Unidos, Gran Bretaña y Suecia principalmente; más recientemente, los restantes países de la Unión Europea).

En América Latina, Perú es el único país que cuenta con una encuesta longitudinal. Sin embargo, otros países utilizan, en sus encuestas tradicionales, esquemas muestrales rotativos que permiten construir paneles donde los mismos hogares son relevados en más de una ocasión. Esto permite construir bases de datos de tipo panel, aunque con dos limitaciones de peso. La primera es que este esquema rotativo por lo general implica un número reducido de relevamientos a lo largo de un período corto de tiempo. La segunda es que la estructura de la rotación varía de un país a otro, lo que limita el alcance de un análisis comparativo. 
Con el fin de aportar evidencia sobre la movilidad de ingresos en América Latina, construimos la base de datos de tipo panel más grande de que tengamos conocimiento para estos países. La base cubre Argentina, Brasil, Costa Rica, Ecuador, México, Paraguay y Perú entre los años 2002 y 2015 (aunque no todos los países presentan información para todos los años). La ventana de observación más grande para un mismo conjunto de hogares es de cuatro observaciones en cuatro años (Perú), mientras que en algunos países solo es posible observar al mismo hogar en dos observaciones en el lapso de un año (Paraguay y Costa Rica).

De este modo, resulta claro que la ventana de observación disponible para los países de la región solo permite el análisis de la movilidad de ingresos en el corto plazo. En ventanas cortas de tiempo, la interpretación de la movilidad como proceso de reducción intertemporal de desigualdades pierde sustento y, en cambio, parece más razonable concentrarse en su aspecto negativo en términos de inestabilidad o volatilidad de ingresos. Sin embargo, la falta de consenso general en la literatura respecto del término indicado a utilizar sugiere que es conveniente hablar, en términos generales, de movilidad de ingresos de corto plazo, a condición de que los resultados obtenidos sean interpretados en términos de inestabilidad o volatilidad y no de otra manera.

Si bien esta interpretación de la movilidad de ingresos ha recibido considerable atención en la literatura empírica centrada en países desarrollados ${ }^{8}$, diversas características de América Latina sugieren que puede ser considerablemente más relevante en esta región. En primer lugar, porque los países latinoamericanos han estado históricamente sujetos a una mayor inestabilidad macroeconómica, atravesando cambios de régimen y episodios recesivos con mucha mayor frecuencia que los países desarrollados. En segundo lugar, porque las instituciones laborales son considerablemente más débiles que en los países más ricos. En particular, la informalidad laboral es un fenómeno de gran relevancia en América Latina y es razonable pensar que este se traduce en niveles mayores de inestabilidad en el flujo de ingresos de los hogares con respecto a lo observado en países donde los mercados de trabajo son totalmente formales. Finalmente, otro rasgo clave de las economías latinoamericanas es el escaso desarrollo de los mercados financieros y crediticios, que limitan seriamente las posibilidades de los hogares de asegurarse contra eventos negativos en sus ingresos o bien de acceder a crédito cuando estos ocurren ${ }^{9}$.

\footnotetext{
${ }^{8}$ Ver referencias en la sección 1.

${ }^{9}$ La capacidad de los hogares de suavizar su consumo en el tiempo ante variaciones en su ingreso fue analizada para la economía estadounidense en Dynarski y Gruber (1997). Los autores concluyen que el nivel de suavización es alto debido a varios factores, que incluyen el se-
} 
Por todo lo dicho, la movilidad de ingresos de corto plazo en América Latina aparece como un campo de estudio relevante y poco abordado hasta el momento. Contamos con algunos aportes en la literatura: Albornoz y Menéndez (2007) y Beccaria y Groisman (2006) analizan la movilidad observada en la década del 90 en Argentina; Fields et al. (2003a), Fields et al. (2003b) y Fields et al. (2015) realiza un trabajo similar para Argentina, México y Venezuela, mientras que Castro (2011) hace lo propio para la economía chilena; Wodon (2001) compara la movilidad de ingresos en Argentina y México en los 90 a través del índice de Gini de movilidad; por último, Cruces y Wodon (2007) estiman para Argentina una medida de pobreza ajustada por riesgo, a partir de la idea de que la inestabilidad de ingresos puede ser incorporada a las medidas tradicionales de pobreza como una dimensión adicional de privación ${ }^{10}$.

Ningún antecedente para la región ha cubierto una cantidad de países tan grande o un período de tiempo tan largo como nos proponemos en este trabajo. Por lo tanto, esperamos que el análisis comparativo que realizamos en esta tesis doctoral permita arrojar luz sobre un fenómeno que aún no ha sido del todo explorado en la literatura. La caracterización de la movilidad de ingresos de corto plazo en América Latina puede conducir a conclusiones novedosas respecto de las condiciones de vida en nuestro continente, muchas de las cuales pueden fundamentar diversas recomendaciones de política $^{11}$.

\section{Contribuciones a la literatura}

La tesis doctoral se estructura en tres capítulos. El primero parte de replicar los resultados de Beccaria y Groisman (2006) para la década de los 2000 en Argentina.

guro de desempleo y el uso de ahorros. Las economías latinoamericanas en general carecen de seguro de desempleo (o, cuando este existe, su monto es muy reducido, como ocurre en Argentina) y existen escasas opciones de ahorro que ofrezcan a los hogares un retorno superior a la inflación. Por otro lado, Corbacho, García-Escribano e Inchauste (2007) analizan diversos efectos de la crisis macroeconómica de 2001-2002 en Argentina, entre ellos la suavización del flujo de ingresos ante eventos negativos grandes. Su conclusión es que el nivel de suavización observado es insuficiente.

${ }^{10}$ Los desarrollos empíricos para países en desarrollo en otros continentes son aún más escasos. Woolard y Klasen (2007) proveen una revisión interesante de algunos trabajos para África y aportan resultados para Sudáfrica. Chen y Cowell (2015) analizan en detalle el caso de China.

${ }^{11}$ Algunos autores han optado por resolver los problemas de disponibilidad de información construyendo pseudo-paneles (por ejemplo, Antman y McKenzie (2007) y Cuesta, Ñopo y Pizzolitto (2011)). No cabe duda de que se trata de una solución atractiva en la medida en que permite construir bases que cubren ventanas temporales mucho mayores a las que tenemos aquí. Sin embargo, la validez de ese tipo de información estadística reposa sobre un supuesto que consideramos poco realista (a saber, que individuos nacidos en el mismo año pueden ser "promediados" para obtener una cohorte que es "observada" a lo largo del tiempo) y por ese motivo preferimos descartar este enfoque. Fields y Viollaz (2013) comparan resultados obtenidos a partir de paneles y de pseudo-paneles para Chile y concluyen que las diferencias son de magnitud considerable, lo que provee sustento a nuestra decisión. 
En ese trabajo, los autores construyen paneles de cuatro observaciones a partir de la Encuesta Permanente de Hogares para el período 1987-2001. Caracterizan la movilidad de ingresos laborales utilizando un indicador tradicional (el coeficiente de variación) y realizan ejercicios de microsimulación para descomponer la variabilidad observada. También llevan a cabo regresiones de convergencia y algunos otros ejercicios econométricos asociados.

La contribución del primer capítulo consiste en repetir el análisis para el mismo país en el período 2003-2015. Esto conduce a varias conclusiones de interés. En primer lugar, la variabilidad de ingresos observada en los 2000 es en promedio mayor a la registrada en los $90 \mathrm{y}$, si bien presenta una leve tendencia declinante en el tiempo, resulta mayormente insensible al ciclo económico. En segundo lugar, diversas características de los jefes de los hogares (como género, edad y nivel educativo) aparecen asociadas a mayores o menores niveles de movilidad. En tercer lugar, la variabilidad es mayor a nivel individual que a nivel de hogares. Por último, algunos ejercicios econométricos sugieren la existencia de cierto grado de convergencia en los ingresos.

El segundo capítulo explota la totalidad de la base de datos construida con el fin de realizar un análisis comparativo de la movilidad de ingresos para siete países de América Latina en el período 2003-2015. A partir de la medida de Fields y Ok (1999a), encontramos que el nivel de inestabilidad de ingresos observado en la región es mayor al usualmente reportado en la literatura para países desarrollados. Nuevamente realizamos ejercicios de microsimulación para descomponer la movilidad por fuente de ingresos. Los resultados indican que la variabilidad observada se explica principalmente por movimientos asociados al mercado de trabajo, tanto a nivel ocupacional (entradas o salidas) como salarial (cambios en las remuneraciones). Nuevamente se observa que la movilidad de ingresos es insensible a ciclos macroeconómicos y no se encuentra un patrón claro de evolución a nivel regional.

A su vez, se proponen dos hipótesis sobre determinantes de la movilidad observada. En primer lugar, se explora la posibilidad de que el capital humano adquirido por los individuos (medido a través de su nivel educativo) afecte las fluctuaciones en sus ingresos, en sintonía con lo hallado en el primer capítulo. En segundo lugar, se analiza el rol del tipo de inserción en el mercado de trabajo al comparar los resultados para asalariados registrados, asalariados no registrados y cuentapropistas.

Finalmente, el tercer capítulo aborda un aspecto de la movilidad de ingresos poco estudiado en la literatura: su relación con los movimientos demográficos, es decir, los cambios de composición de los hogares en el tiempo. Naturalmente, estos cambios 
tienen un impacto sobre el flujo temporal de ingresos del hogar y por ende pueden ser considerados como un determinante adicional de la movilidad de ingresos observada. En este capítulo explotamos la base construida para obtener evidencia sobre el tamaño de los movimientos demográficos de corto plazo en América Latina. Asimismo, calculamos mediante un ejercicio de microsimulación su contribución a la movilidad observada y concluimos que esta es pequeña pero no despreciable.

Por otro lado, planteamos la hipótesis de que existen estrategias de los hogares que tienen por finalidad suavizar el flujo de ingresos ante movimientos demográficos que tienen un impacto negativo sobre el mismo. Para proveer evidencia a favor de esta idea, explotamos los paneles de cuatro observaciones para Argentina y estimamos un modelo de efectos fijos que nos permite concluir que la llegada de niños a los hogares está asociada a determinados movimientos del mercado de trabajo.

\section{Bibliografía}

Albornoz, F., \& Menéndez, M. (2007). Income dynamics in Argentina during the 1990s: "mobiles" did change over time. Económica LIII Nro. 1-2.

Antman, F., \& McKenzie, D. (2007). Earnings mobility ad measurement error: A pseudo-panel approach. Economic Development and Cultural Change 56 (1), 125-161.

Aristei, D., \& Perugini, C. (2015). The drivers of income mobility in Europe. Economic Systems 39, 197-224.

Atkinson, A. (1970). On the Measurement of Inequality. Journal of Economic Theory 2, 244-263.

Atkinson, A., Bourguignon, F., \& Morrison, C. (1988). Earnings mobility. European Economic Review 32, 619-632.

Ayala, L., \& Sastre, M. (2008). The structure of income mobility: empirical evidence from five UE countries. Empirical Economics 35, 452-473.

Bartels, C., \& Bonke, T. (2013). Can households and welfare states mitigate rising earnings instability? The review of income and wealth 59 (2), 250-282.

Beccaria, L., \& Groisman, F. (2006). Inestabilidad, movilidad y distribución del ingreso en Argentina. Revista de la CEPAL 89, 133-156.

Benabou, R., \& Ok, E. (2001). Mobility as progressivity: Ranking income processes according to equality of opportunity. NBER Working Paper w8431.

Bossert, W., \& D'Ambrosio, C. (2013). Measuring Economic Insecurity. International Economic Review 54 (3), 1017-1030.

Cameron, S., \& Tracy, J. (1998). Earnings Variability in the United States: An Examination Using Matched-CPS Data. 1998 Society of Labor Economics Conference. 
Cantó, O., \& Ruiz, D. (2014). The contribution of income mobility to economic insecurity in the US and Spain during the Great Recession. En T. Garner, \& K. Short, Measurement of Poverty, Deprivation, and Economic Mobility (Research on Economic Inequality, Volume 23) (págs. 109-152). Emerald Group Publishing Limited.

Cappellari, L., \& Jenkins, S. (2014). Earnings and labour market volatility in Britain, with a transatlantic comparison. Labour Economics 30, 201-2011.

Castro, R. (2011). Getting ahead, falling behind and standing still. Income mobility in Chile. Estudios de Economía 38 (1), 243-258.

Celik, S., Juhn, C., McCue, K., \& Thompson, J. (2012). Recent trends in earnings volatility: Evidence from surveys and administrative data. The B.E. Journal of Economic Analysis \& Policy 12 (2), 1-24.

Chakravarty, S. (1984). Normative indices for measuring social mobility. Economic Letters 15, 175-180.

Chakravarty, S., Dutta, B., \& Weymark, J. (1985). Ethical Indices of Income Mobility. Social Choice and Welfare 2 (1), 1-21.

Chen, B. Y., \& Cowell, F. (2015). Mobility in China. The review of income and wealth 63 (2), 1-16.

Corbacho, A., Inchauste, G., \& García-Escribano, M. (2007). Argentina: Macroeconomic Crisis and Household Vulnerability. Review of Development Economics 11 Nro. 1, 92-106.

Cowell, F. (1985). Measures of Distributional Change: An Axiomatic Approach. Review of Economic Studies LII, 135-151.

Cowell, F., \& Flachaire, E. (2011). Measuring mobility. ECINEQ Working Paper 199.

Cruces, G., \& Wodon, Q. (2007). Risk-Adjusted Poverty in Argentina: Measurement and Determinants. Journal of Development Studies 43 (7), 1189-1214.

Cuesta, J., \& Ñopo, H. P. (2011). Using pseudo-panels to measure income mobility in Latin America. The review of income and wealth 57 (2), 224-246.

D'Agostino, M., \& Dardanoni, V. (2009). The measurement of rank mobility. Journal of economic theory 144, 1783-1803.

Dahl, M., DeLeire, T., \& Schwabish, J. (2011). Estimates of year-to-year volatility in earnings and in household incomes from administrative and matched data. The Journal of Human Resources 46 (4), 750-774.

Dardanoni, V. (1993). Measuring Social Mobility. Journal of Economic Theory 61, 362394.

Dynan, K., Elmendorf, D., \& Sichel, D. (2012). The Evolution of Household Income Volatility. The B.E. Journal of Economic Analysis \& Policy 12 (2), 1-40. 
Dynarski, S., \& Gruber, J. (1997). Can families smooth variable earnings? Brookings Papers on Economic Activity 1, 229-303.

Fields, G. (2006). The many facets of income mobility. En M. McGillivray, Inequality, poverty and well-being (págs. 123-142). United Nations University.

Fields, G. (2010). Does income mobility equalize long-term incomes? New measures of an old concept. Journal of Economic Inequality 8, 409-427.

Fields, G., \& Ok, E. (1996). The Meaning and Measurement of Income Mobility. Journal of Economic Theory 71, 349-377.

Fields, G., \& Ok, E. (1999a). Measuring Movement of Incomes. Economica 66, 455471.

Fields, G., \& Ok, E. (1999b). The Measuremente of Income Mobility: An Introduction to the Literature. En J. Silber, Handbook of income inequality measurement (págs. 557596). New York: Springer Science+Business Media.

Fields, G., \& Viollaz, M. (2013). Can the Limitations of Panel Datasets be Overcome by Using Pseudo-Panels to Estimate Income Mobility? Mimeo.

Fields, G., Cichello, P., Freije, S., Menendez, M., \& Newhouse, D. (2003a). For richer or for poorer? Evidence from Indonesia, South Africa, Spain and Venezuela. Journal of Economic Inequality 1, 67-99.

Fields, G., Cichello, P., Freije, S., Menendez, M., \& Newhouse, D. (2003b). Household income dynamics: a four country story. The Journal of Development Studies 40 (2), 3054.

Fields, G., Duval-Hernandez, R., Freije, S., \& Sanchez Puerta, M. L. (2015). Earnings mobility, inequality and economic growth in Argentina, Mexico and Venezuela. Journal of Economic Inequality 13, 103-128.

Gardiner, K., \& Hills, J. (1999). Policy implications of new data on income mobility. The Economic Journal 109, 91-111.

Ginsberg, M. (1929). Interchange between Social Classes. The Economic Journal 39 (156), 554-565.

Gottschalk, P., \& Spolaore, E. (2002). On the evaluation of economic mobility. The Review of Economic Studies 69 (1), 191-208.

Hacker, J., Huber, G., Nichols, A., Rehm, P. S., Valletta, R., \& Craig, S. (2014). The Economic Security Index: A new Measure for Research and Policy Analysis. The Review of Income and Wealth 60 Supplement Issue , 5-32.

Haider. (2001). Earnings Instability and Earnings Inequality of Males in the United States: 1967-1991. Journal of Labour Economics 19 (4), 799-836.

Hardy, B., \& Ziliak, J. (2014). Descomposing trends in volatility: the "wild ride" at the top and bottom. Economic Inquiry 52 (1), 459-476. 
Jantti, M., \& Jenkins, S. (2015). Income mobility. En A. Atkinson, \& F. Bourguignon, Handbook of Income Distribution volume $2 A$ (págs. 807-935). North Holland.

Kanbur, R., \& Stiglitz, J. (1986). Intergenerational mobility and dynastic inequality. Princeton: Research memorandum 324, Econometric Research Program, Princeton University.

King, M. (1983). An Index of Inequality: with applications to Horizontal Equity and Social Mobility. Econometrica 51 (1), 99-115.

Maasoumi, E., \& Zandvakili, S. (1986). A class of generalized measures of mobility with applications. Economic letters 22, 97-102.

Markandya, A. (1984). The welfare measurement of changes in economic mobility. Economica 51 (204), 457-471.

Mitra, T., \& Ok, E. (1998). The Measurement of Income Mobility: A Partial Ordering Approach. Economic Theory 12, 77-102.

Moffit, R., \& Gottschalk, P. (2012). Trends in the Transitory Variance of Male Earnings: Methods and Evidence. Journal of Human Resources 47 (1), 204-236.

Nichols, A., \& Rehm, P. (2014). Income risk in 30 countries. The review of income and wealth 60 Supplement Issue, 98-116.

Parker, S., \& Rougier, J. (2001). Measuring social mobility as unpredictability. Economica 68, 63-76.

Prais, S. J. (1955). Measuring Social Mobility. Journal of the Royal Statistical Society $118(1), 56-66$.

Rohde, N., Tang, K. K., \& Rao, P. (2014). Distributional characteristics of income insecurity in the US, Germany and Britain. The review of income and wealth 60 Supplement Issue, 159-176.

Schluter, C., \& Van de Gaer, D. (2011). Upward structural mobility, exchange mobility, and subgroup consistent mobility measurement: US-German mobility rankings revisited. The Review of Income and Wealth 57 (1), 1-22.

Shin, D., \& Solon, G. (2011). Trends in men's earnings volatility: What does the Panel Study of Income Dynamics show? Journal of Public Economics 95 (7-8), 973-982.

Shorrocks, A. (1978a). The Measurement of Mobility. Econometrica 46 (5), 1013-1024.

Sologon, D., \& O'Donoghue, C. (2014). Shaping earnings insecurity: labor market policy and institutional factors. The Review of Income and Wealth 60 Supplementary Issue, 205-232.

Stevens, A. H. (1). Changes in Earnings Instability and Job Loss. Industrial and Labor Relations Review 55 (1), 60-78.

Tsui, K.-y. (2009). Measuremente of income mobility: a re-examination. Social choice and welfare, 629-645. 
Van Kerm, P. (2004). What Lies behind Income Mobility? Reranking and Distributional Change in Belgium, Western Germany and the USA. Economica 71 (282), 223-239.

Wodon, Q. (2001). Income Mobility and Risk during the Business Cycle: Comparing Adjustments in Labor Markets in two Latin American Countries. Economics of Transition 9 (2), 449-461.

Woolard, I., \& Klasen, S. (2007). Determinants of income mobility and household poverty dynamics in South Africa. The Journal of Development Studies 41 (5), 865897.

Yitzhaki, S., \& Wodon, Q. (2005). Mobility, inequality and horizontal inequity. En Y. Amiel, \& J. Bishop, Research on Economic Inequality, Studies on Economic WellBeing: Essays in Honor of John Formby (págs. 177-198). Bingley: Emerald.

Ziliak, J., Hardy, B., \& Bollinger, C. (2011). Earnings volatility in America: Evidence from matched CPS. Labor Economics 18, 742-754. 


\section{Capítulo 1: Movilidad de ingresos y desigualdad en Argentina en los 2000}

\section{Introducción}

La dinámica de ingresos personales y familiares ha concitado la atención de una parte considerable de la literatura en los últimos años. El uso de información de tipo dinámico permite captar diversos aspectos del fenómeno que permanecen ocultos en un análisis de corte transversal. Su principal desventaja es que requiere el uso de datos longitudinales; dado que la mayoría de los países en vías de desarrollo no cuenta con encuestas de este tipo, el análisis se ha centrado hasta ahora, principalmente, en datos provenientes de países desarrollados.

En Argentina, el esquema rotatorio de la Encuesta Permanente de Hogares (EPH) puede ser aprovechado para construir paneles de 4 observaciones, a partir de los cuales es posible desarrollar un análisis de la dinámica ocupacional y de ingresos, entre otras. En un trabajo pionero para el campo en Argentina, Beccaria y Groisman (2006) analizan estas bases de datos para la década del 90 y obtienen conclusiones respecto de la movilidad observada del ingreso laboral, sus determinantes y consecuencias. En este trabajo, nos proponemos extender este análisis a la década de los 2000 y evaluar continuidades y rupturas en las tendencias que estos autores encuentran en la década anterior.

La contribución de este trabajo consiste en caracterizar la dinámica de ingresos laborales personales y familiares para el período 2003-2013 en Argentina, esto es, cuantificar la magnitud de los cambios en los ingresos mediante algunos indicadores de uso habitual en la literatura especializada. En segundo lugar, apuntamos a identificar los factores asociados a esta movilidad de ingresos a nivel demográfico: sexo, edad, nivel educativo, composición del hogar y procedencia geográfica. En tercer lugar, buscamos profundizar en la diferenciación entre la dinámica de ingresos y la dinámica ocupacional. Finalmente, proponemos algunas hipótesis sobre la relación entre movilidad absoluta y movilidad de orden para el período analizado en nuestro país.

El trabajo está organizado de la siguiente manera. La sección 2 releva brevemente el estado del arte. La sección 3 describe la fuente de información empleada. La sección 4 contrasta el contexto macroeconómico de los 2000 con el de los 90. La sección 5 presenta los resultados correspondientes al análisis descriptivo de la movilidad de ingresos y su descomposición en dinámica salarial y ocupacional. La sección 5 presenta los resultados del análisis de regresión que apunta a cuantificar la influencia de diversos factores demográficos. La sección 6 aporta evidencia a favor de la existencia 
de convergencia en la movilidad de ingresos. Finalmente, la sección 7 ofrece algunas conclusiones.

\section{Antecedentes}

La literatura sobre movilidad de ingresos reconoce como principales antecedentes los trabajos seminales de Atkinson, Bourguignon y Morrison (1988), Fields y Ok (1996, 1999a, 1999b) y Shorrocks (1978b), entre otros. Estos dieron origen a una creciente literatura que analiza los ingresos de los hogares o individuos desde una perspectiva dinámica, en contraposición a los enfoques estáticos habituales en el análisis de la distribución del ingreso. Las principales características de este campo de análisis, todavía heterogéneo y poco sistemático, pueden ser consultadas en el survey realizado por Jantti y Jenkins (2015).

Una característica de este campo es la necesidad de contar con encuestas de tipo longitudinal, que existen hace algún tiempo en países desarrollados (particularmente Estados Unidos, Gran Bretaña y Suecia) pero que no existen todavía en la mayoría de los países en desarrollo. Sin embargo, el uso de esquemas rotatorios en las encuestas de hogares tradicionales en países latinoamericanos permite la construcción de paneles, aunque con ventanas de observación limitadas. Esto dio lugar a algunos trabajos que contribuyen al análisis de la movilidad de ingresos en países de esta región.

En el caso de Argentina, un punto de partida viene dado por el trabajo pionero de Beccaria y Groisman (2006), que realiza un análisis de la movilidad de ingresos laborales para el período 1987-2001. Los autores ofrecen una cuantificación del nivel de movilidad observado a partir de un indicador tradicional (el coeficiente de variación) y analizan su relación con el ciclo económico, sus componentes y sus consecuencias en términos de convergencia de ingresos. A pesar de ciertas limitaciones en la fuente de información (particularmente la cobertura geográfica y la modalidad "puntual" de la EPH en ese período), se trata del trabajo de mayor alcance hasta el momento.

Gutierrez (2004) realiza un análisis similar pero restringido al período 1998-2002, con el fin de profundizar en el estudio de las consecuencias de la crisis económica de 2001. Por su parte, Albornoz y Menéndez (2007) trabajan con un período algo más reducido y hacen mayor hincapié en la cuestión de la convergencia, aunque sus conclusiones son consistentes con las de Beccaria y Groisman en líneas generales. A su vez, Fields et al. (2015) profundizan en el análisis de convergencia (mediante la aplicación de sucesivas correcciones econométricas a las regresiones tradicionales) y 
comparan el caso argentino al de México y Venezuela. Finalmente, Wodon (2001) también aborda una parte de este período para Argentina a través de un indicador particular conocido como índice de Gini de movilidad.

Por otro lado, cabe señalar que algunos autores han emprendido un análisis similar utilizando pseudo-paneles, principalmente Antman y McKenzie (2007), Cuesta, Ñopo y Pizzolitto (2011) y Navarro (2010). Si bien las conclusiones provistas por estos trabajos son de gran valor, preferimos aquí evitar este enfoque metodológico ya que requiere la formulación de supuestos muy estrictos. En particular, los pseudo-paneles asumen que que individuos nacidos en el mismo año pueden ser "promediados" para obtener una cohorte que es "observada" a lo largo del tiempo. A pesar de las evidentes ventajas de esta metodología, la validez de un supuesto tan fuerte siempre resulta discutible $^{12}$. El trabajo con paneles, esperamos, puede conducir a conclusiones igualmente valiosas sin necesidad de apelar a hipótesis de este tipo.

\section{Fuentes de información}

En Argentina, la EPH es realizada de manera continua por el Instituto Nacional de Estadísticas y Censos (INDEC) desde 2003 en adelante ${ }^{13}$; las bases de datos correspondientes son publicadas con frecuencia trimestral. Si bien no se trata de una encuesta longitudinal en términos estrictos, su esquema rotatorio puede ser aprovechado para construir paneles. Esta rotación es de tipo 2-2-2: un hogar es entrevistado en dos trimestres consecutivos, luego es retirado del relevamiento durante dos trimestres consecutivos y finalmente es visitado nuevamente en dos trimestres consecutivos, para luego ser retirado definitivamente. En consecuencia, cada hogar seleccionado en la muestra de la EPH es entrevistado hasta 4 veces a lo largo de una ventana temporal de 18 meses, lo que permite la construcción de bases de datos de tipo panel para llevar adelante un análisis dinámico.

Si bien la attrition afecta la disponibilidad de datos, como típicamente ocurre en paneles, es interesante notar que la EPH no sufre este problema en demasía: para más del $70 \%$ de la muestra total 2003-2013 los hogares son efectivamente relevados en 4 ocasiones, de modo que optamos por ignorar en esta presentación los problemas

\footnotetext{
${ }^{12}$ De hecho, Fields y Viollaz (2013) comparan resultados obtenidos a partir de paneles y de pseudo-paneles para Chile y concluyen que las diferencias son de magnitud considerable, lo que provee sustento a nuestra decisión

${ }^{13}$ Hasta 2003, contamos con la versión puntual de la EPH, cuya frecuencia y esquema rotatorio eran diferentes. No recurriremos aquí a esas bases de datos de manera directa aunque sí compararemos nuestros resultados con los de Beccaria y Groisman, obtenidos a partir de ellas.
} 
relacionados con el sesgo por truncamiento y las correspondientes correcciones que habitualmente se aplican.

De este modo, construimos 36 paneles de cuatro ondas que abarcan toda la información disponible entre el tercer trimestre de 2003 (primer relevamiento de la EPH continua) y el cuarto trimestre de 2013 (última base disponible al momento de la realización de este capítulo). Luego, agrupamos esos paneles en una sola estructura, lo que en la literatura se conoce como un pool de paneles. La variable de interés es el ingreso laboral total individual, que es deflactado utilizando un índice de precios construido a partir de las series provistas por diversos institutos de estadísticas provinciales que se han mantenido a salvo de la intervención política que la mayoría sufrió a partir de 2007. Por otra parte, cabe señalar que se eliminaron las observaciones que presentaban inconsistencias temporales en género, edad o nivel educativo.

Adicionalmente, agregamos el ingreso laboral individual a nivel de hogares para analizar la movilidad a nivel de hogares y no solo de individuos, lo que permite enriquecer las conclusiones. Con el fin de mantener la comparabilidad con resultados anteriores, excluimos del análisis al ingreso de origen no laboral. Un análisis de la dinámica del ingreso total del hogar, incluyendo el componente de origen no laboral, es emprendido en el capítulo siguiente.

\section{El contexto macroeconómico}

El período 2003-2013 se caracteriza por una notable mejora en los indicadores del mercado de trabajo argentino, que pueden ser interpretados como consecuencia de un cambio de régimen macroeconómico a raíz de la salida de la Convertibilidad a fines de 2001. Repasar algunas de las diferencias centrales en la performance macroeconómica argentina en cada década puede ser útil para comprender la evolución de la movilidad de ingresos y sus determinantes ${ }^{14}$.

La década de los 90 estuvo caracterizada por lo que habitualmente se conoce como el régimen de la Convertibilidad. Si bien la Ley de Convertibilidad (que rigió en nuestro país entre 1991 y 2001) se limitaba a fijar el tipo de cambio en paridad a la divisa estadounidense, en la práctica expresaba un conjunto más general de políticas enmarcadas en el Consenso de Washington: apertura comercial, desregulación financiera y una intervención reducida del sector público en la mayor parte de los merca-

\footnotetext{
${ }^{14}$ Seguimos aquí el análisis de Damill, Frenkel y Maurizio (2003) para la década de los 90 y el de Damill, Frenkel y Rapetti (2015) para la década del 2000. Adicionalmente, se puede consultar Heymann (2001).
} 
dos. En lo que respecta al mercado de trabajo, la política más relevante fue la Ley de Flexibilización Laboral de 1995, que permitió extender los períodos de prueba, introdujo diversas formas de contratación a tiempo determinado y redujo las contribuciones patronales en alrededor de $40 \%$.

Si bien el PBI creció a tasas muy altas entre 1991-1994 y 1996-1998, estos aumentos del producto no siempre coexistieron con caídas del desempleo; a su vez, el crecimiento del desempleo se aceleró en la recesión de 1994 y, luego de una breve caída en 1996, retomó un alto ritmo de crecimiento en la recesión de 1998-2002, alcanzando su máximo histórico de $21.5 \%$ en mayo de 2002.

A partir de 2003, la economía argentina comenzó nuevamente un proceso de crecimiento, a tasas muy altas en 2003-2007 y algo más bajas en 2008-2013. La posconvertibilidad se caracteriza por una mayor intervención pública en algunos mercados, así como por políticas fiscales y monetarias de corte expansivo. Este contexto macroeconómico favorable se vio potenciado por la aplicación de diversas políticas orientadas específicamente al mercado de trabajo, entre las que sobresalen el aumento del salario mínimo, el fortalecimiento de las negociaciones colectivas anuales y diversos esquemas de incentivos a la formalización laboral. El efecto sobre el mercado de trabajo fue inicialmente muy fuerte: el desempleo se redujo a un ritmo muy acelerado en 2003-2006, hasta alcanzar niveles por debajo del 10\%, donde se mantuvo hasta el final del período analizado. De un nivel de desempleo promedio de $16 \%$ en los 90 , la década siguiente pasó a una media de 9.3\%; al mismo tiempo, la tasa de empleo media aumentó de $35.4 \%$ a $42 \%$.

La recuperación del mercado de trabajo a lo largo de los 2000 no solo se manifiesta en el aumento del empleo sino también en mejoras en las remuneraciones: el salario real promedio creció un 42.8\% entre 2003 y 2013. Por otro lado, en 2009 se implementó la Asignación Universal por Hijo (AUH), el mayor programa de transferencias condicionales de ingreso a los hogares de toda América Latina. Al aumentar el ingreso no laboral de los hogares de menores ingresos, la AUH podría impactar positivamente sobre el salario de reserva de los trabajadores pertenecientes a dichos hogares, contribuyendo favorablemente a su inserción en puestos mejor remunerados. De conjunto, observamos un proceso de mejora generalizada en el mercado de trabajo así como de los indicadores sociales de nuestro país.

Por otra parte, la tasa de inflación también varió considerablemente entre períodos. La Convertibilidad se caracteriza por una estabilidad casi plena de precios y de 
salarios, mientras que en la posconvertibilidad se advierten dos momentos bien diferenciados: entre 2003-2007 la tasa de inflación anual promedio es de 9.2\% (una cifra baja en relación a los valores históricos de nuestro país), mientras que en 2008-2013 esta media asciende a $22.6 \%$, la segunda más alta del mundo.

Tanto el crecimiento económico como la inflación pueden ser considerados factores determinantes de la movilidad de ingresos, al igual que las políticas públicas aplicadas, tanto a nivel macroeconómico como aquellas específicamente dirigidas al mercado de trabajo. Sin embargo, no resulta evidente cuál debería ser el impacto esperado de este cambio de régimen macroeconómico sobre la movilidad de ingresos. Se espera que un acelerado crecimiento económico conduzca a aumentos considerables en los salarios; a la vez, una alta tasa de inflación puede estar asociada a cambios en los precios relativos que impacten positivamente sobre la variabilidad salarial. En cuanto a las políticas laborales, mientras que algunas posiblemente conducen a mayores cambios en los ingresos laborales (el aumento del salario mínimo o el fortalecimiento de las negociaciones colectivas), otras podrían generar mayor estabilidad en las remuneraciones (particularmente la formalización laboral). No se puede descartar que efectos de signos opuestos y magnitudes similares se contrarresten entre sí. En la siguiente sección investigamos la evidencia empírica correspondiente y proponemos algunas hipótesis tentativas.

\section{Movilidad de ingresos laborales en los 2000}

Dado que no existe una única definición teórica de movilidad de ingresos, tampoco existe una forma unívoca de medir su tamaño. Como explicamos en la introducción, dado que las ventanas de observación disponibles son cortas, estamos interesados en captar aquí la inestabilidad o variabilidad de los ingresos, a la que también nos referimos como movilidad de corto plazo (o simplemente movilidad). En particular, con el fin de mantener la comparabilidad con los resultados de Beccaria y Groisman, utilizamos como indicador el coeficiente de variación tradicional (CV):

$$
C V_{i}=\frac{\sqrt{\frac{1}{T} \sum_{t=1}^{T}\left(w_{i t}-\bar{w}_{i}\right)^{2}}}{\bar{w}_{i}}
$$

En nuestra notación, $w_{i t}$ es el ingreso laboral real del individuo $i$ en el momento $t$ y $\bar{w}_{i}$ es la media calculada a lo largo de la ventana temporal de longitud $T$. Esta medida permite una primera aproximación a la cuantificación de la movilidad de ingresos; en el Gráfico 1 presentamos su evolución a lo largo del período considerado. 


\section{Gráfico 1. Evolución del coeficiente de variación y el coeficiente de Gini del in- greso laboral individual}

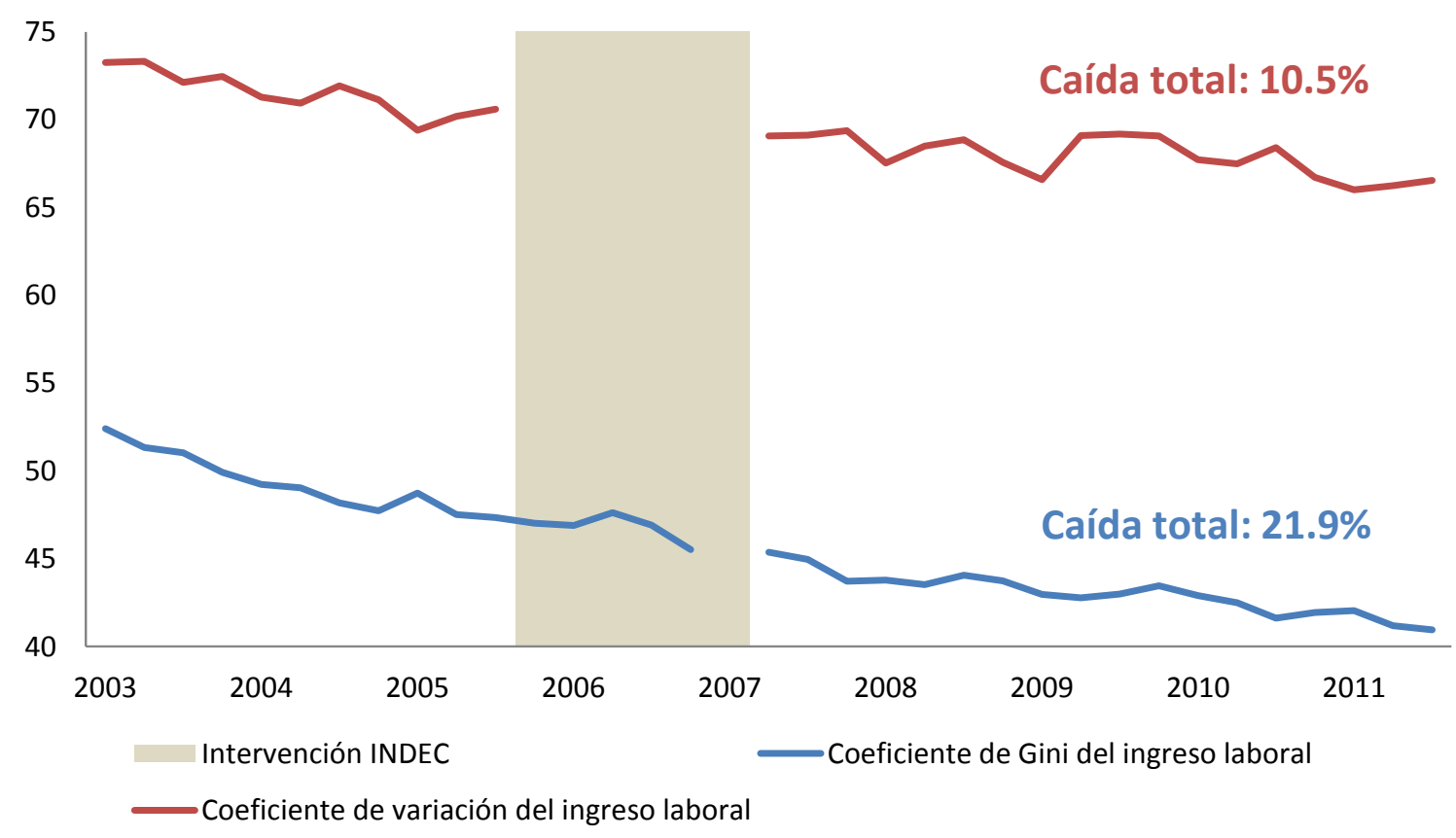

Fuente: Elaboración propia en base a EPH

A lo largo de la década considerada, observamos una reducción en el coeficiente de variación del ingreso laboral individual de algo más de 10 puntos porcentuales punta a punta. Esta caída podría responder al contexto macroeconómico de la posconvertibilidad, a las políticas sociales y laborales aplicadas o a una combinación de ambos. También es posible que el nivel de movilidad observado en 2003 fuera alto como consecuencia de la reciente crisis de 2001-2002 y la reducción posterior respondiera a una reversión a niveles de movilidad "típicos".

Por un lado, el crecimiento económico es equivalente a un aumento en el ingreso promedio de los individuos, lo cual a su vez se traduce en cambios en los ingresos individuales de acuerdo a una cierta estructura distributiva. Por lo tanto, es razonable pensar que crecimiento a tasas altas conduce a movilidad elevada. Por otro lado, una tasa de inflación elevada generalmente implica un contexto macroeconómico donde los precios relativos son inestables; en esas circunstancias, es factible que el ingreso real de algunos agentes (aquellos que anticipan correctamente la inflación o bien tienen mayor poder de negociación) aumente mientras que el de otros (aquellos que subestiman la inflación futura o bien tienen menor poder de negociación) disminuya debido a cambios en los precios absolutos. Nuevamente esto se traduciría en mayor movilidad de ingresos, combinando aumentos y caídas. 
La baja inflación que caracterizó al período 2003-2007 podría explicar la reducción en el CV, aunque es llamativo que esta convive con altas tasas de crecimiento económico. A su vez, esta reducción continúa en el período 2008-2012, cuando la inflación aumentó considerablemente. La relativa insensibilidad del CV a los cambios en el contexto macroeconómico favorece la hipótesis de que son las políticas sociales implementadas y los progresos en el mercado de trabajo los que determinan este comportamiento o, alternativamente, que este se "normalizó" luego de atravesar un pico circunstancial en 2002.

Corresponde notar la ausencia de información para el tercer trimestre de 2007, cuando el relevamiento no se realizó de manera completa debido a conflictos gremiales originados por la intervención política del INDEC. Hasta la fecha, la base con información parcial no ha sido publicada por el organismo, de modo que no es posible computar el dato correspondiente al trimestre en cuestión. Adicionalmente, puesto que cada base trimestral es utilizada varias veces en esta metodología (ya que los individuos que participan de un relevamiento individual formarán parte de diversos paneles), es dable pensar que varios de los paneles 2006-2007 estarán viciados por la falta de una observación. Por este motivo es que hemos excluido dichos paneles de la serie de CV presentada en el gráfico.

En el Gráfico 1 incluimos también la serie de coeficiente de Gini del ingreso laboral individual. Esta medida tradicional de desigualdad en la distribución también presenta una caída monótona a lo largo de la ventana temporal elegida, aunque de casi el doble de magnitud (21.9\%). Esta presentación responde a un interrogante habitual en esta literatura: la existencia o no de relación entre movilidad de ingresos y equidad distributiva. Si bien la correlación que exhiben las series no es suficiente para aventurar hipótesis de causalidad, la consideramos una evidencia interesante a favor de la existencia de una relación entre estos dos aspectos de la estructura distributiva de nuestro país.

Resulta de interés separar dos aspectos de la movilidad de ingresos: por un lado, la dinámica ocupacional, es decir, los cambios de los ingresos que ocurren como consecuencia de la entrada o salida del mercado de trabajo; en segundo lugar, la dinámica de las remuneraciones, esto es, los cambios en el salario real que recibe un trabajador en un determinado puesto de trabajo. Para satisfacer este objetivo, Beccaria y Groisman proponen dos variantes del CV: 


$$
\begin{gathered}
C V_{i}^{A O}=\frac{\sqrt{\frac{1}{T^{*}} \sum_{t=1}^{T^{*}}\left(w_{i t}^{*}-\bar{w}_{i}^{*}\right)^{2}}}{\bar{w}_{i}^{*}} \text { donde } w_{i t}^{*}=w_{i t} \text { solo si } w_{i t}>0 \\
C V_{i}^{A R}=\frac{\sqrt{\frac{1}{T^{* *}} \sum_{t=1}^{T^{* *}}\left(w_{i t}^{* *}-\bar{w}_{i}^{* *}\right)^{2}}}{\bar{w}_{i}^{* *}} \text { donde } w_{i t}^{* *}=\left\{\begin{array}{ccc}
w_{i}^{1} & \text { si } & w_{i t}>0 \\
0 & \text { caso contrario }
\end{array}\right.
\end{gathered}
$$

El coeficiente de variación aislado de cambios ocupacionales (CVAO) elimina aquellas observaciones donde el ingreso laboral es nulo (lo que denota que el individuo no está ocupado), con el fin de capturar la movilidad originada estrictamente por cambios en el salario real, a la que denominamos movilidad salarial. Por el contrario, el coeficiente de variación aislado de cambios en las remuneraciones (CVAR) reemplaza todas las observaciones no nulas por $w_{i}^{1}$, la primera observación distinta de cero, en aras de capturar la movilidad originada estrictamente por entradas y salidas del mercado de trabajo, a la que denominamos movilidad ocupacional. Si bien esta descomposición no es aditiva (el trabajo con cocientes desvío/media impide aplicar resultados que típicamente rigen en el análisis de la varianza), veremos que la suma del CVAO y el CVAR en general no difiere considerablemente del CV.

Cuadro 1. Media del CV, CVAO y CVAR del ingreso individual por períodos
\begin{tabular}{lcccccc} 
& $\mathbf{1 9 8 7 - 1 9 9 1}$ & $\mathbf{1 9 9 1 - 1 9 9 4}$ & $\mathbf{1 9 9 5 - 1 9 9 8}$ & $\mathbf{1 9 9 8 - 2 0 0 1}$ & $\mathbf{2 0 0 3 - 2 0 1 3}$ (GBA) & $\mathbf{2 0 0 3 - 2 0 1 3}$ (TP) \\
\hline CV & 56.2 & 55.8 & 56.5 & 57.8 & 70.4 & 69.1 \\
CV AO & 28.0 & 21.1 & 19.4 & 19.0 & 30.4 & 30.0 \\
CV AR & 32.6 & 38.9 & 42.1 & 43.9 & 52.5 & 54.5
\end{tabular}

Fuente: Elaboración propia en base a EPH, Beccaria y Groisman (2006)

El Cuadro 1 compara las medias de los coeficientes de variación calculados para la muestra 2003-2013 con los reportados por Beccaria y Groisman para diversos subperíodos de la ventana temporal comprendida entre 1987 y 2001. Los datos están expresados en puntos porcentuales. Cabe señalar que el trabajo citado restringe la muestra a Gran Buenos Aires (GBA), dado que la cantidad de aglomerados urbanos relevados en la EPH cambió a lo largo de la década de los 90 . En este trabajo no es necesario aplicar una restricción de este tipo, habida cuenta de que la muestra de la EPH ha mantenido su cobertura de 31 aglomerados urbanos desde 2003 hasta la fecha. Sin embargo, en aras de preservar la comparabilidad de los guarismos, presentamos nuestros cálculos realizados para el total del país (TP) y también para GBA, con el fin de establecer que no existen diferencias de peso, lo que avala la comparabilidad general. 
Encontramos que el CV se mantuvo aproximadamente constante en los 90, en torno a 56, pero trepó a una media de 69 en la década siguiente. En otras palabras, encontramos evidencia de mayor movilidad de ingresos en la posconvertibilidad que en años anteriores. Por su parte, la descomposición de la dinámica ofrece una caracterización más fina de este cambio. Tanto el CVAO como el CVAR aumentaron respecto a sus valores medios de la década de los 90 , lo que indica que tanto la movilidad de origen ocupacional como la de origen salarial crecieron en magnitud. Sin embargo, el aumento observado en el CVAO (de alrededor de 20 a 30) es relativamente mayor al observado en el CVAR (de alrededor de 40 a 54.5), de modo que podemos afirmar que la dinámica salarial creció más fuertemente que la dinámica ocupacional.

Los datos presentados arrojan otras dos conclusiones relevantes. La primera es que el CVAR es sistemáticamente mayor al CVAO, tanto en los 90 como en los 2000, lo que indica que los movimientos de entrada y salida del mercado de trabajo tienen mayor peso explicativo en los cambios de ingresos individuales en nuestro país. La segunda es que, si bien ambas medidas registran un aumento en la posconvertibilidad, el mayor aumento relativo del CVAO señala un incremento en la dinámica salarial mayor al observado en la dinámica ocupacional, lo que puede atribuirse a diferencias de contexto macroeconómico (la combinación entre baja inflación y alto desempleo en los 90 dificultaba los aumentos salariales nominales) o bien a algunas políticas aplicadas en los 2000 que contribuyeron a aumentos salariales considerables (el fortalecimiento de las negociaciones colectivas o bien el aumento del salario mínimo). 


\section{Gráfico 2. Evolución de los coeficientes de variación del ingreso laboral indivi-}

dual

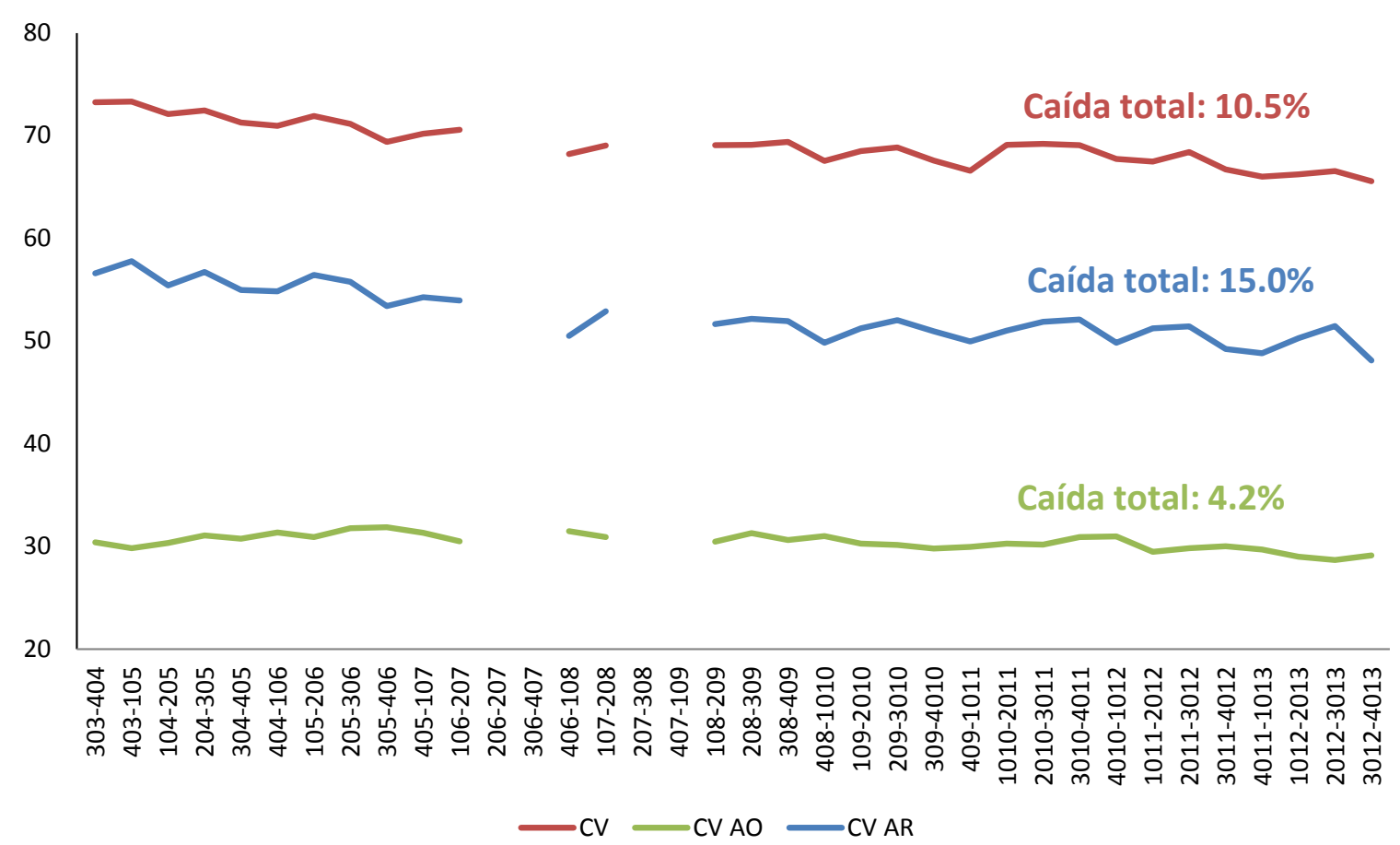

Fuente: Elaboración propia en base a EPH

El Gráfico 2 complementa el análisis anterior al exhibir la evolución de cada indicador a lo largo de la ventana temporal seleccionada. Como mencionamos anteriormente, el CV cae 10.5 puntos porcentuales en este lapso; vemos en el gráfico que la caída en el CVAR es algo mayor (15\%), mientras que la del CVAO es apenas perceptible (4.2\%). Adicionalmente, la correlación entre el CV y el CVAR es elevada, mientras que no ocurre lo mismo con el CVAO, cuya variabilidad es reducida. De este modo, el mayor nivel de movilidad salarial alcanzado en la posconvertibilidad parece relativamente independiente de la evolución macroeconómica, mientras que es la evolución de la dinámica ocupacional la que explica los movimientos observados. Esto contribuye a la idea de que el comportamiento observado en el CVAO responde a un nuevo marco de políticas públicas más que a factores cíclicos.

Este análisis realizado para los ingresos individuales puede ser reproducido tomando como unidad de observación al hogar, aunque las medidas utilizadas deben modificarse de manera apropiada. En la nueva notación, $w_{h t}$ es el ingreso laboral real del hogar $h$ en el momento $t$ y $\bar{w}_{h}$ es la media calculada a lo largo de la ventana temporal de longitud $T$. El coeficiente de variación tradicional toma entonces la siguiente forma: 


$$
C V_{h}=\frac{\sqrt{\frac{1}{T} \sum_{t=1}^{T}\left(w_{h t}-\bar{w}_{h}\right)^{2}}}{\bar{w}_{h}}
$$

Nuevamente, resulta de interés distinguir la parte de la movilidad de ingresos que es producto de entradas y salidas del mercado de trabajo de aquella que es consecuencia de cambios en las remuneraciones. Por lo tanto, procedemos a distinguir los cambios en el ingreso del hogar ocasionados por cambios en la cantidad de ocupados al interior del mismo de aquellos provenientes de cambios en las remuneraciones que los ocupados reciben.

$$
\begin{aligned}
& C V_{h}^{A O}=\frac{\sqrt{\frac{1}{T^{*} \sum_{t=1}^{T^{*}}\left(w_{h t}^{*}-\bar{w}_{h}^{*}\right)^{2}}}}{\bar{w}_{h}^{*}} \text { donde } \\
& w_{h t}^{*}=\sum_{i \in h} w_{i t}^{*}, w_{i t}^{*}=\left\{\begin{array}{rll}
w_{i t} & \text { si } & w_{i t}>0 \\
w_{i}^{1} w_{t} / w_{1} & \text { si } w_{i t}=0
\end{array}\right. \\
& C V_{h}^{A R}=\frac{\sqrt{\frac{1}{T^{* *}} \sum_{t=1}^{T^{* *}}\left(w_{h t}^{* *}-\bar{w}_{h}^{* *}\right)^{2}}}{\bar{w}_{h}^{* *}} \quad \text { donde } \\
& w_{h t}^{* *}=\sum_{i \in h} w_{i t}^{* *}, w_{i t}^{* *}=\left\{\begin{array}{ccc}
w_{i}^{1} & \text { si } & w_{i t}>0 \\
0 & \text { si } & w_{i t}=0
\end{array}\right.
\end{aligned}
$$

El coeficiente de variación aislado de cambios ocupacionales (CVAO) imputa $w_{i}^{1}$, el primer ingreso no nulo observado del individuo, a todas aquellas observaciones donde el individuo no está ocupado (y por ende no percibe ingreso laboral), corrigiendo este valor por la razón $w_{t} / w_{1}$, la evolución del ingreso laboral real promedio entre el período inicial y el corriente. De este modo, podemos interpretarlo como una medida de la variabilidad de ingresos del hogar aislada de los cambios en la cantidad de miembros ocupados en el hogar. El coeficiente de variación aislado de cambios en las remuneraciones (CVAR) imputa $w_{i}^{1}$ en todos los casos en que el ingreso laboral observado es positivo y mantiene las observaciones nulas, con el fin de captar la variabilidad de ingresos del hogar aislada de cambios en los salarios reales percibidos por los sus miembros. 
Cuadro 2. Media del CV, CVAO y CVAR del ingreso del hogar 1987-1991 1991-1994 1995-1998 1998-2001 2003-2013 (GBA) 2003-2013 (TP)

\begin{tabular}{lcccccc}
\hline CV & 36.4 & 30.0 & 31.7 & 33.2 & 47.3 & 47.6 \\
CV AO & 31.2 & 24.4 & 25.9 & 25.5 & 43.3 & 44.0 \\
CV AR & 9.4 & 13.0 & 12.7 & 14.7 & 36.0 & 35.6
\end{tabular}

Fuente: Elaboración propia en base a EPH, Beccaria y Groisman (2006)

En el Cuadro 2 comparamos nuestros resultados con los de la década anterior. Nuevamente encontramos muy pequeñas diferencias entre TP y GBA para nuestros datos, de modo que la comparación resulta válida. Al igual que con los datos individuales, constatamos que la variabilidad de ingresos es mayor en 2003-2013 respecto de la década de los 90, con un aumento de alrededor de 15 puntos en el CV. Este aumento se corresponde con incrementos tanto del CVAO como del CVAR, como ocurre a nivel individual, aunque aquí es el CVAR el que presenta un crecimiento relativamente mayor.

Resulta claro que el nivel de variabilidad en los ingresos del hogar es considerablemente menor al de los ingresos individuales. Este resultado es razonable, ya que los hogares cuentan con la posibilidad de modificar la asignación del tiempo de trabajo entre sus miembros frente a cambios significativos en su ingreso total. Reducciones del ingreso del hogar suelen incentivar a miembros inactivos a salir al mercado de trabajo, ajuste que no es posible a nivel individual. En consecuencia, el ingreso del hogar presenta mayor estabilidad en el tiempo que el individual ${ }^{15}$.

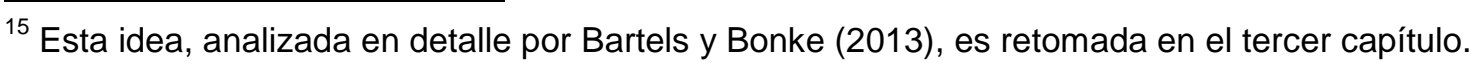




\section{Gráfico 3. Evolución de los coeficientes de variación del ingreso laboral de los hogares}

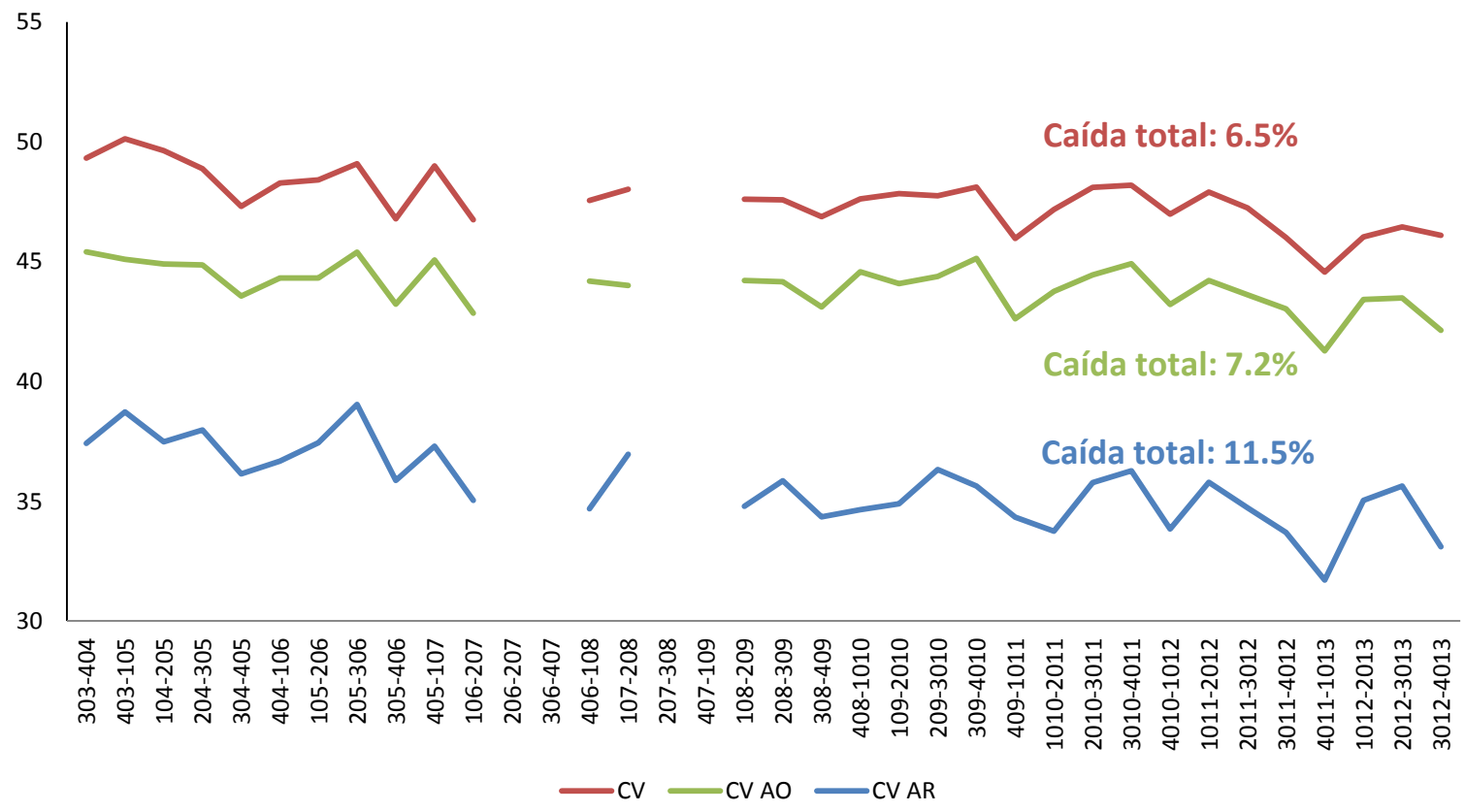

Fuente: Elaboración propia en base a EPH

El Gráfico 3 permite extender este análisis al horizonte dinámico. Nuevamente observamos una reducción en la variabilidad de los ingresos a lo largo del período analizado, aunque de solo 6.5 puntos, con caídas algo mayores en el CVAO y en el CVAR. Una novedad interesante es que aquí las tres series se compartan de manera análoga, lo que sugiere que a nivel del hogar la variabilidad de ingresos de origen salarial y la de origen ocupacional evolucionan de manera similar, lo que no ocurre a nivel individual.

\section{Factores asociados a la movilidad de ingresos}

Con el fin de identificar los factores asociados a la movilidad de ingresos, podemos utilizar los coeficientes de variación presentados como variables dependientes en modelos de regresión, que a su vez es posible estimar mediantes Mínimos Cuadrados Ordinarios aplicados sobre el pool de paneles. Excluimos a los individuos menores de 25 años para evitar que la adquisición de capital humano a través de la educación genere algún efecto dinámico a lo largo de la ventana considerada. A su vez, aplicamos la corrección propuesta por White para heterocedasticidad de forma desconocida aunque cabe señalar que la significatividad de los resultados no varía respecto de la estimación convencional. 
El Cuadro 3 presenta la estadística descriptiva de las variables explicativas utilizadas. Estas incluyen dummies de género, educativas y regionales, además de la edad del individuo y la cantidad de niños en el hogar (empleada como proxy de la cantidad de hijos, no relevada en la EPH). Las categorías base de las dummies son género mas-culino, educación secundaria completa y región Gran Buenos Aires, respectivamente.

En la columna referente a hogares, las medias presentadas corresponden a las características del jefe del hogar. En todos los casos, las medias de las variables presentadas se refieren al período inicial, aunque es de notar que se trata de variables que factiblemente no presentan variación en el tiempo (a excepción, trivialmente, de la edad).

Cuadro 3. Estadística descriptiva para el pool de paneles 2003-2013

\begin{tabular}{lcc} 
& Individuos & Hogares \\
\hline Dummy mujer & 0.45 & 0.30 \\
Edad & 42.68 & 48.85 \\
Dummy educación HPI & 0.08 & 0.12 \\
Dummy educación PC & 0.23 & 0.28 \\
Dummy educación SI & 0.17 & 0.17 \\
Dummy educación TI & 0.11 & 0.09 \\
Dummy educación TC & 0.18 & 0.14 \\
Dummy NOA & 0.22 & 0.21 \\
Dummy NEA & 0.12 & 0.12 \\
Dummy Cuyo & 0.11 & 0.11 \\
Dummy Pampa & 0.30 & 0.30 \\
Dummy Patagonia & 0.12 & 0.12 \\
Cantidad niños & 1.35 & 1.31
\end{tabular}

Fuente: Elaboración propia en base a EPH

La muestra posee una ligera mayoría de hombres, el 55\% del total, aunque cuando se trabaja con las variables a nivel de hogares, encontramos que solo un $30 \%$ de los mismos tienen un jefe de sexo femenino, un hecho ampliamente reportado en nuestro país. La edad media de los individuos es de 42.68 años pero asciende a 48.85 años entre los jefes de hogar. El 52\% de los individuos ha completado estudios secundarios, guarismo que se reduce a $43 \%$ entre los jefes de hogar, lo que configura un nivel educativo alto en comparación con otros países de la región. El 13.5\% de los individuos relevados pertenece a GBA, mientras que el resto de las regiones aparecen representadas en pro-porciones similares, a excepción de la región pampeana, que 
comprende una fracción algo más alta, de 30\%. Por último, el promedio de niños por hogar se ubica ligeramente por encima de 1.3.

Cuadro 4. Resultados del análisis de regresión de ingresos individuales

\begin{tabular}{|c|c|c|c|}
\hline Variable & CV & CV AO & CV AR \\
\hline Dummy mujer & $25.4232^{\star \star \star}$ & $0.2870^{* *}$ & $30.4611^{\star \star \star}$ \\
\hline Edad & $-6.2587^{* * *}$ & $-0.3918^{* * *}$ & $-7.2959^{\star * *}$ \\
\hline $\mathrm{Edad}^{\wedge} 2$ & $0.0735^{\star * *}$ & $0.0048^{\star * \star}$ & $0.0855^{\star \star \star}$ \\
\hline Dummy educación HPI & $19.8977^{\star \star \star}$ & $6.2337^{* * *}$ & $18.9884^{\star \star *}$ \\
\hline Dummy educación PC & $11.5850^{\star \star \star}$ & $3.0950^{* * *}$ & $11.2614^{\star \star \star}$ \\
\hline Dummy educación SI & $8.2542^{\star \star \star}$ & $2.3067^{* \star *}$ & $7.8542^{\star \star \star}$ \\
\hline Dummy educación TI & $1.6805^{\star \star \star}$ & -0.0162 & $1.8836^{\star \star \star}$ \\
\hline Dummy educación TC & $-17.4197^{\star \star \star}$ & $-1.2871^{\star * *}$ & $-20.0335^{\star * *}$ \\
\hline Dummy NOA & $2.2500^{* * *}$ & $2.8476^{\star \star \star}$ & -0.0479 \\
\hline Dummy NEA & $2.3750^{\star * *}$ & $1.0304^{* * *}$ & $1.6271^{* *}$ \\
\hline Dummy Cuyo & $-2.2383^{* * *}$ & $1.5833^{* * *}$ & $-4.4068^{\star * *}$ \\
\hline Dummy Pampa & -0.0177 & -0.0375 & -0.1997 \\
\hline Dummy Patagonia & $-6.5037^{* * *}$ & $-0.7417^{* * *}$ & $-7.5397^{* \star *}$ \\
\hline Cantidad niños & $0.8402^{* * *}$ & $0.3130^{* * *}$ & $0.7129^{* * *}$ \\
\hline Observaciones & 117587 & 103078 & 117587 \\
\hline R cuadrado & 0.13 & 0.0154 & 0.1346 \\
\hline
\end{tabular}

Errores estándar robustos, ${ }^{* * *} p<0.01,{ }^{* *} p<0.05,{ }^{*} p<0.1$

Fuente: Elaboración propia en base a EPH

Casi todas las variables explicativas empleadas resultan significativas al $99 \%$ de confianza, aunque los coeficientes de determinación son bajos, lo que indica que la mayor parte de la variabilidad de ingresos no está explicada por los regresores utilizados.

El primer hallazgo relevante es el hecho de que la variabilidad de ingresos es considerablemente mayor en mujeres que en hombres: el coeficiente estimado asociado a la dummy correspondiente es de 25 puntos, equivalente a alrededor de un tercio de la media general del período. Sin embargo, en las regresiones que usan el CVAO y el CVAR como variables respuesta encontramos un panorama distinto: el coeficiente estimado es de magnitud irrelevante en el primer caso y tiene mayor tamaño en el segundo. De esto podemos inferir que la mayor variabilidad en los ingresos de las mujeres se debe a una mayor inestabilidad ocupacional y no a mayor variabilidad salarial. Una interpretación posible de este fenómeno es la participación relativamente alta de la mujer en sectores típicamente informales y/o inestables (particularmente, el servicio doméstico), además de la mayor tasa de entrada a la inactividad observada en mujeres (Maurizio, 2011). 
Los coeficientes estimados para la variable edad son negativos en el término lineal y positivos en el cuadrático, lo que indica una forma de parábola convexa. Esta alcanza su mínimo alrededor de los 42 años para el CV y el CVAR y en torno a los 40 años para el CVAO. Concluimos entonces que la variabilidad de ingresos es alta al comienzo y al final de la vida laboral activa y relativamente más baja en su etapa intermedia.

Las dummies educativas presentan un claro patrón de proporcionalidad inversa: cuanto mayor es el nivel educativo del individuo, menor variabilidad sufre su ingreso; en particular, los individuos con educación superior completa son aquellos que experimentan el menor grado de variabilidad. La descomposición señala que estos efectos son similares para el CVAR pero considerablemente menores para el CVAO. De este modo, podemos afirmar que la educación elevada reduce sensiblemente la magnitud de los cambios de origen ocupacional pero no tanto así la de los de origen salarial. La asociación entre nivel educativo bajo y variabilidad de ingresos, tanto ocupacional como salarial, plausiblemente esté relacionada con el hecho de que los individuos con menor nivel educativo son los que se insertan más frecuentemente en puestos informales.

Las dummies regionales ofrecen un panorama variado. La región pampeana no resulta significativamente diferente de la categoría base; en cambio, sí encontramos evidencia de mayor variabilidad de ingresos en NOA y NEA, y de menor variabilidad en Cuyo y Patagonia (esta última con coeficientes estimados considerablemente mayores en valor absoluto).

Estos resultados están en sintonía con los reportados por Beccaria y Groisman, tanto en términos de los signos de los coeficientes estimados como de sus magnitudes relativas. Cabe señalar que los autores encontraron muchos casos de estimaciones no significativas, un problema que casi no existe en nuestro ejercicio, factiblemente debido a que el tamaño de la muestra empleada aquí es sensiblemente mayor, merced a la mayor cobertura actual de la EPH y al hecho de que hemos optado por no subdividir la ventana temporal.

Este análisis puede reproducirse para los coeficientes de variación de los ingresos de los hogares. Aquí la unidad de observación será el hogar y las variables explicativas capturan las características del jefe del hogar. Presentamos los resultados correspondientes en el Cuadro 5. 
Cuadro 5. Resultados del análisis de regresión de ingresos de los hogares

\begin{tabular}{|c|c|c|c|}
\hline Variable & CV & CV AO & CV AR \\
\hline Dummy mujer & $10.8293^{* \star \star}$ & $10.0797^{\star \star \star}$ & $11.4490^{\star \star \star}$ \\
\hline Edad & $-1.7423^{\star \star \star}$ & $-2.2822^{\star \star \star}$ & $-1.5797^{\star \star \star}$ \\
\hline $\mathrm{Edad}^{\wedge} 2$ & $0.0239^{\star * *}$ & $0.0286^{\star * \star}$ & $0.0231^{\star \star *}$ \\
\hline Dummy educación HPI & $11.8150^{\star \star \star}$ & $9.2614^{\star \star \star}$ & $11.4328^{\star \star \star}$ \\
\hline Dummy educación PC & $6.5646^{\star \star \star}$ & $4.8206^{\star \star \star}$ & $6.5531^{\star \star *}$ \\
\hline Dummy educación SI & $5.3460^{\star * \star}$ & $3.9887^{\star \star \star}$ & $5.0898^{\star * *}$ \\
\hline Dummy educación TI & -0.5819 & -0.5638 & $-1.6687^{\star *}$ \\
\hline Dummy educación TC & $-6.4785^{\star \star \star}$ & $-5.0026^{\star \star \star}$ & $-9.2804^{\star \star \star}$ \\
\hline Dummy NOA & 0.3768 & 0.4982 & -0.9231 \\
\hline Dummy NEA & $3.0389^{\star \star \star}$ & $4.9845^{\star \star \star}$ & $4.9099^{\star \star *}$ \\
\hline Dummy Cuyo & $-1.3042^{\star \star}$ & -0.5780 & $-2.7962^{\star \star *}$ \\
\hline Dummy Pampa & $2.2444^{\star \star \star}$ & $2.9019^{\star \star \star}$ & $1.9926^{\star \star \star}$ \\
\hline Dummy Patagonia & -0.7982 & 0.6174 & $-1.8012^{\star \star \star}$ \\
\hline Cantidad niños & $-0.4978^{\star \star \star}$ & $-0.8500^{\star \star \star}$ & $-0.2452^{*}$ \\
\hline Observaciones & 70634 & 71718 & 71714 \\
\hline R cuadrado & 0.1149 & 0.1035 & 0.1126 \\
\hline
\end{tabular}

Errores estándar robustos, ${ }^{* * *} p<0.01,{ }^{* *} p<0.05,{ }^{*} p<0.1$

Fuente: Elaboración propia en base a EPH

Nuevamente encontramos una mayoría de estimaciones estadísticamente significativas con un $99 \%$ de confianza, aunque algunos signos y magnitudes presentan cambios relevantes. Las dummies asociadas a jefe de hogar de sexo femenino presentan signo positivo en los tres casos pero el tamaño del coeficiente estimado es notablemente menor al obtenido en las regresiones para individuos. Los hogares cuyo jefe es mujer experimentan una mayor variabilidad de ingresos que aquellos con jefe masculino, debido tanto a mayores cambios ocupacionales como salariales, pero la magnitud de esta diferencia no es tan grande como la hallada a nivel individual.

Las variables de edad vuelven a presentar un patrón de parábola convexa, aunque ahora los puntos mínimos estimados se encuentran en torno a los 36 años. En las dummies educativas encontramos nuevamente una relación inversa entre nivel educativo y movilidad de ingresos, aunque con coeficientes estimados más pequeños que los registrados previamente. Aquí es interesante señalar que no hay diferencia relevante de tamaño entre los coeficientes estimados para el CVAO y los estimados para las otras variables dependientes.

Las dummies regionales presentan un cuadro diferente al de las regresiones individuales. Tanto NOA como Patagonia presentan ahora coeficientes no significativos, 
mientras que Pampa exhibe coeficientes positivos y significativos. De todos modos, las magnitudes de estas estimaciones siguen siendo pequeñas en términos generales.

Las conclusiones son, en términos cualitativos, similares a las que se obtienen en el análisis de la variabilidad de los ingresos individuales, aunque aquí la influencia de casi todas las variables explicativas se reduce en tamaño. El hecho de que las características demográficas del jefe del hogar no tengan un impacto tan grande sobre la variabilidad de ingresos del hogar en conjunto sugiere que un porcentaje relevante de este ingreso total proviene de otros miembros, de modo que las características negativas del jefe podrían ser compensadas por las características positivas de los demás miembros y viceversa.

\section{Convergencia de ingresos}

La mayor parte de la literatura coincide en destacar como aspecto positivo de la movilidad de ingresos su potencial rol en la reducción intertemporal de desigualdades. Desde esta perspectiva, una sociedad con elevada movilidad sería aquella donde el peso de las desigualdades iniciales se diluye en el tiempo, mientras que una sociedad poco móvil sería aquella donde estas permanecen relativamente inalteradas. Sin embargo, no es posible afirmar que la movilidad siempre reduzca la desigualdad intertemporal de los ingresos; un alto grado de movilidad es a priori compatible con un aumento en el coeficiente de Gini u otras medidas habituales de desigualdad.

El coeficiente de variación puede no ser la medida de movilidad más adecuada para analizar este concepto de movilidad, ya que este agrega todos los cambios en ingresos individuales, independientemente de si estos aumentan o reducen el nivel observado de desigualdad. En esta sección, apuntamos a cuantificar el proceso de movilidad en términos de su contribución a la reducción de desigualdades iniciales en los niveles de ingreso. Para ello, es preciso introducir la noción de convergencia en ingresos individuales y una medida empírica acorde a ella.

Decimos que existe convergencia en los ingresos individuales si los individuos que parten de ingresos iniciales elevados experimentan un crecimiento en su ingreso menor que aquellos que comienzan con ingresos más bajos. Una medida habitual de este tipo de movilidad es la pendiente de una regresión que relaciona el ingreso real final con el ingreso real inicial del siguiente modo:

$$
y_{i t}=\beta y_{i t-1}+x_{i t} \gamma+u_{i t}
$$


En esta expresión, $y_{i t}$ representa el logaritmo del ingreso laboral real e $y_{i t-1}$, su rezago. Al expresar las variables relevantes en logaritmos, el coeficiente de interés $\beta$ es interpretado como la elasticidad del ingreso final respecto del inicial. Por lo general, esta elasticidad toma valores entre cero y uno. Valores cercanos a uno indican que, si bien es posible que exista movilidad en términos de cambios en los ingresos individuales, estos no contribuyen a una reducción en la desigualdad observada ya que los individuos con ingresos iniciales altos también presentan ingresos finales elevados (algo que puede ser interpretado, por ejemplo, como consecuencia de ventajas acumulativas o trampas de pobreza). En cambio, valores cercanos a cero sugieren que existe independencia del origen, en el sentido de que las condiciones iniciales tienen una débil incidencia sobre los resultados finales y por lo tanto los movimientos observados en los ingresos contribuyen a que ricos y pobres iniciales se igualen intertemporalmente ${ }^{16}$. El vector $x_{i t}$ contiene variables de control que pueden variar en el tiempo o no.

El coeficiente $\beta$ es una medida estándar de movilidad de uso frecuente en la literatura. En particular, Benabou y Ok (2001) argumentan a favor de su uso a partir de un modelo de distribución intertemporal del ingreso donde la movilidad es vista como positiva solo en la medida en que equivale a una redistribución progresiva del ingreso. En Argentina, diversos trabajos han calculado esta elasticidad utilizando datos provenientes de la $\mathrm{EPH}$, la mayoría de ellos recurriendo a pseudo-paneles. Beccaria y Groisman presentan resultados para la década de los 90 tanto a partir de paneles como de pseudo-paneles. Navarro (2010) realiza estimaciones a partir de pseudopaneles para 1985-2010 y Cuesta, Ñopo y Pizzolitto (2011) aplican esta misma metodología para 1992-2003.

A continuación, presentamos nuestros resultados para 2003-2013. Dado que no contamos con variables de control que varíen en el tiempo, optamos por estimar el modelo mediante Mínimos Cuadrados Ordinarios utilizando la última observación de ingreso de cada individuo como variable dependiente y la primera como variable independiente. Este procedimiento puede aplicarse sobre todos los individuos que presentan ingresos en al menos dos períodos; alternativamente, es posible restringir la muestra a aquellos que presenten ingresos en las 4 observaciones. Si bien esta consideración no afecta sensiblemente a los resultados, ambos son presentados en el Cuadro 6.

\footnotetext{
${ }^{16}$ La independencia del origen es un tipo particular de movilidad: un elevado grado de independencia del origen indica que existe suficiente movilidad en la sociedad como para que individuos con ingresos iniciales bajos puedan acceder a ingresos finales altos con similares probabilidades a los de los individuos con ingresos iniciales altos.
} 


\section{Cuadro 6. Convergencia en los ingresos individuales}

\begin{tabular}{lcccc} 
& \multicolumn{2}{c}{ 4 observaciones } & \multicolumn{2}{c}{ Al menos 2 observaciones } \\
\hline Beta & $0.8396^{* * *}$ & $0.7869^{\star * *}$ & $0.8375^{\star \star *}$ & $0.7883^{\star \star *}$ \\
& $(0.0027)$ & $(0.0032)$ & $(0.0024)$ & $(0.0028)$ \\
\hline Controles & No & Sí & No & Sí \\
Observaciones & 67374 & 67374 & 89316 & 89316 \\
R cuadrado & 0.7074 & 0.716 & 0.7109 & 0.7185 \\
\hline
\end{tabular}

Errores estándar robustos, ${ }^{* * *} p<0.01,{ }^{* *} p<0.05,{ }^{*} p<0.1$

Fuente: Elaboración propia en base a EPH

Las variables de control incluidas son las mismas que en las regresiones anteriores. Como se ve, la inclusión de controles produce una reducción en el coeficiente beta estimado. Esto ha sido reportado previamente en la literatura y es por eso que se suele hablar de "convergencia condicional" cuando la estimación incluye variables de control y de "convergencia incondicional" cuando estas no son utilizadas.

Nuestros resultados señalan la existencia de cierto grado de convergencia incondicional y de un grado aun mayor de convergencia condicional. Todas las estimaciones son significativas al 99\% de confianza y los coeficientes de determinación están por encima de 0.7 , lo que indica que buena parte de la variabilidad en los ingresos finales es explicada por los ingresos iniciales (la inclusión de controles naturalmente mejora el ajuste, pero no en una proporción importante). Sin embargo, la estimación de beta sin controles realizada por Beccaria y Groisman arroja un resultado de 0.74, inferior al obtenido aqui ${ }^{17}$. Esto sugiere que encontramos evidencia de que la convergencia en los 2000 se da a un ritmo ligeramente menor que en la década anterior. Nuestros resultados son similares a los presentados por Cuesta, Nopo y Pizzolitto (2011), aunque Navarro (2010) obtiene valores menores.

\section{Conclusiones}

El presente trabajo apunta a proveer un punto de partida en el análisis de la dinámica de ingresos a partir de datos de panel en Argentina en la década de los 2000. Los importantes cambios de régimen macroeconómico que nuestro país atravesó en las últimas dos décadas invitan a indagar en las consecuencias que estos tuvieron sobre las trayectorias de ingresos de individuos y hogares, tarea que puede ser llevada adelante utilizando las bases de datos provistas por la EPH.

\footnotetext{
${ }^{17}$ Los resultados de Beccaria y Groisman son a su vez consistentes con los presentados por Fields et al. (2015), donde se analiza convergencia en 1996-2003 diferenciando entre el coeficiente correspondiente a años de crecimiento y el correspondiente a años de contracción.
} 
Presentamos aquí evidencia de un aumento en la variabilidad de ingresos individuales en los 2000 con respecto a los 90, a partir de un indicador sencillo como el coeficiente de variación. A continuación, mostramos que esta mayor movilidad responde tanto a una mayor dinámica salarial como a una mayor dinámica ocupacional. Estos hallazgos deben ser revalidados en futuros trabajos mediante el cálculo de otros indicadores alternativos o bien mediante la aplicación de metodologías más sofisticadas.

Este aumento en la movilidad puede ser atribuido tanto a factores macroeconómicos como a efectos de las políticas sociales y laborales aplicadas en la última década. Sin embargo, la relativa insensibilidad del CV a la evolución del ciclo económico provee respaldo a la segunda hipótesis. También es posible que la crisis del 20012002 haya producido un salto abrupto en el nivel de variabilidad de ingresos y el proceso de reducción posterior responda a una reversión a valores históricos. Futuros avances en el campo deberían permitir echar luz sobre estas posibilidades.

Por otra parte, constatamos que la dinámica de ingresos individuales está asociada a determinadas características demográficas de los individuos. En particular, las mujeres y los individuos con nivel educativo bajo experimentan mayor movilidad. Asimismo, encontramos que la movilidad es elevada al comienzo y al final de la vida laboral activa pero se reduce en la etapa intermedia de la misma. Estos hallazgos están en sintonía con otros similares presentados previamente en la literatura.

Algo similar ocurre cuando se analiza la movilidad de ingresos utilizando como unidad receptora al hogar en lugar del individuo. Nuevamente aquí encontramos un nivel de variabilidad mayor en el período 2003-2013 respecto a lo observado en los 90. Las características individuales de los jefes del hogar resultan explicativas de este nivel de variabilidad aunque en menor medida en relación a lo que ocurre cuando se trabaja con datos individuales.

La variabilidad de los ingresos del hogar es sustancialmente menor a la de los ingresos individuales, un hallazgo que también es habitual en la literatura. Resulta claro que al menos parte de esta diferencia puede ser atribuida a un proceso de asignación del tiempo de trabajo dentro del hogar, que permite que los miembros inactivos salgan al mercado laboral cuando se reduce el ingreso total del hogar y viceversa. Este mecanismo de compensación forma parte de las estrategias que los hogares utilizan para mitigar la inestabilidad de ingresos ocasionada por fluctuaciones macroeconómicas o shocks negativos. 
La corta ventana de observación que ofrece la EPH sugiere interpretar la movilidad observada como una medida de la inestabilidad de los ingresos en el corto plazo, lo que implica un costo social. Sin embargo, presentamos en este trabajo evidencia de cierto grado de convergencia de ingresos individuales. Esto implica que el proceso de movilidad de ingresos analizado contribuye a reducir el grado de desigualdad en la distribución ya que los individuos con mayores ingresos iniciales observan un menor crecimiento en sus ingresos que aquellos con ingresos iniciales más bajos. Este hallazgo sugiere que, a pesar del potencial costo social asociado a las fluctuaciones de ingresos, la movilidad de ingresos cumple, en parte al menos, con un papel igualador que suele recibir una valoración positiva en términos normativos.

\section{Bibliografía}

Antman, F., \& McKenzie, D. (2007). Earnings mobility ad measurement error: A pseudo-panel approach. Economic Development and Cultural Change 56 (1), 125-161.

Atkinson, A., Bourguignon, F., \& Morrison, C. (1988). Earnings mobility. European Economic Review 32, 619-632.

Bartels, C., \& Bonke, T. (2013). Can households and welfare states mitigate rising earnings instability? The review of income and wealth 59 (2), 250-282.

Beccaria, L., \& Groisman, F. (2006). Movilidad de ingresos y desigualdad en la Argentina. En L. Beccaria, \& F. Groisman, Argentina desigual (págs. 39-92). Buenos Aires: UNGS.

Benabou, R., \& Ok, E. (2001). Mobility as progressivity: Ranking income processes according to equality of opportunity. NBER Working Paper Series.

Cuesta, J., \& Ñopo, H. P. (2011). Using pseudo-panels to measure income mobility in Latin America. The review of income and wealth 57 (2), 224-246.

Damill, M., Fenkel, R., \& Rapetti, M. (2015). Macroeconomic Policy in Argentina During 2002-2013. Comparative Economic Studies 57 (3), 369-400.

Damill, M., Frenkel, R., \& Maurizio, R. (2003). Políticas macroeconómicas y vulnerabilidad social. La Argentina en los años noventa. Serie Financiamiento del desarrollo 135.

Fields, G., \& Ok, E. (1996). The Meaning and Measurement of Income Mobility. Journal of Economic Theory 71, 349-377.

Fields, G., \& Ok, E. (1999a). Measuring Movement of Incomes. Economica 66, 455471.

Fields, G., \& Ok, E. (1999b). The Measuremente of Income Mobility: An Introduction to the Literature. En J. Silber, Handbook of income inequality measurement (págs. 557596). New York: Springer Science+Business Media. 
Fields, G., \& Sánchez Puerta, M. L. (2010). Earnings mobility in times of growth and decline: Argentina from 1996 to 2003. World Development 38 (6), 870-880.

Fields, G., \& Viollaz, M. (2013). Can the Limitations of Panel Datasets be Overcome by Using Pseudo-Panels to Estimate Income Mobility? Mimeo.

Fields, G., Duval-Hernandez, R., Freije, S., \& Sanchez Puerta, M. L. (2015). Earnings mobility, inequality and economic growth in Argentina, Mexico and Venezuela. Journal of Economic Inequality 13, 103-128.

Gottschalk, P., \& Spolaore, E. (2002). On the evaluation of economic mobility. The Review of Economic Studies 69 (1), 191-208.

Gutiérrez, F. (2004). Dinámica salarial y ocupacional: Análisis de panel para Argentina 1998-2002. Documentos de Trabajo del CEDLAS.

Heymann, D. (2001). Políticas de reforma y comportamiento macroeconómico. En D. Heymann, \& B. Kosacoff, Desempeño económico en un contexto de reformas. Buenos Aires: Eudeba-CEPAL.

Jantti, M., \& Jenkins, S. (2015). Income mobility. En A. Atkinson, \& F. Bourguignon, Handbook of Income Distribution volume $2 A$ (págs. 807-935). North Holland.

Maurizio, R. (2011). Inestabilidad en el mercado de trabajo. Un análisis dinámico para Argentina. La Plata: Editorial de la Universidad de La Plata.

Navarro, A. (2010). Estimating long term earnings mobility with pseudo-panel data. Revista de Análisis Económico 25, 65-90.

Shorrocks, A. (1978b). Income Inequality and Income Mobility. Journal of Economic Theory 19, 376-393.

Wodon, Q. (2001). Income Mobility and Risk during the Business Cycle: Comparing Adjustments in Labor Markets in two Latin American Countries. Economics of Transition 9 (2), 449-461. 


\section{Capítulo 2: Inestabilidad de ingresos en América Latina en los 2000}

\section{Introducción}

El estudio de la movilidad de ingresos ha cobrado gran importancia en la literatura en las últimas dos décadas. Dentro de este campo, una parte de las investigaciones se ha orientado al análisis de la inestabilidad o volatilidad de los ingresos de los hogares, es decir, a indagar el tamaño, características y consecuencias de las fluctuaciones de corto plazo en los ingresos percibidos por los hogares. El supuesto general que da sentido a esta línea de investigación es la idea de que los hogares experimentan una pérdida de bienestar por las fluctuaciones en su flujo de ingresos en relación al bienestar que obtendrían si recibieran el valor medio de dicho flujo de manera constante (hipótesis que guarda similitud con la idea tradicional de aversión al riesgo).

Este problema resulta de especial interés en América Latina debido a ciertas características estructurales de estas economías y, en particular, de sus mercados de trabajo. En primer lugar, los frecuentes cambios de régimen macroeconómico tienen un impacto fuerte sobre las trayectorias de los ingresos de los hogares a través de movimientos en la demanda de trabajo, modificaciones de los esquemas de protección social y cambios en la tasa de inflación. En segundo lugar, el reducido tamaño de los mercados de crédito y las barreras al acceso a ellos para buena parte de los hogares se traducen en una incapacidad casi total para suavizar en el tiempo los shocks negativos. En tercer lugar, la debilidad de buena parte de las instituciones propias del mercado laboral aumenta la exposición de los trabajadores al riesgo de despido o de fluctuaciones fuertes en sus remuneraciones. Por último, la informalidad laboral, una característica tradicional de la región, contribuye notablemente a la volatilidad de los ingresos de los hogares.

Desde comienzos de este siglo, América Latina ha experimentado un proceso de importantes mejoras en los indicadores sociales, particularmente aquellos correspondientes al mercado de trabajo. Estos avances son fruto, por un lado, de un acelerado crecimiento económico (uno de los procesos de más rápido crecimiento en la historia del continente), pero también de la adopción de diversas políticas laborales y sociales tales como ampliación de la cobertura previsional, aumento del salario mínimo, fiscalización laboral, transferencias condicionales de ingreso y otras.

La inexistencia de encuestas longitudinales en países en desarrollo ha dictaminado que la casi totalidad de la literatura sobre inestabilidad de ingresos se centre en países desarrollados. En este trabajo, explotamos el esquema rotativo de las encues- 
tas de hogares de algunos países latinoamericanos para construir paneles que permiten extender este análisis a nuestra región. Nuestra contribución consiste en cuantificar el nivel de las fluctuaciones de ingresos de corto plazo, analizar su evolución en el tiempo, caracterizar su origen a través de descomposiciones por fuentes de ingresos y realizar un análisis comparativo. La muestra de países empleada contiene a Argentina, Brasil, Costa Rica, Ecuador, México, Paraguay y Perú y cubre el período 2002-2015. Se trata del pool de paneles más grande de que tengamos conocimiento para la región.

El resto del trabajo se encuentra estructurado de la siguiente manera. La sección 2 provee una breve revisión de la literatura específica. La sección 3 presenta la metodología utilizada para medir inestabilidad de ingresos en nuestra base de datos. La sección 4 indica las fuentes de información utilizadas. La sección 5 repasa someramente la performance macroeconómica de América Latina en el período considerado. La sección 6 presenta los resultados del análisis realizado sobre la inestabilidad de ingresos. Finalmente, la sección 7 provee algunas conclusiones.

\section{Revisión de la literatura}

El nivel de fluctuación temporal de los ingresos de los hogares ha atraído la atención de una parte relevante de la literatura especializada en los últimos años. La inestabilidad de ingresos (usualmente vinculada a otros fenómenos tales como la inseguridad de ingresos o el riesgo en los ingresos) constituye un problema importante en la medida en que reduce el bienestar de los hogares si los shocks negativos no pueden ser anticipados o si no existen mecanismos de mercado que permitan amortiguarlos o asegurarse contra ellos.

La disponibilidad de información estadística resulta una limitación clave en esta rama de la literatura, razón por la cual la casi totalidad de los trabajos hasta el momento se han centrado en países desarrollados, donde existen encuestas de tipo longitudinal que permiten observar el ingreso de un individuo u hogar a lo largo del tiempo. De particular importancia son los trabajos realizados para Estados Unidos a partir de la Panel Study of Income Dynamics (PSID) o bien de registros administrativos (aunque otras encuestas también han sido utilizadas). En esta línea encontramos los aportes de Haider (2001), Celik et al. (2012), Dynan, Elmendorf y Sichel (2012) y Shin y Solon (2011). El eje principal de estos trabajos está puesto en la evolución de la volatilidad de ingresos en la economía estadounidense en las últimas décadas. Si bien existe cierta evidencia de una tendencia creciente, los estudios muestran que esta es sensible a la metodología y la fuente de datos utilizada. 
Otros trabajos se han centrado en la comparación de niveles de inestabilidad entre países. Aristei y Perugini (2015) analizan la inestabilidad de ingresos en 25 países europeos a partir del European Union Statistics on Income and Living Conditions (EUSILC), mientras que Chen (2009) reporta resultados para Estados Unidos, Canadá, Alemania y Gran Bretaña. Estos trabajos coinciden en el hallazgo de una importante variabilidad internacional en los niveles de volatilidad de ingresos. Por otro lado, Cappellari y Jenkins (2014) comparan la volatilidad observada en Estados Unidos y Gran Bretaña, centrándose en la contribución del componente laboral en cada caso. A su vez, Bartels y Bonke (2013) interpretan las diferencias de inestabilidad de ingresos entre Gran Bretaña y Alemania en términos de efectos de las políticas sociales.

Una parte de la literatura concibe la inestabilidad de ingresos como parte de un fenómeno más amplio conocido como inseguridad de ingresos o riesgo de ingresos. Por ejemplo, Hacker et al. (2012) señalan que "la variabilidad observada en los ingresos no logra captar dos dimensiones cruciales de la inseguridad: el riesgo de gastos grandes e involuntarios (tales como gastos en salud no cubiertos) y la capacidad de los individuos u hogares de usar su riqueza para reducir el efecto de los cambios en ingreso sobre el consumo". De este modo, algunos trabajos analizan las fluctuaciones en los ingresos de los hogares como evidencia de inseguridad de ingresos, es decir, de una pérdida de bienestar causada por la incertidumbre sobre la evolución de diversas variables que afectan el bienestar de los hogares.

Bossert y D'Ambrosio (2013) realizan un abordaje axiomático de la inseguridad de ingresos a partir de la evolución en la riqueza individual o del hogar y proveen dos medidas lineales distintas, cada una compatible con un conjunto distinto de axiomas. Entre los trabajos que cuantifican la inseguridad de ingresos a través de las fluctuaciones en los ingresos de los hogares, encontramos Cantó y Ruiz (2014), Nichols y Rehm (2014), Rohde, Tang y Rao (2014) y Sologon y O’Donoghue (2014). Si bien la muestra de países y la metodología utilizada varían en cada caso, los trabajos coinciden en presentar la volatilidad de los ingresos como evidencia de un problema de inseguridad de ingresos que afecta el bienestar de los hogares. Por otra parte, Hacker et al. (2012) presentan un índice de inseguridad de ingresos para la economía estadounidense construido a partir de mediciones de caídas en los ingresos, gastos no anticipados en salud y riqueza financiera.

En América Latina, la escasez de información estadística de tipo longitudinal ha limitado seriamente el desarrollo de esta literatura, aunque existen algunos aportes relevantes, especialmente en países que ya han aplicado esquemas rotatorios durante 
cierto tiempo en sus encuestas de hogares (Argentina es el principal ejemplo ya que utiliza esquemas de este tipo desde hace ya más de dos décadas). En un trabajo pionero para Argentina, Beccaria y Groisman (2006) analizan la volatilidad de ingresos en este país entre fines de los 80 y comienzos de los 2000, con el fin de determinar el impacto que tienen sobre ella los cambios de régimen macroeconómico. Fields y Sánchez Puerta (2008) realizan un aporte similar, aunque poniendo mayor énfasis sobre la existencia de convergencia o divergencia en los cambios de ingresos observados. Por su parte, Glewwe y Hall (1998) evalúan la sensibilidad de los ingresos de distintos grupos de hogares a los shocks macroeconómicos en Perú, un enfoque que fue replicado para Argentina luego de la crisis de 2001-2002 en los trabajos de McKenzie (2004) y Corbacho, Inchauste y García-Escribano (2007). Albornoz y Menéndez (2007) estudian la movilidad de ingresos para Argentina en términos de convergencia de ingresos, hipótesis ampliamente analizada en la literatura, aunque no abordada en este trabajo. Por último, corresponde considerar también el aporte de Cruces y Wodon (2007), que calculan medidas de pobreza ajustadas por riesgo de ingresos en Argentina.

\section{Medición y descomposición de la inestabilidad de ingresos}

La metodología utilizada para medir la intensidad de la inestabilidad de ingresos es fuertemente dependiente del tipo de información estadística disponible. Como se detalla en la sección siguiente, en América Latina solo Perú realiza una encuesta de tipo longitudinal (para un número reducido de años); en el resto de los países considerados los paneles son construidos a partir del esquema rotativo de las encuestas de hogares tradicionales. El período temporal cubierto y la cantidad de observaciones temporales varían de un país a otro.

Dado que nuestro objetivo es realizar un análisis comparativo entre países, elegimos una ventana de observación que permita el mayor grado de comparabilidad posible, tanto entre los países de interés de este estudio como con otros relevados en la literatura. Por ende, construimos para cada país todos los paneles posibles de dos observaciones separadas por un año y luego agregamos esos paneles en un pool de paneles para cada país. Consideramos el hogar como unidad receptora de ingresos pero utilizamos los ingresos individuales en algunos de los ejercicios de descomposición realizados.

Para medir el grado de inestabilidad de ingresos observado recurrimos al indicador de Fields y Ok (1998), de uso habitual en la literatura: 


$$
m\left(y_{1}, y_{2}\right)=\frac{1}{n} \sum_{i=1}^{n}\left|\ln y_{2 i}-\ln y_{1 i}\right|
$$

Donde $y_{1}$ e $y_{2}$ son los vectores de ingresos de los hogares en cada observación y $n$ es el tamaño de la muestra. Como se puede apreciar, este indicador mide el tamaño medio de los cambios relativos de ingresos, independientemente de su dirección (aumento o disminución). Es preciso señalar que todos los ingresos son deflactados por el índice de precios al consumidor correspondiente a cada país de modo tal que en todo momento trabajamos con ingresos reales, es decir, ajustados por inflación.

Fields y Ok proponen una descomposición de $m$ en dos términos, uno que captura el crecimiento del ingreso y otro que captura la transferencia de ingreso entre unos hogares y otros. Esta descomposición responde a la siguiente expresión:

$$
m\left(y_{1}, y_{2}\right)=\frac{1}{n} \sum_{i=1}^{n}\left(\ln y_{2 i}-\ln y_{1 i}\right)+\frac{2}{n} \sum_{i \in L}\left(\ln y_{1 i}-\ln y_{2 i}\right)
$$

Donde $L=\left\{i: y_{2 i}<y_{1 i}\right\}$. En otras palabras, $L$ es el conjunto de los hogares "perdedores" (aquellos cuyo ingreso se reduce de un período al otro). Nos referimos al primer término como "efecto crecimiento" y al segundo término como "efecto transferencia" y analizamos sus tamaños relativos para cada país.

A continuación, procedemos a realizar ejercicios de descomposición de la inestabilidad por fuentes de ingresos. En primera instancia, dividimos el ingreso de los hogares en ingresos laborales y no laborales; en segunda instancia, los ingresos no laborales son divididos entre los provenientes de jubilaciones y pensiones, por un lado, y un colectivo amplio que denominamos "otros ingresos no laborales", por el otro. Este segundo grupo engloba transferencias de ingresos (posiblemente originadas en planes de ayuda social), así como ingresos por remesas y otras fuentes similares. De este modo, resulta de interés calcular la contribución de cada uno de estos componentes a la inestabilidad total observada. También es posible realizar una descomposición interesante al interior de los ingresos laborales, ya que estos pueden modificarse por dos razones distintas: porque individuos en el hogar entran o salen del mercado de trabajo, o bien porque individuos que se mantienen en el mercado de trabajo perciben cambios en sus remuneraciones reales.

Una limitación de la medida utilizada reside en el hecho de que no es aditivamente descomponible por fuentes de ingresos, de modo tal que no es posible computar la contribución específica de cada fuente a la inestabilidad efectivamente observa- 
da. Para superar esta dificultad, recurrimos a la metodología de microsimulación. Simulamos un ingreso constante en todas las fuentes excepto una y de ese modo obtenemos una medida de la contribución de esa fuente a la variabilidad del ingreso total. Por ejemplo, para calcular la contribución a la inestabilidad de los ingresos no laborales realizamos los cálculos siguientes:

$$
\begin{gathered}
y_{t i}=y_{t i}^{L}+y_{t i}^{N L} \\
y_{2 i}^{C}=y_{1 i}^{L}+y_{2 i}^{N L} \\
m^{N L}=\frac{1}{n} \sum_{i=1}^{n}\left|\ln y_{2 i}^{C}-\ln y_{1 i}\right|
\end{gathered}
$$

Donde $y_{t i}^{L}$ y $y_{t i}^{N L}$ son el ingreso laboral y el ingreso no laboral del hogar $i$ en el período $t$ y $y_{2 i}^{C}$ es un ingreso total contrafáctico construido a partir de mantener constante el ingreso laboral observado en el período inicial e incorporar la variación observada en del ingreso no laboral. Esta metodología sencilla puede ser adaptada para calcular la contribución del ingreso laboral y de cada una de las fuentes de ingreso no laboral a la inestabilidad observada.

En cambio, la descomposición de la inestabilidad de ingresos laborales requiere un tratamiento diferente. Algunos individuos experimentan salidas o entradas al mercado de trabajo mientras que otros permanecen en él pero experimentan cambios en su remuneración. El mismo hogar puede contener ambas clases de individuos a su interior. Por lo tanto, el tratamiento aplicado aquí es diferente.

Para calcular la inestabilidad originada en movimientos de entrada o salida al mercado de trabajo (a la que llamamos "inestabilidad ocupacional"), calculamos ingresos totales contrafácticos que mantienen constantes las remuneraciones de aquellos individuos que se mantienen laboralmente activos en ambas observaciones, ajustadas por el incremento promedio en el salario real verificado entre ambos períodos. En cambio, para calcular la inestabilidad originada en cambios en las remuneraciones de los individuos que permanecen en el mercado de trabajo (a la que llamamos "inestabilidad salarial") imputamos ingresos laborales a aquellos individuos que entran o salen del mercado de trabajo. Cuando un individuo no posee ingreso laboral en una observación pero sí en la otra, se le imputa la observación faltante con la del otro período, ajustada por inflación. De este modo obtenemos medidas de inestabilidad ocupacional y salarial respectivamente. 
Sin embargo, esta metodología enfrenta una limitación. La contribución de una fuente de ingresos determinada a la inestabilidad observada puede ser pequeña porque dicha fuente presenta movimientos pequeños en el tiempo o bien porque su peso relativo en el ingreso total de los hogares es reducida. Esta distinción resulta de cabal interés en nuestra base de datos dado que, como mostramos a continuación, en los países latinoamericanos los ingresos no laborales presentan elevada variabilidad en el tiempo pero su participación en el ingreso total de los hogares es por lo general baja. Por este motivo, un ejercicio alternativo consiste en calcular el índice $m$ para una fuente de ingreso específica, ignorando los ingresos por otras fuentes. De este modo obtenemos una medida de la inestabilidad específica de la fuente independientemente de su contribución a la volatilidad total del ingreso del hogar. Este cálculo se realiza de manera directa para la descomposición entre ingresos laborales y no laborales y también para la descomposición de los ingresos no laborales entre ingresos por pensiones y otros no laborales.

En cambio, para la descomposición de los ingresos laborales es preciso recurrir nuevamente a la imputación de ingresos. Para calcular la inestabilidad ocupacional específica, se computa $m$ solo sobre el ingreso laboral y para aquellos hogares que verifican al menos una entrada o salida del mercado de trabajo en alguno de sus miembros, nuevamente imputando salarios a los individuos que permanecen en el mercado de trabajo. Por otro lado, para calcular la inestabilidad salarial específica, el mismo cómputo se realiza sobre los hogares que no verifican entradas ni salidas entre sus miembros, sin mantener constantes sus salarios.

Debemos introducir una última modificación merced a las limitaciones de las bases de datos utilizadas. Las encuestas de hogares de México y Brasil solo relevan ingresos laborales, de modo que en esos países solo es posible utilizar este tipo de ingresos en los cálculos. Para preservar la comparabilidad, los cálculos realizados en los demás países son reproducidos eliminando los ingresos no laborales del total, sin que esto arroje diferencias relevantes en los resultados.

\section{Fuentes de información}

Perú es el único país de América Latina que realiza una encuesta de hogares de tipo longitudinal. En los restantes países, construimos paneles explotando el esquema rotativo de las encuestas de hogares convencionales. Estos esquemas reducen el costo del muestreo rotando una parte de la muestra entre cada relevamiento, de modo que el mismo hogar es visitado una cierta cantidad de veces a lo largo de una determinada ventana temporal. Dado que no todas las encuestas tienen cobertura nacional, 
y atendiendo a las diferencias que suelen existir entre los mercados de trabajo urbano y rural, restringimos el análisis a las áreas urbanas. Para deflactar los ingresos relevados se utilizó el índice de precios al consumidor oficial de cada país, excepto para el caso de Argentina donde la manipulación de estadísticas obliga a utilizar un índice de precios construido a partir de promedios de índices provenientes de institutos de estadísticas provinciales que mantuvieron relevamientos confiables.

A continuación detallamos las encuestas empleadas para cada país y el período cubierto por cada una:

- Argentina: Encuesta Permanente de Hogares (EPH), realizada por el Instituto Nacional de Estadísticas y Censos (INDEC), 2003-2015

- Brasil: Pesquisa Mensal de Emprego (PME), realizada por el Instituto Brasileiro de Geografia e Estadistica (IBGE), 2003-2015

- Costa Rica: Encuesta de Hogares de Propósitos Múltiples (EHPM), luego reemplazada por la Encuesta Nacional de Hogares, ambas realizadas por el Instituto Nacional de Estadística y Censos (INEC), 2006-2009 y 20102013 respectivamente

- Ecuador: Encuesta Nacional de Empleo, Desempleo y Subempleo (ENEMDU), realizada por el Instituto Nacional de Estadística y Censos (INEC), 2004-2014

- México: Encuesta Nacional de Ocupación y Empleo (ENOE), realizada por el Instituto Nacional de Estadística y Geografía (INEGI), 2005-2015

- Paraguay: Encuesta Continua de Empleo (ECE), realizada por la Dirección General de Estadística, Encuestas y Censos (DGEEC), 2010-2014

- Perú: Encuesta Nacional de Hogares (ENAHO), realizada por el Instituto Nacional de Estadistica e Informatica (INEI), 2002-2010

Es posible que la cantidad efectiva de observaciones en cada relevamiento no coincida con la que dictamina el esquema rotativo debido al tradicional problema de atrición existente en paneles. Sin embargo, estas encuestas no contienen variables que puedan ser utilizadas como insumo para aplicar correcciones por sesgo de selección, de modo tal que este problema es ignorado en el análisis posterior. Del mismo modo, es sabido que estas encuestas pueden sufrir de error de medición en la recolección de información sobre ingresos. Realizamos algunas pruebas de robustez sobre los resultados discutidos en la sección 6 que nos llevan a concluir que el error de medición no resulta de una magnitud relevante para nuestros fines. 


\section{Tendencias recientes en la performance económica en América Latina}

A comienzos de este siglo, América Latina inició un proceso de vigoroso crecimiento económico, posiblemente el más acelerado de la historia de la región. Este fue particularmente intenso entre 2003 y 2008, cuando el PBI per cápita de la región creció a una tasa anual de $3,7 \%$. A partir de 2009 , la tasa de crecimiento se redujo sensiblemente (lo que es frecuentemente atribuido al impacto de la crisis financiera internacional sobre los países de la región), aunque se mantuvo en niveles elevados para la historia de la región (1,8\% anual entre 2009 y 2015).

El rápido crecimiento económico favoreció particularmente la creación de puestos de trabajo, especialmente en el sector formal. La tasa de empleo media de la región aumentó de 52,7\% a 55,7\% entre 2003 y 2015, mientras que la tasa de desempleo cayó de $11,2 \%$ a $6,6 \%$ en el mismo período. Estas mejoras fueron particularmente notorias entre 2003 y 2008 y continuaron luego de 2009 aunque a un ritmo menor.

Este marco de crecimiento económico combinado con mejora en los mercados de trabajo de la región propició un fuerte crecimiento de los salarios, aunque también es importante subrayar la importancia de diversas políticas laborales implementadas en estos países, tales como aumentos sustanciales del salario mínimo, fortalecimiento de las negociaciones colectivas y fiscalización laboral. De este modo, la proporción de trabajadores cubiertos por la seguridad social aumentó de una media de 67,6\% en 2000 a 79,4\% en 2015. Asimismo, diversos trabajos documentan una reducción sustancial de la desigualdad de ingresos en este período ${ }^{18}$. También se aprecia una reducción fuerte en la pobreza por ingresos, de un nivel medio de 43,9\% en 2002 a $29,2 \%$ en $2015^{19}$.

Los siete países analizados en este trabajo exhiben una performance algo superior a la del resto de los países de la región. La tasa de crecimiento anual media del PBI per cápita a lo largo de toda la ventana temporal considerada es de 2,7\% para estos países y de solo 2,2\% para el conjunto de la región. Argentina y Perú exhiben los mayores ritmos de crecimiento medio aunque en el primer caso este se concentró mayormente en el período 2003-2008 para luego sufrir una considerable desaceleración (y algo similar ocurrió en Brasil). Las mejoras en indicadores sociales y laborales también son sustanciales en los países analizados, donde nuevamente se aprecian importantes aumentos en la tasa de empleo, así como caídas relevantes en la tasa de

\footnotetext{
${ }^{18}$ Amarante y Arim (2015), Beccaria, Maurizio y Vázquez (2015).

${ }^{19}$ ECLAC (2014).
} 
desempleo y en la proporción de empleo informal. Costa Rica y México exhiben las peores performances en este aspecto, aunque nuevamente estas resultan muy positivas en relación a la experiencia histórica de estos países.

No resulta evidente a priori cuál debería ser el efecto del crecimiento económico sobre la inestabilidad o variabilidad temporal de los ingresos de los hogares. Por un lado, resulta claro que en este contexto macroeconómico muchos hogares experimentan trayectorias ascendentes en sus ingresos debido a ingresos de sus miembros al mercado de trabajo, aumentos de salarios o una combinación de ambos efectos. Sin embargo, mostramos en la sección siguiente que la proporción de trayectorias descendentes se mantiene en valores relevantes, factiblemente debido a ciertas características negativas de los mercados de trabajo que persisten de la región (principalmente la debilidad de las instituciones laborales y la informalidad, que conducen a una elevada inestabilidad ocupacional y también salarial). De este modo, no resulta claro que la inestabilidad debiera ser menor que en otros períodos. En cambio, tanto el contexto institucional general como la estructura del mercado de trabajo sí sugieren niveles de volatilidad de ingresos mayores que los de las economías desarrolladas (donde la fortaleza de las instituciones laborales debería amortiguar los movimientos en los ingresos).

\section{Resultados}

\subsection{Estadística descriptiva}

Para comenzar, presentamos en el Cuadro 1 un resumen descriptivo de la información contenida en la base de datos utilizada. En lo sucesivo y a lo largo de toda esta sección, los ingresos utilizados son deflactados por el índice de precios al consumidor correspondiente a cada país, de modo que en todo momento las variaciones computadas de ingresos son reales y no nominales.

Cuadro 1. Estadística descriptiva

\begin{tabular}{lccccccc} 
& Argentina & Brasil & Costa Rica & Ecuador & México & Paraguay & Perú \\
\hline Período cubierto & $2003-2015$ & $2003-2015$ & $2006-2013$ & $2004-2014$ & $2005-2015$ & $2010-2014$ & $2002-2010$ \\
Cantidad de hogares (sin ponderación) & 45,201 & 625,797 & 6,414 & 39,000 & 539,104 & 937 & 6,193 \\
& & & & & & & \\
Cantidad de hogares (con ponderación) & $17,446,870$ & $311,586,220$ & $1,028,582$ & $9,116,317$ & $141,286,050$ & 699,019 & $15,201,894$ \\
$\begin{array}{l}\text { Tasa de crecimiento anual promedio del } \\
\text { ingreso total del hogar }\end{array}$ & $13.2 \%$ & & $18.9 \%$ & $27.0 \%$ & & $16.3 \%$ & $19.4 \%$ \\
$\begin{array}{l}\text { Tasa de crecimiento anual promedio del } \\
\text { ingreso laboral del hogar }\end{array}$ & $9.9 \%$ & $3.4 \%$ & $13.9 \%$ & $21.7 \%$ & $2.2 \%$ & $14.0 \%$ & $22.2 \%$ \\
$\begin{array}{l}\text { Participación media del ingreso laboral en el } \\
\text { total del hogar }\end{array}$ & $68.7 \%$ & & $72.1 \%$ & $79.7 \%$ & & $74.4 \%$ & $79.4 \%$
\end{tabular}

Fuente: Elaboración propia en base a encuestas de hogares (ver sección 4) 
La cantidad de hogares reportada en cada caso corresponde al total de hogares en el panel que cuentan con datos sobre ingresos y por lo tanto resultan útiles para los fines de este trabajo. Como se puede observar, el tamaño de la muestra varía mucho de un país a otro pero todas gozan de elevada representatividad por tratarse de relevamientos oficiales y satisfacen requisitos generales de potencia estadística. De acuerdo con lo explicado en la sección anterior, el período analizado exhibe un importante crecimiento del ingreso real de los hogares en la región, lo que se corresponde con lo observado en nuestra muestra. Todos los países que cuentan con información sobre ingreso total del hogar registran una tasa de crecimiento media anual de dos dígitos. En cambio, cuando se analiza el ingreso laboral de los hogares, el panorama resulta más variado, con valores más reducidos en Brasil y México y más elevados en Ecuador y Perú ${ }^{20}$.

Resulta claro que el crecimiento del ingreso total de los hogares responde en parte a aumentos en el ingreso no laboral, como fruto de la aplicación de diversas políticas públicas entre las que destacan la ampliación de la cobertura previsional y las transferencias condicionales de ingresos a los hogares. Sin embargo, una fuerte limitación de estas políticas en Latinoamérica es que, aun en los casos en que logran amplia cobertura, los ingresos que los hogares reciben a través de ellas son reducidos. Podemos constatar esto en la fila correspondiente del Cuadro 1, donde se observa que la participación del ingreso laboral en el total del hogar oscila en torno a las tres cuartas partes (Argentina es el país donde mayor peso relativo presenta el ingreso no laboral, que en promedio explica más del $31 \%$ del ingreso total del hogar). Esto tiene importancia para el análisis de la inestabilidad de ingresos ya que, como veremos a continuación, el ingreso laboral y el no laboral exhiben niveles de variabilidad muy diferentes.

Para entender la importancia de la inestabilidad de ingresos en las economías latinoamericanas, resulta de interés analizar las trayectorias de ingresos observadas en el período bajo análisis. El Gráfico 1 muestra, para cada país, la proporción de hogares según su ingreso total aumente, disminuya o se mantenga constante entre la primera y la segunda observación. También presentamos estos cálculos aplicando umbrales de $10 \%$ y $20 \%$, es decir, suponiendo que los cambios menores a esas magnitudes son nulos. El uso de estos umbrales responde a dos razones. En primer lugar, los ingresos captados en encuestas suelen sufrir error de medición, de modo que las va-

\footnotetext{
${ }^{20}$ Para el cálculo de los valores presentados en el Cuadro 1, se eliminó el $1 \%$ de los valores mayores de las tasas de crecimiento de los ingresos, una variable cuya distribución es fuertemente asimétrica.
} 
riaciones pequeñas podrían atribuirse a un problema de este tipo y no a genuina inestabilidad. En segundo lugar, se podría argumentar que variaciones pequeñas no tienen un impacto relevante en el bienestar de los hogares.

\section{Gráfico 1. Trayectorias de ingresos}

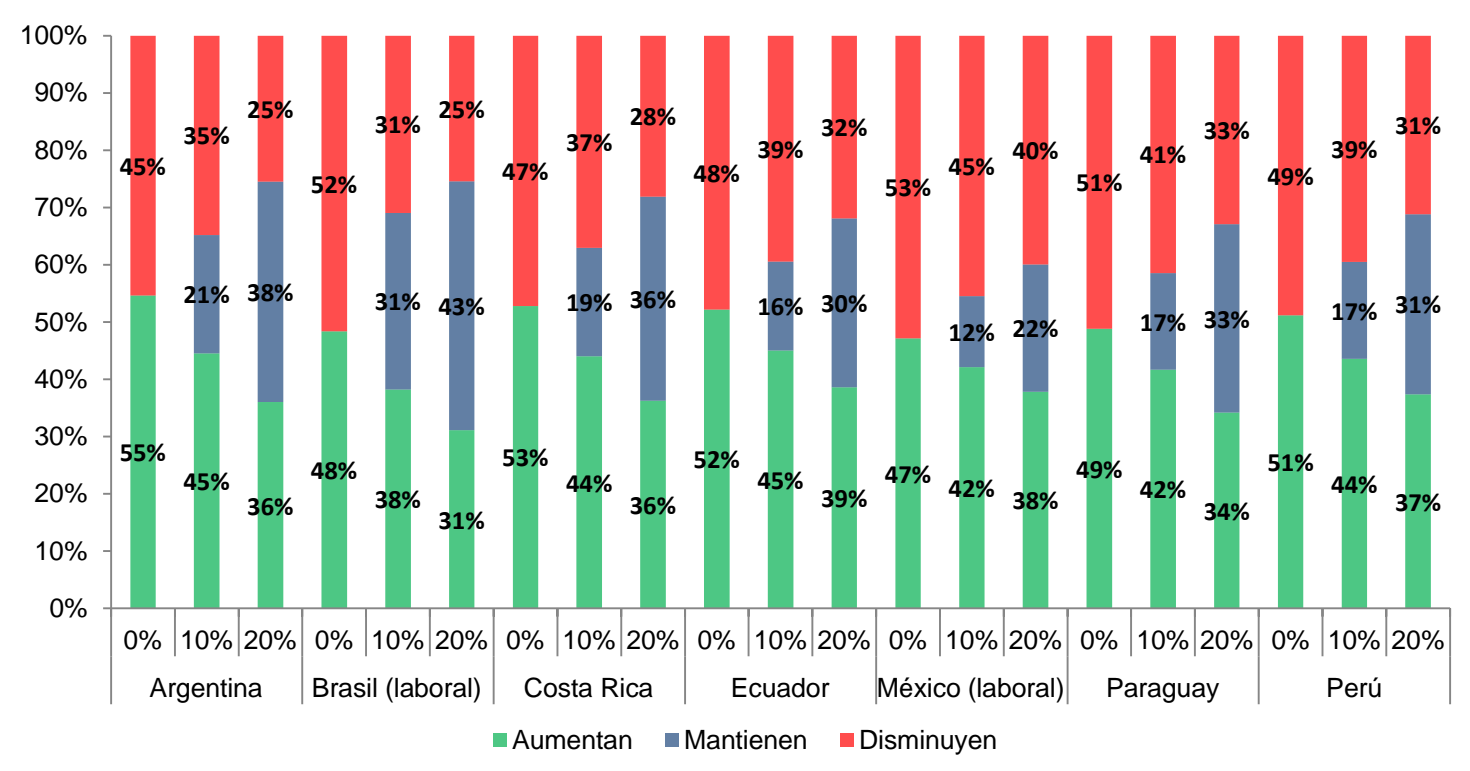

Fuente: Elaboración propia en base a encuestas de hogares (ver sección 4)

La principal conclusión que se obtiene del análisis del Gráfico 1 radica en que, en todos los países, se observa una elevada proporción de caídas en los ingresos. Aun recurriendo al umbral más exigente de $20 \%$, encontramos una proporción considerable de hogares que experimentan reducciones de esa magnitud o mayores de un año al siguiente, proporción que oscila entre el $25 \%$ observado en Argentina y el $42 \%$ observado en México. Asimismo, en la mayoría de los casos, la proporción de hogares cuyo ingreso se mantiene constante es reducida, particularmente en Ecuador, México, Paraguay y Perú, donde aun aplicando el umbral de $20 \%$ esta es inferior a un tercio.

Podemos interpretar esto como evidencia del fenómeno conocido como inseguridad de ingresos: la probabilidad que enfrenta un hogar de experimentar una reducción considerable en sus ingresos de un año a otro es elevada. Este hallazgo resulta de particular importancia si se tiene en cuenta que, de acuerdo con lo explicado en la sección anterior, el período analizado está caracterizado por un acelerado crecimiento económico y una mejora sustancial en los indicadores del mercado de trabajo. Aun en un contexto macroeconómico favorable, las economías latinoamericanas presentan una preocupantemente elevada proporción de hogares que experimentan caídas en sus ingresos reales. Este problema es aún más importante si recordamos que se trata de economías donde el acceso al mercado de crédito es muy restringido, lo que impli- 
ca que las familias no cuentan con mecanismos de mercado para suavizar este tipo de fluctuaciones en el tiempo.

\subsection{Intensidad de la inestabilidad de ingresos y evolución temporal}

El Gráfico 2 presenta los resultados del cálculo de la inestabilidad de ingresos a partir del indicador $m$ discutido en la sección 3. Calculamos la inestabilidad de los ingresos totales y también la de los ingresos laborales para permitir la comparabilidad entre todos los países incluidos en este trabajo.

\section{Gráfico 2. Inestabilidad de ingresos por país}

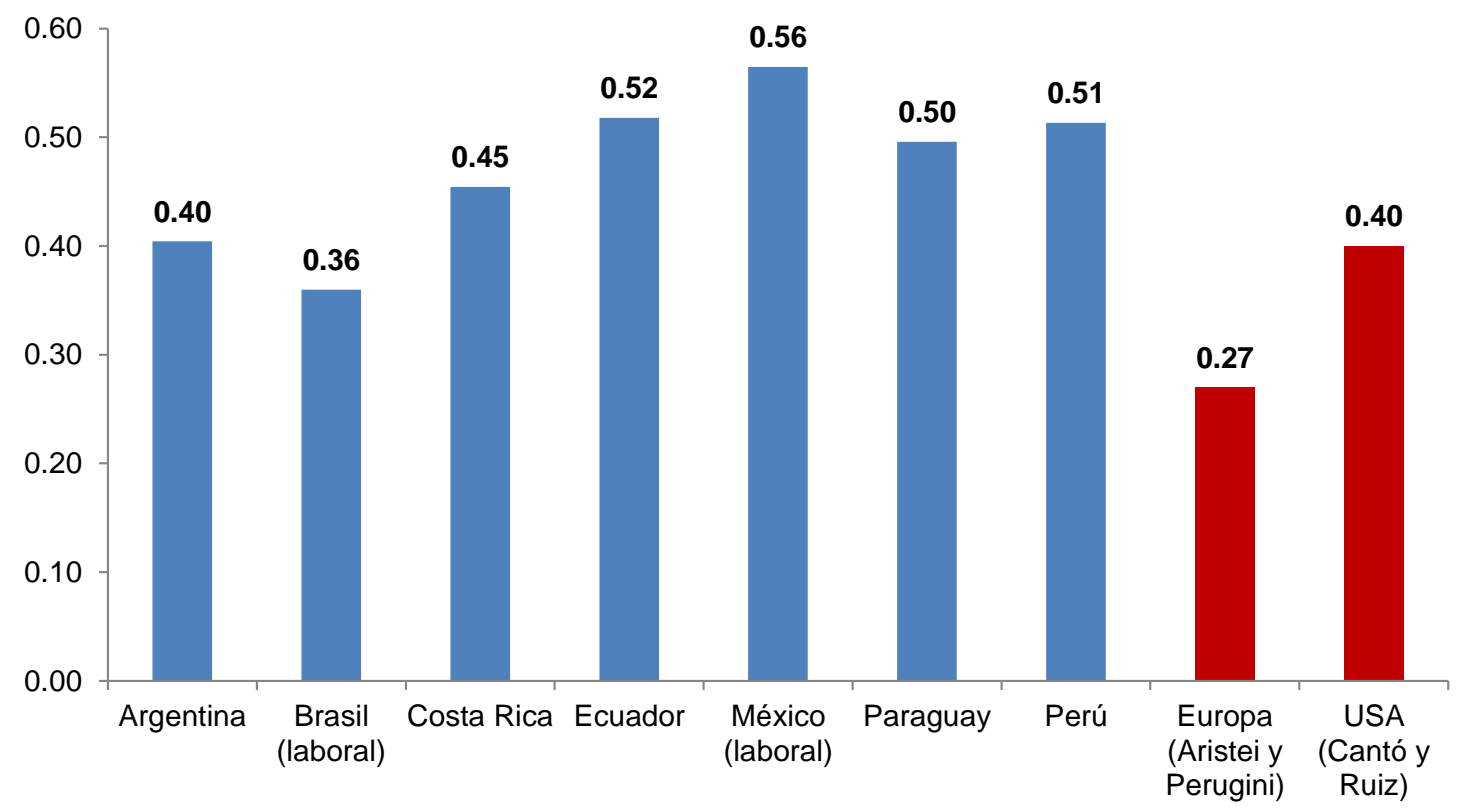

Fuente: Elaboración propia en base a encuestas de hogares (ver sección 4)

Nuestros resultados muestran cierta variabilidad en el nivel de inestabilidad de ingresos entre países. Si analizamos el ingreso total, Brasil muestra el nivel más bajo de inestabilidad $(0,36)$, mientras que México registra el nivel más alto $(0,56)$. Ecuador, Paraguay y Perú se ubican en niveles elevados (mayores a 0,5), mientras que Argentina registra un valor bajo $(0,4)$ y Costa Rica uno intermedio $(0,45)$. Debe tenerse en cuenta que en Brasil y México estos valores corresponden al ingreso laboral; en los países donde el ingreso no laboral es observado, la inestabilidad del ingreso total es ligeramente menor a la del ingreso laboral, de modo tal que es posible que lo mismo ocurra en esos países, lo que acercaría más a México al resto de los casos presentados y reduciría aún más el nivel de Brasil.

En líneas generales, estos valores resultan elevados si se los compara con los presentados por otros trabajos que utilizan el mismo indicador para medir la intensidad 
de la inestabilidad de ingresos en países desarrollados. Por ejemplo, Aristei y Perugini (2015) calculan esta medida para 25 países europeos para 2004-2006 y obtienen un valor promedio de 0,27 , con solo 3 países por encima de 0,4 . Por su parte, Cantó y Ruiz (2014) obtienen un valor medio de 0,4 para Estados Unidos y España, también para el período 2004-2006. Por otro lado, Chen (2009) presenta resultados para Canáda, Estados Unidos, Gran Bretaña y Alemania utilizando ventanas de cinco años. Los promedios obtenidos para cada país son, respectivamente, 0,31, 0,4, 0,39 y 0,27. Esto significa que de los países analizados aquí solo Argentina y Brasil presentan valores similares a los de países desarrollados, mientras que el resto de nuestra muestra se ubica en niveles sensiblemente mayores.

Este elevado nivel de fluctuación de los ingresos en el tiempo puede reflejar, hasta cierto punto, el favorable contexto macroeconómico que caracteriza a este período para América Latina, ya que el aumento en el empleo, la formalización laboral y el crecimiento en las transferencias a los hogares factiblemente contribuyeron a una movilidad ascendente de los ingresos. Sin embargo, como vimos en el Gráfico 1, estos aumentos coexistieron con caídas de magnitud similar, lo que podemos atribuir a los elevados niveles de informalidad, inestabilidad y rotación ocupacional que históricamente caracterizan a la región ${ }^{21}$. También es posible que los ingresos no laborales hayan sufrido reducciones relevantes como consecuencia de cambios institucionales en las políticas públicas aplicadas.

Como explicamos en la sección 3, Fields y Ok proponen una descomposición del indicador $m$ en un componente que captura el efecto del crecimiento del ingreso y otro que captura la transferencia de ingreso entre hogares. Realizamos esta descomposición tanto para el ingreso total como para el ingreso laboral y exponemos los resultados en el Cuadro 2.

Cuadro 2. Descomposición de Fields y Ok

\begin{tabular}{|c|c|c|c|c|c|c|c|}
\hline & Argentina & Brasil & Costa Rica & Ecuador & México & Paraguay & Perú \\
\hline \multicolumn{8}{|c|}{ Ingreso total } \\
\hline Inestabilidad total & 0,40 & & 0,45 & 0,52 & & 0,50 & 0,51 \\
\hline Crecimiento & 0,03 & & 0,03 & 0,03 & & $-0,02$ & 0,00 \\
\hline Transferencia & 0,37 & & 0,43 & 0,49 & & 0,51 & 0,51 \\
\hline \multicolumn{8}{|c|}{ Ingreso laboral } \\
\hline Inestabilidad total & 0,43 & 0,36 & 0,48 & 0,54 & 0,56 & 0,50 & 0,57 \\
\hline Crecimiento & 0,05 & 0,04 & 0,03 & 0,03 & $-0,03$ & 0,02 & 0,02 \\
\hline Transferencia & 0,38 & 0,32 & 0,45 & 0,51 & 0,59 & 0,48 & 0,55 \\
\hline
\end{tabular}

Fuente: Elaboración propia en base a encuestas de hogares (ver sección 4)

\footnotetext{
${ }^{21}$ Maurizio (2016) analiza el fenómeno de los contratos a término entre los trabajadores formales. La evidencia presentada indica que el crecimiento de esta modalidad contractual podría ser un factor explicativo de la inestabilidad del ingreso laboral.
} 
Tanto para el ingreso total como para el laboral, podemos observar que la contribución del efecto crecimiento es muy reducida (el mayor valor que esta adopta en términos relativos lo encontramos en el caso del ingreso laboral en Argentina, donde explica el $11 \%$ de la inestabilidad total) y de hecho esta es negativa en algunos casos (Paraguay en el ingreso total, México en el laboral). Esto indica que la mayor parte de las fluctuaciones captadas por el indicador corresponden a un proceso donde el ingreso de unos hogares aumenta mientras el de otros disminuye y no a un proceso de crecimiento uniforme de los ingresos. Este hallazgo refuerza la interpretación que proponemos de los resultados anteriores: observamos un proceso donde el crecimiento económico y la recuperación de los indicadores laborales coexiste con importantes reducciones de corto plazo en el ingreso de algunos hogares, lo que configura un cuadro de inestabilidad de ingresos elevada que afecta negativamente el bienestar de los hogares.

\section{Gráfico 3. Evolución de la inestabilidad en el tiempo}

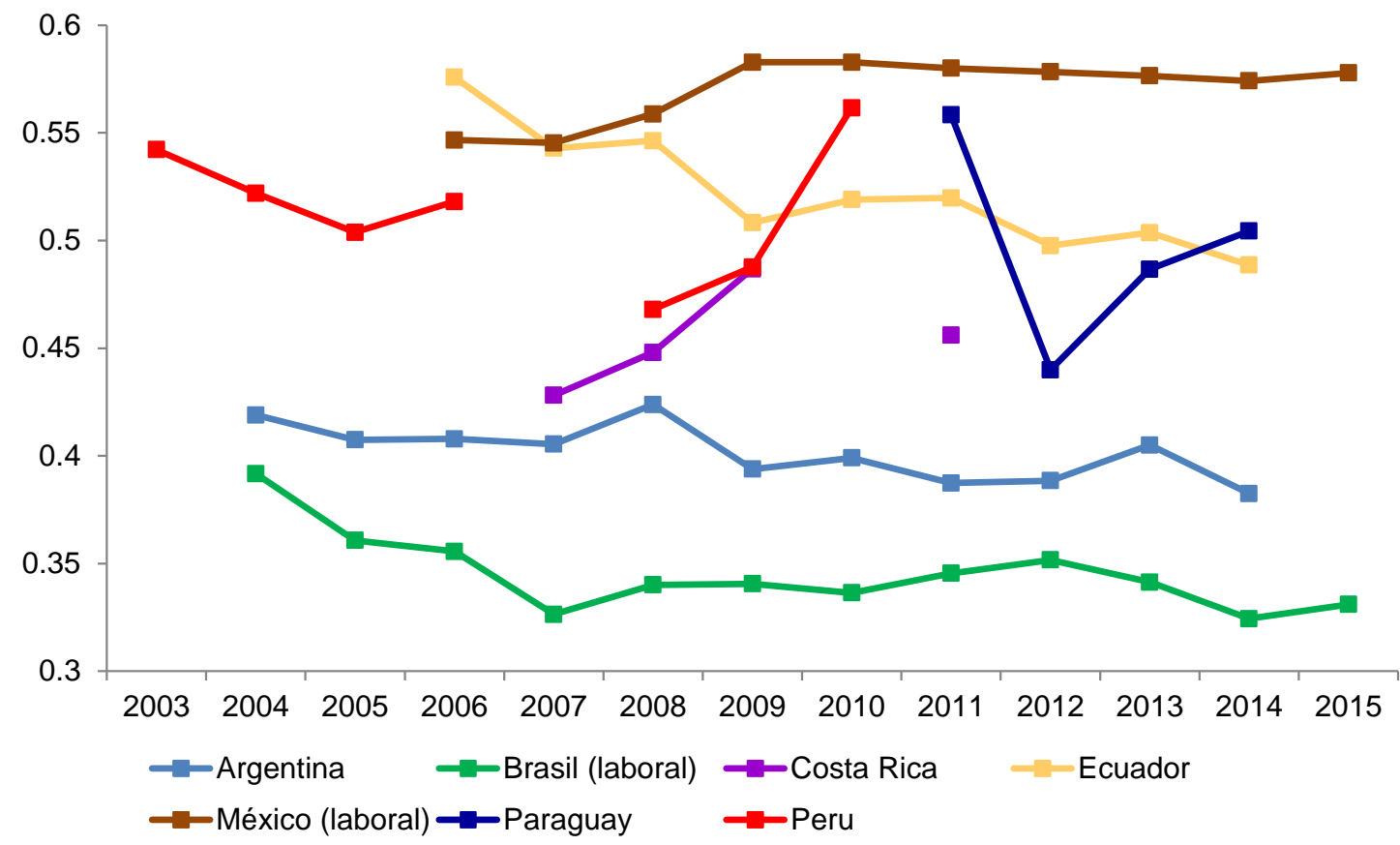

Fuente: Elaboración propia en base a encuestas de hogares (ver sección 4)

Por último, el Gráfico 3 analiza la evolución de la inestabilidad de ingresos medida año por año en cada país. De conjunto, no se observa un patrón uniforme en los países analizados. En Argentina y Brasil, el nivel de inestabilidad se mantiene aproximadamente constante en el tiempo. En México, se observa una tenue tendencia positiva, mientras que en Ecuador ocurre lo contrario. En los restantes países, la cantidad de años observados es muy pequeña, lo cual, sumado a la presencia de algunos saltos, impide extraer conclusiones útiles. Tampoco se aprecian quiebres generales en 
las series; en particular, no observamos efectos perceptibles de la crisis financiera de 2008/09, hipótesis que ha sido explorada en la literatura centrada en países desarrollados.

\subsection{Descomposición de la inestabilidad por fuentes de ingresos}

Los Cuadros 3 y 4 presentan los resultados de las microsimulaciones realizadas para computar la importancia de cada fuente de ingresos en la inestabilidad de ingresos observada de acuerdo a lo desarrollado en la sección 3. En el Cuadro 3 utilizamos el ingreso total, para aquellos países de la muestra donde ello es posible, mientras que en el Cuadro 4 se emplean solo ingresos laborales, con el fin de permitir la comparabilidad con Brasil y México.

Cuadro 3. Descomposición de la inestabilidad por fuentes. Ingreso total

\begin{tabular}{lccccc} 
& Argentina & Costa Rica & Ecuador & Paraguay & Perú \\
\hline No laboral & 0,15 & 0,13 & 0,16 & 0,19 & 0,15 \\
\hline No laboral: jubilaciones y pensiones & 0,09 & 0,05 & 0,04 & 0,04 & 0,03 \\
No laboral: otros & 0,08 & 0,10 & 0,14 & 0,16 & 0,14 \\
\hline Laboral & 0,33 & 0,39 & 0,46 & 0,40 & 0,47 \\
\hline Laboral: salarios & 0,29 & 0,29 & 0,35 & 0,30 & 0,19 \\
Laboral: ocupación & 0,27 & 0,45 & 0,49 & 0,50 & 0,87 \\
\hline Total & 0,40 & 0,45 & 0,52 & 0,50 & 0,51
\end{tabular}

Fuente: Elaboración propia en base a encuestas de hogares (ver sección 4)

\section{Cuadro 4. Descomposición de la inestabilidad por fuentes. Ingreso laboral}

\begin{tabular}{lccccccc} 
& Argentina & Brasil & Costa Rica & Ecuador & México & Paraguay & Perú \\
\hline Laboral & 0,43 & 0,36 & 0,48 & 0,54 & 0,56 & 0,50 & 0,57 \\
\hline Laboral: salarios & 0,26 & 0,21 & 0,27 & 0,32 & 0,23 & 0,25 & 0,18 \\
Laboral: ocupación & 0,17 & 0,15 & 0,41 & 0,46 & 0,32 & 0,44 & 0,97
\end{tabular}

Fuente: Elaboración propia en base a encuestas de hogares (ver sección 4)

Del análisis del Cuadro 3 se desprenden diversas conclusiones. En primer lugar, la principal fuente de inestabilidad de los ingresos de los hogares son las fluctuaciones en los ingresos laborales. La contribución de la volatilidad en ingresos no laborales al total observado es, en general, pequeña, con valor máximo en Paraguay y valor mínimo en Argentina. Una diferencia importante entre los países analizados es que, mientras en Argentina la inestabilidad originada en movimientos en jubilaciones es similar a la originada en movimientos de otros ingresos no laborales, esto no es así en el resto de los países, donde las jubilaciones o pensiones presentan una contribución menor que la del segundo grupo de ingresos no laborales. Factiblemente pueda atribuirse este fenómeno a la ampliación de la cobertura previsional operada en Argentina a comienzos del período analizado, cuando esta alcanzó, durante cierto tiempo al menos, 
a la casi totalidad de individuos pasivos, fenómeno que no ocurrió en los restantes países (aunque tampoco es posible descartar la influencia de los problemas de captación de los ingresos no laborales en los relevamientos).

En segundo lugar, al analizar los ingresos laborales constatamos que la inestabilidad salarial y la ocupacional tienen magnitudes similares en Argentina pero esto no ocurre en el resto de la muestra: en los restantes países, las fluctuaciones causadas por entradas y salidas de individuos al mercado de trabajo son mayores que las generadas por cambios en las remuneraciones. Argentina presenta la variabilidad de ingresos laborales más reducida y Perú la más alta (el ordenamiento es casi idéntico al que se obtiene analizando la inestabilidad total, aunque Perú y Ecuador intercambian lugares por pequeñas diferencias no significativas).

Los resultados se mantienen en líneas generales al eliminar los ingresos no laborales del análisis, aunque al hacerlo la inestabilidad salarial en Argentina se vuelve algo mayor que la ocupacional. Por otro lado, la incorporación de Brasil y México al análisis ofrece un panorama más variado en la medida en que la inestabilidad salarial es ligeramente más alta que la ocupacional en el primero, mientras que esta última es llamativamente reducida en el segundo. Es posible que estos resultados respondan a características particulares de los mercados de trabajo de cada país, donde la proporción de contratos a tiempo determinado y el nivel de rotación laboral son de importancia crucial (Maurizio, 2016).

Como explicamos en la sección 3, este análisis enfrenta una limitación importante en la medida en que la contribución de una determinada fuente de ingresos a la inestabilidad observada puede ser reducida debido a la baja volatilidad en dicha fuente o bien a la reducida participación de la misma en el ingreso total del hogar. Como indica el Cuadro 1, la participación del ingreso no laboral en el total del hogar es siempre inferior al 32\%, de modo que los valores bajos observados en la primera línea del Cuadro 3 podrían deberse a esta segunda razón. Para ampliar el análisis, presentamos en los Cuadros 4 y 5 los niveles de inestabilidad para cada fuente específica. 
Cuadro 5. Inestabilidad específica por fuentes de ingreso. Ingreso total

\begin{tabular}{lccccc} 
& Argentina & Costa Rica & Ecuador & Paraguay & Perú \\
\hline No laboral & 0,36 & 0,50 & 0,52 & 0,56 & 0,81 \\
\hline No laboral: jubilaciones y pensiones & 0,27 & 0,26 & 0,34 & 0,26 & 0,18 \\
No laboral: otros & 0,47 & 0,68 & 0,57 & 0,66 & 0,98 \\
\hline Laboral & 0,44 & 0,48 & 0,54 & 0,50 & 0,57 \\
\hline Laboral: salarios & 0,34 & 0,35 & 0,41 & 0,33 & 0,27 \\
Laboral: ocupación & 0,56 & 0,66 & 0,66 & 0,69 & 1,04 \\
\hline
\end{tabular}

Fuente: Elaboración propia en base a encuestas de hogares (ver sección 4)

Cuadro 6. Inestabilidad específica por fuentes de ingreso. Ingreso laboral

\begin{tabular}{lccccccc} 
& Argentina & Brasil & Costa Rica & Ecuador & México & Paraguay & Perú \\
\hline Laboral & 0,43 & 0,36 & 0,48 & 0,54 & 0,56 & 0,50 & 0,57 \\
\hline Laboral: salarios & 0,34 & 0,25 & 0,35 & 0,41 & 0,40 & 0,33 & 0,27 \\
Laboral: ocupación & 0,54 & 0,54 & 0,66 & 0,66 & 0,66 & 0,69 & 1,04
\end{tabular}

Fuente: Elaboración propia en base a encuestas de hogares (ver sección 4)

La contribución reducida de los ingresos no laborales a la inestabilidad total no es fruto de su menor volatilidad, sino de su reducida participación en el ingreso total del hogar. De hecho, el ingreso no laboral es más volátil que el laboral en Costa Rica, Paraguay y Perú (en este último caso la diferencia es particularmente grande). A su vez, cabe destacar la inestabilidad observada en la categoría otros ingresos no laborales, que resulta particularmente elevada en todos los países (se trata del segundo componente más volátil en todos los países excepto en Costa Rica, donde es el primero).

En lo que respecta a la inestabilidad laboral, resulta ahora claro que la de origen ocupacional es siempre mayor en tamaño a la de origen salarial (la diferencia es particularmente alta en Perú). En el caso particular de Argentina, esta diferencia es considerable, lo que indica que el resultado hallado en el análisis del Cuadro 3 responde al hecho de que las entradas y salidas del mercado de trabajo tienen una frecuencia relativamente baja. Este hallazgo es razonable a la luz del hecho de que el mercado de trabajo argentino exhibió una de las mejores performances en el período analizado, particularmente entre 2003 y 2008.

El indicador $m$ utilizado como medida de movilidad, a pesar de sus propiedades teóricas analizadas en la sección 3, podría resultar problemático en estos ejercicios de microsimulación, dado que solo está definido para ingresos estrictamente positivos. Los casos de hogares con ingreso total nulo en la base de datos son escasos y fueron descartados de lleno por considerarlos fruto del error de medición habitual en este tipo de encuestas. Sin embargo, un valor nulo en alguna fuente particular sí es razonable a 
priori, lo que indica que su exclusión en los cálculos anteriores (particularmente en los presentados en los Cuadros 5 y 6) podría ser incorrecta.

Para constatar que la elección del indicador no tiene un peso sustancial en los resultados obtenidos, incluimos en el Anexo $A$ los resultados alcanzados utilizando otros dos indicadores de movilidad de ingresos. El primero es el que corresponde a Fields y Ok (1996), donde los autores plantean una axiomática diferente y arriban a una medida similar a $m$ pero sin logaritmos (que llaman $d$ ), lo que elimina el problema de trabajar con valores nulos. El segundo es el coeficiente de variación (CV) tradicional que, si bien no proviene de una formulación axiomática, ha sido utilizado asiduamente en la literatura (por ejemplo en Beccaria y Groisman (2006)). Reproducimos los cálculos de inestabilidad específica por fuente de ingresos para cada uno de estos indicadores y presentamos los resultados, que no exhiben diferencias conceptualmente relevantes. Si bien las magnitudes relativas cambian (en algunos casos, sensiblemente), los resultados aquí analizados se mantienen.

\subsection{Determinantes de la inestabilidad: algunas hipótesis}

No resulta claro a priori cuáles son los determinantes del nivel de inestabilidad de ingresos observado en una economía, un interrogante que aún no ha sido abordado en profundidad en la literatura teórica. De acuerdo con los resultados anteriores, podemos afirmar que las condiciones estructurales del mercado de trabajo tienen importancia capital, pero al mismo tiempo es factible que las características de los hogares sean capaces de explicar una parte relevante de los niveles observados. En este apartado, contribuimos a enriquecer la interpretación de los resultados anteriores proveyendo evidencia exploratoria para estos dos fenómenos.

Para ilustrar la importancia de las condiciones laborales en la determinación de la inestabilidad de ingresos, computamos la inestabilidad de los ingresos a nivel individual en lugar del hogar y luego separamos el cálculo según la categoría ocupacional del individuo, distinguiendo entre asalariados formales, asalariados informales y cuentapropistas. Dado que no es inusual que el ingreso de un individuo sea nulo, utilizamos aquí el coeficiente de variación como medida de variabilidad de ingresos. El Cuadro 7 presenta los resultados obtenidos. 


\section{Cuadro 7. Inestabilidad del ingreso individual por categoría ocupacional}

\begin{tabular}{lccccccc} 
& Argentina & Brasil & Costa Rica & Ecuador & México & Paraguay & Perú \\
\hline Total & 0,38 & 0,43 & 0,39 & 0,46 & 0,74 & 0,41 & 0,50 \\
Asalariados formales & 0,25 & 0,38 & 0,27 & 0,31 & 0,61 & 0,21 & 0,29 \\
Asalariados informales & 0,52 & 0,53 & 0,55 & 0,49 & 0,72 & 0,43 & 0,50 \\
Cuentapropistas & 0,49 & 0,48 & 0,56 & 0,56 & 0,86 & 0,53 & 0,57
\end{tabular}

Fuente: Elaboración propia en base a encuestas de hogares (ver sección 4)

Los ingresos individuales son más inestables que los de los hogares, un hallazgo razonable en la medida en que factiblemente existen mecanismos de suavización de los shocks de ingresos al interior del hogar ${ }^{22}$. Sin embargo, el resultado central de este ejercicio radica en las sensibles diferencias que existen entre categorías ocupacionales: en todos los países, los asalariados formales exhiben un nivel de inestabilidad de ingresos sustancialmente menor al de las otras dos categorías. Los cuentapropistas presentan los valores más altos en todos los países a excepción de Argentina y Brasil.

Resulta claro que los puestos de trabajo formales gozan de mayor estabilidad, tanto en términos del flujo de remuneraciones percibido por el trabajador como de la continuidad del puesto en el tiempo. La informalidad laboral, una característica distintiva de los mercados de trabajo latinoamericanos, potencialmente explica una parte significativa de la inestabilidad observada, en particular a la luz de los valores más reducidos presentados en la literatura para países desarrollados.

Alternativamente, es posible que ciertos atributos de los hogares expliquen el nivel de inestabilidad de ingresos observado. No resulta sencillo identificar estos factores, particularmente habida cuenta de que muchos son potencialmente inobservables. Optamos aquí por analizar la inestabilidad de ingresos en función del nivel educativo del jefe del hogar. El nivel educativo suele ser utilizado como un proxy del nivel de capital humano o, en algunos casos, del ingreso permanente de un individuo u hogar; a su vez, la correlación entre el nivel educativo de los miembros de un mismo hogar es por lo general muy elevada. Esto nos permite utilizar el nivel educativo del jefe de un hogar como una medida del stock de capital humano o bien de otros atributos (observables o inobservables) que correlacionan con este. El Cuadro 8 presenta los cálculos del indicador $m$ dividiendo a los hogares en nivel educativo bajo (aquellos donde el jefe no ha completado el nivel secundario) y nivel educativo alto (aquellos donde el jefe posee formación terciaria o superior).

${ }^{22}$ Esta hipótesis, analizada por Bartels y Bonke (2013) para países europeos, es abordada para los países de nuestra muestra en el tercer capítulo. 


\section{Cuadro 8. Inestabilidad del ingreso individual por nivel educativo}

\begin{tabular}{lccccccc} 
& Argentina & Brasil & Costa Rica & Ecuador & México & Paraguay & Perú \\
\hline \multicolumn{7}{c}{ Ingreso total } \\
\hline Nivel educativo bajo & 0,43 & 0,47 & 0,52 & & 0,54 & 0,55 \\
Nivel educativo alto & 0,36 & 0,38 & 0,49 & 0,42 & 0,44 \\
\hline \multicolumn{7}{c}{ Ingreso laboral } \\
\hline Nivel educativo bajo & 0,47 & 0,35 & 0,50 & 0,54 & 0,59 & 0,53 & 0,61 \\
Nivel educativo alto & 0,36 & 0,32 & 0,38 & 0,50 & 0,56 & 0,50 & 0,47
\end{tabular}

Fuente: Elaboración propia en base a encuestas de hogares (ver sección 4)

En todos los casos, los hogares cuyos jefes tienen menor nivel educativo sufren de una mayor variabilidad temporal en sus ingresos que los hogares cuyos jefes tienen un nivel educativo mayor. Esto puede ser en parte resultado de la existencia de correlación entre nivel educativo y categoría ocupacional, de modo que sean los individuos con mayor nivel educativo quienes accedan a puestos formales ${ }^{23}$. A su vez, también es posible que el nivel de capital humano (u otros atributos que estén correlacionados con aquel) afecte la probabilidad de que un hogar acceda a fuentes de ingreso no laboral de manera sostenida en el tiempo (en particular, jubilaciones y pensiones). En cualquier caso, resulta claro que la inseguridad de ingresos afecta en mayor medida a hogares cuyos niveles educativos son menores lo cual refuerza su condición de vulnerabilidad.

\section{Conclusiones}

Este trabajo contribuye al análisis de la movilidad de ingresos, una rama de la literatura de creciente importancia en países centrales, aunque todavía poco desarrollada en otros países. Explotando el esquema rotatorio de las encuestas de hogares de siete países latinoamericanos, cuantificamos el tamaño de los movimientos de ingresos de los hogares a corto plazo (empleando una ventana anual), que interpretamos como una medida de la inestabilidad o volatilidad de ingresos.

Si bien la movilidad de ingresos puede tener atributos positivos valorables (particularmente la reducción intertemporal de las desigualdades), fluctuaciones no triviales en el flujo temporal de ingresos de un hogar reducirán su bienestar si asumimos, en particular si estas no pueden ser anticipadas. Diversas características de las economías latinoamericanas indican que este problema es relevante: debilidad de las instituciones del mercado laboral, informalidad, restricciones al mercado de crédito, etcétera. La evidencia provista indica que la inestabilidad de ingresos es efectivamente más alta

\footnotetext{
${ }^{23}$ Si bien esta correlación efectivamente existe, el análisis de regresión permite concluir que el nivel educativo tiene efectos sobre la inestabilidad de ingresos incluso luego de controlar por categoría ocupacional en casi todos los casos analizados.
} 
en América Latina que en los países desarrollados, lo que indica la necesidad de aplicar políticas específicas para mitigar sus efectos negativos.

Mediante ejercicios de microsimulación, se procedió a descomponer la inestabilidad por fuente de ingresos. Los resultados muestran que, si bien los ingresos no laborales son más volátiles que los laborales, su reducido peso en el ingreso total de los hogares dictaminan que sean los cambios en ingresos laborales los que explican la mayor parte de la volatilidad observada. Este hallazgo indica que la reducción de la inestabilidad necesariamente implica la aplicación de políticas específicas dirigidas al mercado de trabajo (donde la fiscalización laboral aparece como una de las más destacadas).

Por último, se proponen algunas hipótesis sobre los determinantes de la inestabilidad de ingresos. Tanto las características estructurales del mercado de trabajo como los atributos de los hogares son factores que potencialmente explican los niveles observados (y sus diferencias entre países), aunque es necesario mayor desarrollo en esta línea antes de alcanzar conclusiones definitivas. La falta de información estadística idónea para análisis de movilidad de ingresos ha sido la mayor limitante para el desarrollo de esta rama de la literatura en América Latina; en el futuro, la implementación de encuestas de tipo longitudinal posiblemente permita profundizar este análisis.

\section{Bibliografía}

Albornoz, F., \& Menéndez, M. (2007). Income dynamics in Argentina during the 1990s: "mobiles" did change over time. Económica LIII Nro. 1-2.

Amarante, V., \& Arim, R. (2015). Desigualdad e informalidad. Un análisis de cinco experiencias latinoamericanas. Santiago de Chile: CEPAL.

Aristei, D., \& Perugini, C. (2015). The drivers of income mobility in Europe. Economic Systems 39, 197-224.

Bartels, C., \& Bonke, T. (2013). Can households and welfare states mitigate rising earnings instability? The review of income and wealth 59 (2), 250-282.

Beccaria, L., \& Groisman, F. (2006). Inestabilidad, movilidad y distribución del ingreso en Argentina. Revista de la CEPAL 89, 133-156.

Beccaria, L., Maurizio, R., \& Vázquez, G. (2015). Recent decline in wage inequality and formalization of the labor market in Argentina. International Review of Applied Economics 29 (5), 677-700.

Bossert, W., \& D'Ambrosio, C. (2013). Measuring Economic Insecurity. International Economic Review 54 (3), 1017-1030. 
Cantó, O., \& Ruiz, D. (2014). The contribution of income mobility to economic insecurity in the US and Spain during the Great Recession. ECINEQ Working Paper Series.

Cappellari, L., \& Jenkins, S. (2014). Earnings and labour market volatility in Britain, with a transatlantic comparison. Labour Economics 30, 201-2011.

Celik, S., Juhn, C., McCue, K., \& Thompson, J. (2012). Recent trends in earnings volatility: Evidence from surveys and administrative data. The B.E. Journal of Economic Analysis \& Policy 12 (2), 1-24.

Chen, W.-H. (2009). Cross-national differences in income mobility: evidence from Canada, the United States, Great Britain and Germany. The Review of Income and Wealth 55 (1), 75-100.

Corbacho, A., Inchauste, G., \& García-Escribano, M. (2007). Argentina: Macroeconomic Crisis and Household Vulnerability. Review of Development Economics 11 Nro. 1, 92-106.

Cruces, G., \& Wodon, Q. (2007). Risk-Adjusted Poverty in Argentina: Measurement and Determinants. Journal of Development Studies 43 (7), 1189-1214.

Dynan, K., Elmendorf, D., \& Sichel, D. (2012). The Evolution of Household Income Volatility. The B.E. Journal of Economic Analysis \& Policy 12 (2), 1-40.

factors, S. e. (2014). Sologon, Denisa; O'Donoghue, Catal. The Review of Income and Wealth 60 Supplementary Issue.

Glewwe, P., \& Hall, G. (1998). Are some groups more vulnerable to macroeconomic shocks than others? Hypothesis tests based on panel data from Peru. Journal of Development Economics 56, 181-206.

Hacker, J., Huber, G., Nichols, A., Rehm, P. S., Valletta, R., \& Craig, S. (2014). The Economic Security Index: A new Measure for Research and Policy Analysis. The Review of Income and Wealth 60 Supplement Issue , 5-32.

Haider. (2001). Earnings Instability and Earnings Inequality of Males in the United States: 1967-1991. Journal of Labour Economics 19 (4), 799-836.

Maurizio, R. (2016). Non-standard forms of employment in Latin America: Prevalence, characteristics and impacts on wages. Conditions of Work and Employment Series 75, $1-62$.

McKenzie, D. (2004). Aggregate Shocks and Urban Labor Market Responses: Evidence from Argentina's Financial Crisis. Economic Development and Cultural Change 52 Nro. 4 , 719-758.

Nichols, A., \& Rehm, P. (2014). Income risk in 30 countries. The review of income and wealth 60 .

Rohde, N., Tang, K. K., \& Rao, P. (2014). Distributional characteristics of income insecurity in the US, Germany and Britain. The review of income and wealth 60 . 
Shin, D., \& Solon, G. (2011). Trends in men's earnings volatility: What does the Panel Study of Income Dynamics show? Journal of Public Economics 95 (7-8), 973-982. 
Anexo A. Inestabilidad específica por fuentes de ingreso con indicadores alternativos

Cuadro 1A. Inestabilidad específica por fuentes de ingreso. Indicador $\boldsymbol{d}$. Ingreso total

Argentina Costa Rica Ecuador Paraguay Perú

\begin{tabular}{lccccc}
\hline No laboral & 0,97 & 0,86 & 1,48 & 1,16 & 0,95 \\
\hline No laboral: jubilaciones y pensiones & 1,16 & 1,40 & 3,87 & 2,25 & 1,96 \\
No laboral: otros & 3,64 & 1,58 & 2,36 & 1,95 & 1,41 \\
\hline Laboral & 0,50 & 0,54 & 0,62 & 0,58 & 0,52 \\
\hline Laboral: salarios & 0,37 & 0,42 & 0,45 & 0,30 & 0,35 \\
Laboral: ocupación & 0,55 & 0,49 & 0,59 & 0,91 & 0,47 \\
\hline
\end{tabular}

Fuente: Elaboración propia en base a encuestas de hogares (ver sección 4)

Cuadro 2A. Inestabilidad específica por fuentes de ingreso. Indicador $d$. Ingreso laboral

\begin{tabular}{lccccccc} 
& Argentina & Brasil & Costa Rica & Ecuador & México & Paraguay & Perú \\
\hline Laboral & 0,50 & 0,38 & 0,54 & 0,62 & 0,70 & 0,58 & 0,52 \\
\hline Laboral: salarios & 0,37 & 0,25 & 0,42 & 0,45 & 0,31 & 0,30 & 0,35 \\
Laboral: ocupación & 0,55 & 0,48 & 0,49 & 0,59 & 0,83 & 0,91 & 0,47
\end{tabular}

Fuente: Elaboración propia en base a encuestas de hogares (ver sección 4)

Cuadro 3A. Inestabilidad específica por fuentes de ingreso. Indicador CV. Ingreso total

Argentina Costa Rica Ecuador Paraguay Perú

\begin{tabular}{lccccc}
\hline No laboral & 0,56 & 0,63 & 0,63 & 0,80 & 0,82 \\
\hline No laboral: jubilaciones y pensiones & 0,38 & 0,35 & 0,57 & 0,46 & 0,36 \\
No laboral: otros & 0,96 & 0,77 & 0,70 & 0,99 & 0,90 \\
\hline Laboral & 0,40 & 0,42 & 0,42 & 0,44 & 0,42 \\
\hline Laboral: salarios & 0,22 & 0,26 & 0,28 & 0,22 & 0,29 \\
Laboral: ocupación & 0,65 & 0,31 & 0,54 & 0,60 & 0,48 \\
\hline
\end{tabular}

Fuente: Elaboración propia en base a encuestas de hogares (ver sección 4)

Cuadro 4A. Inestabilidad específica por fuentes de ingreso. Indicador CV. Ingreso laboral

\begin{tabular}{lccccccc} 
& Argentina & Brasil & Costa Rica & Ecuador & México & Paraguay & Perú \\
\hline Laboral & 0,40 & 0,38 & 0,42 & 0,43 & 0,63 & 0,44 & 0,42 \\
\hline Laboral: salarios & 0,22 & 0,17 & 0,26 & 0,29 & 0,26 & 0,22 & 0,29 \\
Laboral: ocupación & 0,65 & 0,74 & 0,60 & 0,58 & 0,84 & 0,58 & 0,48
\end{tabular}

Fuente: Elaboración propia en base a encuestas de hogares (ver sección 4) 


\section{Capítulo 3: Movilidad de ingresos y movimientos demográficos en América Lati-}

na

\section{Introducción}

El análisis de los movimientos de los ingresos de los hogares en el tiempo ha capturado la atención de una parte considerable de la literatura especializada en los últimos años. En Beccaria et al. (2015), se cuantifica el tamaño de los movimientos de corto plazo en los ingresos de los hogares en América Latina, interpretando esto como una medida de la variabilidad o inestabilidad de ingresos en esta región. Si asumimos que los hogares son aversos al riesgo, la inestabilidad de ingresos constituye una considerable pérdida de bienestar, que resulta particularmente relevante si se tiene en cuenta que los mercados de crédito están poco desarrollados en estos países, de modo que existen escasos mecanismos que permitan suavizar las fluctuaciones.

En este trabajo proponemos avanzar en la línea anterior evaluando la relevancia de los movimientos demográficos en el nivel de variabilidad observada en los ingresos de los hogares. Definimos como movimientos demográficos a todos aquellos cambios de tamaño o composición que un hogar puede experimentar a partir de llegadas de nuevos miembros, salidas de miembros anteriores o la combinación de ambas. Estos pueden ser fruto de fenómenos biológicos (nacimientos o fallecimientos), fenómenos migratorios, fusiones de hogares previamente existentes (frecuentemente, aunque no exclusivamente, debido a matrimonios), división de un hogar en otros varios, entre otras razones. La relevancia de estos movimientos en la evolución temporal del ingreso del hogar responde a varias razones.

En primer lugar, un porcentaje elevado de los miembros que entran o salen de un hogar son perceptores de ingresos, ya sea por su condición de ocupados o bien porque reciben ingresos no laborales de algún tipo (principalmente transferencias de origen público), de modo que el ingreso total del hogar es afectado automáticamente por estos movimientos. En segundo lugar, aun si los movimientos demográficos no involucran a perceptores de ingresos, sí alteran las necesidades de consumo del hogar como unidad económica, lo que se ve reflejado en un cambio en el ingreso per cápita del mismo. En tercer lugar, los cambios de composición del hogar factiblemente afectan el mecanismo de distribución del ingreso intra-hogar (sharing rule) a partir de las diferentes características de los integrantes (por ejemplo, es concebible que gastos asociados al consumo de niños pequeños sean priorizados por sobre los de otros miembros). Por último, y como consecuencia de lo anterior, es posible que los compor- 
tamientos de los individuos (en particular en lo que respecta a participación en el mercado de trabajo) sean sensibles al tamaño y composición del hogar que integran.

Siguiendo la línea de trabajos anteriores, explotamos el esquema rotativo de las encuestas de hogares de siete países latinoamericanos para construir paneles anuales que permiten observar y descomponer los cambios del ingreso del hogar en ventanas temporales de un año. La muestra de países empleada contiene a Argentina, Brasil, Costa Rica, Ecuador, México, Paraguay y Perú y cubre el período 2003-2015. Utilizamos esta base de datos para cumplir varios objetivos: cuantificar el tamaño y la frecuencia de los movimientos demográficos, computar su contribución a las fluctuaciones de ingresos observadas y analizar la existencia de estrategias al interior de los hogares que permitan suavizar su impacto.

El resto del trabajo se encuentra estructurado de la siguiente manera. La sección 2 provee una breve revisión de la literatura específica. La sección 3 repasa la metodología seguida por trabajos anteriores para medir la variabilidad de ingresos en bases de datos de este tipo e indica las fuentes de información utilizadas. La sección 4 presenta los resultados de diversos ejercicios realizados con el fin de computar la contribución de los movimientos demográficos a la movilidad observada. La sección 5 analiza la existencia de estrategias al interior de los hogares que pueden ser interpretadas como respuestas a estos movimientos. Finalmente, la sección 6 provee algunas conclusiones.

\section{Revisión de la literatura}

Existe abundante literatura que enfatiza el rol del hogar como unidad perceptora de ingresos en lugar del individuo. Si bien son los individuos quienes reciben directamente ingresos, sea laborales (trabajando para una empresa o para sí mismos) o no laborales (a través de derechos de propiedad sobre activos o como beneficiarios de transferencias), existe un consenso general sobre la idea de que este ingreso es distribuido dentro del hogar de acuerdo a reglas que generalmente dependen de las preferencias de más de uno de los miembros. La modelización más habitual de este problema de optimización del uso de los recursos al interior del hogar es provista por el trabajo pionero de Chiappori (1992). En este marco de análisis, la solución al problema puede interpretarse en términos de la existencia de una regla de asignación del ingreso intra-hogar (sharing rule). Los hallazgos empíricos presentados aquí son consistentes con esta formulación del problema aunque no se restringen a ella y también resultan compatibles con otras estrategias posibles de modelización. 
Existe una abundante literatura que analiza la movilidad de ingresos de corto plazo en términos de inestabilidad, volatilidad o inseguridad de ingresos. Sin embargo, el espectro de trabajos empíricos que analizan la importancia de los movimientos demográficos en la determinación del sendero temporal de ingreso de los hogares es más bien reducido. A continuación analizamos los principales aportes existentes en la literatura.

Duncan y Morgan (1981) proveen uno de los primeros análisis de este vínculo a partir de datos de la Panel Study of Income Dynamics (PSID) para Estados Unidos. Los autores proveen evidencia de una considerable relevancia de los cambios de composición de los hogares en la dinámica de ingresos, al punto de señalar que "las personas pueden tener mayor control de su status económico a través de decisiones sobre matrimonio, divorcio, procreación, duplicando o reduciendo a la mitad los cambios experimentados a partir de acciones tales como buscar un mejor empleo o más trabajo o invertir en su propio capital humano". En otras palabras, aquí aparece la hipótesis de que los cambios de composición del hogar pueden ser endógenos en naturaleza y en sí mismos poseer un objetivo de dinámica de ingresos. Sin embargo, los autores aclaran que algunos movimientos pueden ser de naturaleza exógena, discusión que retomamos en la sección 5. Los resultados de Duncan y Morgan indican que una parte relevante de los cambios observados en los ingresos de los hogares en períodos cortos de tiempo responden a cambios de composición. Por ejemplo, en mujeres, esta proporción es de casi $20 \%$, aunque se reduce a $12 \%$ si se controla por otras variables.

Los resultados de Fritzell (1990) coinciden con los anteriores. En este trabajo, el autor analiza la movilidad de ingresos en Suecia y compara sus resultados con los de Duncan y Morgan. Nuevamente la evidencia presentada indica que los cambios demográficos tienen un peso importante en los cambios en el ingreso del hogar (contribuyen a aumentar el $\mathrm{R}$ cuadrado de las regresiones en alrededor de 10 puntos) y, al igual que en Estados Unidos, el impacto es mayor en los hogares con jefes de sexo femenino (aunque el tamaño de esta brecha se reduce considerablemente si la mujer tiene hijos, debido a la existencia de políticas de protección social para niños en Suecia). En particular, el trabajo señala que los cambios de composición del hogar pueden tener un impacto mayor sobre el ingreso futuro del hogar que otros determinantes de orden más estructural como la edad o nivel educativo de los miembros.

Los hallazgos originales de Duncan y Morgan coinciden en líneas generales con los de trabajos posteriores que utilizan nuevamente los datos de la PSID a lo largo de 
un horizonte temporal mayor. En particular, Gittleman y Joyce (1999) reportan resultados análogos luego de incorporar las sucesivas ondas del relevamiento hasta 1991. Estos autores encuentran efectos similares del cambio de composición del hogar, aunque la variable dependiente que utilizan no es el cambio en el ingreso sino la probabilidad de experimentar un aumento en la posición dentro de la distribución del ingreso de cada período.

La contribución de Jarvis y Jenkins (1999) se centra en un tipo particular de movimiento demográfico, la división de un hogar producto de un divorcio o separación. Los autores utilizan información proveniente de la British Household Panel Survey (BHPS) y concluyen que este tipo de movimientos tiene un fuerte impacto sobre el ingreso de mujeres y niños aunque no tanto así para los varones adultos. Asimismo, analizan brevemente el impacto de estos movimientos sobre la participación laboral de varones y mujeres por separado. Sus resultados indican que tanto hombres como mujeres reducen su participación laboral debido a la división del hogar y la magnitud de la caída es relativamente mayor en mujeres. Sin embargo, este efecto es en buena medida fruto del esquema de protección social existente.

Por su parte, Bartels y Bonke (2013) enfatizan el rol de los hogares como estructuras de distribución del riesgo (risk-sharing): si los shocks de ingresos que sufren los miembros de un hogar son, hasta cierto punto al menos, independientes entre sí, entonces la distribución del ingreso al interior del hogar actúa como un mecanismo de seguro contra los shocks idiosincráticos negativos. Para medir este efecto, utilizan encuestas de hogares longitudinales de Alemania y Gran Bretaña para comparar la varianza de los ingresos individuales con la de los ingresos del hogar. Sus resultados indican que tanto el componente permanente como el transitorio de la varianza son menores cuando se analizan los ingresos de los hogares, lo que los lleva a concluir que, efectivamente, la distribución del ingreso al interior del hogar cumple un rol en la reducción del riesgo agregado que este enfrenta.

Partiendo de un marco de análisis similar, Alves y Martins (2014) retoman el análisis del impacto de los cambios demográficos sobre los cambios del ingreso del hogar y encuentran, al igual que los trabajos anteriores, que este efecto tiene un tamaño considerable usando datos tanto de Portugal como de los restantes países de la Unión Europea. Como se puede observar, se trata de un hallazgo general en la literatura para países desarrollados, sin embargo, no existen hasta el momento trabajos que lleven a cabo análisis de este tipo para países de América Latina. El resto de este trabajo se aboca precisamente a ese objetivo. 


\section{Datos y metodología}

Perú es el único país de América Latina que realiza una encuesta de hogares de tipo longitudinal. En los restantes países, construimos paneles explotando el esquema rotativo de las encuestas de hogares convencionales. Dado que no todas las encuestas tienen cobertura nacional, y atendiendo a las diferencias que suelen existir entre los mercados de trabajo urbano y rural, restringimos el análisis a las áreas urbanas. Para deflactar los ingresos relevados se utilizó el índice de precios al consumidor oficial de cada país, excepto para el caso de Argentina donde la manipulación de estadísticas oficiales obliga a utilizar un índice de precios construido a partir de promedios de índices provenientes de institutos de estadísticas provinciales que mantuvieron relevamientos confiables. De este modo, construimos el pool de paneles más grande de que tengamos conocimiento para la región ${ }^{24}$.

Por otra parte, la metodología utilizada para medir la intensidad de la variabilidad de ingresos es fuertemente dependiente del tipo de información estadística disponible. Dado que las encuestas con que contamos visitan a los hogares a lo largo de una ventana temporal reducida, y con el fin de poder realizar un análisis comparativo entre los países de la muestra y otros reportados en la literatura, construimos para cada país todos los paneles posibles de dos observaciones separadas por un año y luego agregamos esos paneles en un pool de paneles para cada país. Por lo expuesto anteriormente, consideramos el hogar como unidad receptora de ingresos pero veremos luego que el análisis de los ingresos individuales será relevante para ciertos ejercicios.

Para medir el grado de inestabilidad de ingresos observado recurrimos al indicador de Fields y Ok (1999), de uso habitual en la literatura:

$$
m\left(y_{1}, y_{2}\right)=\frac{1}{n} \sum_{i=1}^{n}\left|\ln y_{2 i}-\ln y_{1 i}\right|
$$

Donde $y_{1}$ e $y_{2}$ son los vectores de ingresos de los hogares en cada observación y $n$ es el tamaño de la muestra. Como se puede apreciar, este indicador mide el tamaño medio de los cambios relativos de ingresos, independientemente de su dirección (aumento o disminución). Es preciso señalar que todos los ingresos son deflactados de modo tal que en todo momento trabajamos con ingresos reales, es decir, ajustados

\footnotetext{
${ }^{24}$ Para mayor detalle sobre el origen de la información utilizada y el proceso de elaboración de la base de datos, ver sección 4 del capítulo 2 .
} 
por inflación. Las encuestas de hogares de México y Brasil solo relevan ingresos laborales, de modo que en esos países solo es posible utilizar este tipo de ingresos en los cálculos.

\section{La importancia de los movimientos demográficos en la movilidad de in- gresos}

\subsection{Movimientos demográficos: quiénes entran y quiénes salen}

El Cuadro 1 presenta estadísticas sobre entradas y salidas de miembros en los hogares del panel analizado para cada país. En términos generales, la composición de los hogares parece ser estable en el tiempo, ya que la proporción de hogares que no experimentan movimientos demográficos oscila entre un $68 \%$ y un $85 \%$ del total. Sin embargo, la frecuencia e intensidad de este tipo de movimientos presenta diferencias relevantes entre los países analizados. Brasil muestra la mayor estabilidad: la cantidad de miembros no varía en más del $85 \%$ de los casos, mientras que aumentos o reducciones considerables del tamaño del hogar (entrada o salida neta de 2 miembros o más) son muy poco frecuentes. Algo similar ocurre en Argentina y Ecuador. En el extremo opuesto encontramos a Paraguay y a Perú, donde los movimientos demográficos resultan sensiblemente más frecuentes, afectando a más del $30 \%$ de los hogares y con una proporción mayor de movimientos de 2 o más miembros en términos netos. Costa Rica y México constituyen casos intermedios. La proporción de entradas y la de salidas son similares entre sí en todos los países a excepción de Brasil y Paraguay, donde se registra una mayor proporción de salidas que de entradas ${ }^{25}$.

\section{Cuadro 1. Proporción de entradas y salidas y cambio en cantidad de miembros}

\begin{tabular}{|c|c|c|c|c|c|c|c|}
\hline & Argentina & Brasil & Costa Rica & Ecuador & México & Paraguay & Perú \\
\hline \multicolumn{8}{|c|}{ Proporción de entradas y salidas } \\
\hline Hogares que registran entradas & $10.4 \%$ & $6.2 \%$ & $11.4 \%$ & $10.3 \%$ & $16.7 \%$ & $16.8 \%$ & $18.6 \%$ \\
\hline Hogares que registran ambas & $2.0 \%$ & $0.5 \%$ & $0.1 \%$ & $0.0 \%$ & $4.4 \%$ & $8.0 \%$ & $7.4 \%$ \\
\hline \multicolumn{8}{|c|}{ Cambio en la cantidad de miembros } \\
\hline Se mantiene constante & $82.0 \%$ & $85.4 \%$ & $76.7 \%$ & $81.0 \%$ & $74.6 \%$ & $74.2 \%$ & $70.8 \%$ \\
\hline Baja en 1 & $6.6 \%$ & $6.8 \%$ & $8.0 \%$ & $5.7 \%$ & $7.1 \%$ & $12.1 \%$ & $9.7 \%$ \\
\hline Baja en 2 o más & $2.5 \%$ & $2.0 \%$ & $4.0 \%$ & $3.1 \%$ & $4.9 \%$ & $4.2 \%$ & $5.8 \%$ \\
\hline
\end{tabular}

Fuente: Elaboración propia en base a encuestas de hogares (ver sección 3)

\footnotetext{
${ }^{25}$ Las características particulares de los relevamientos de Brasil y Paraguay dificultan la identificación de niños menores de 10 años, por tratarse de encuestas orientadas a captar variables laborales referidas a la población económicamente activa. Por este motivo, los movimientos demográficos considerados en esos países no incluyen niños menores de 10 años, lo cual factiblemente reduce la cantidad de entradas observadas.
} 
Los movimientos demográficos no pueden ser considerados intrínsecamente positivos o negativos en términos del bienestar de un hogar. Sin embargo, sí es posible plantear la hipótesis de que al menos algunos de ellos pueden correlacionar con características negativas o con eventos que tienen consecuencias negativas para el hogar. Por ejemplo, la evidencia es clara respecto a la mayor fertilidad en hogares de nivel educativo bajo, lo que obedece a diversos factores, entre ellos al menor acceso a información sobre métodos de planificación familiar. De igual manera, los movimientos migratorios pueden estar correlacionados con el capital humano de los miembros de un hogar si este determina la probabilidad de inserción en determinadas ramas productivas.

Por otra parte, como se muestra en Beccaria et al. (2015), la inestabilidad del ingreso es mayor en los hogares con menor nivel educativo y esto podría ser en sí mismo un factor determinante de movimientos demográficos, especialmente si los agentes toman ciertas decisiones sobre la composición de sus hogares como medio para influir sobre su flujo futuro de ingresos, como sugieren Duncan y Morgan. Por estos motivos, resulta de interés determinar si existe evidencia de correlación entre algunos movimientos demográficos y las características del hogar.

Cuadro 2. Características de los hogares que registran movimientos demográfi$\cos$

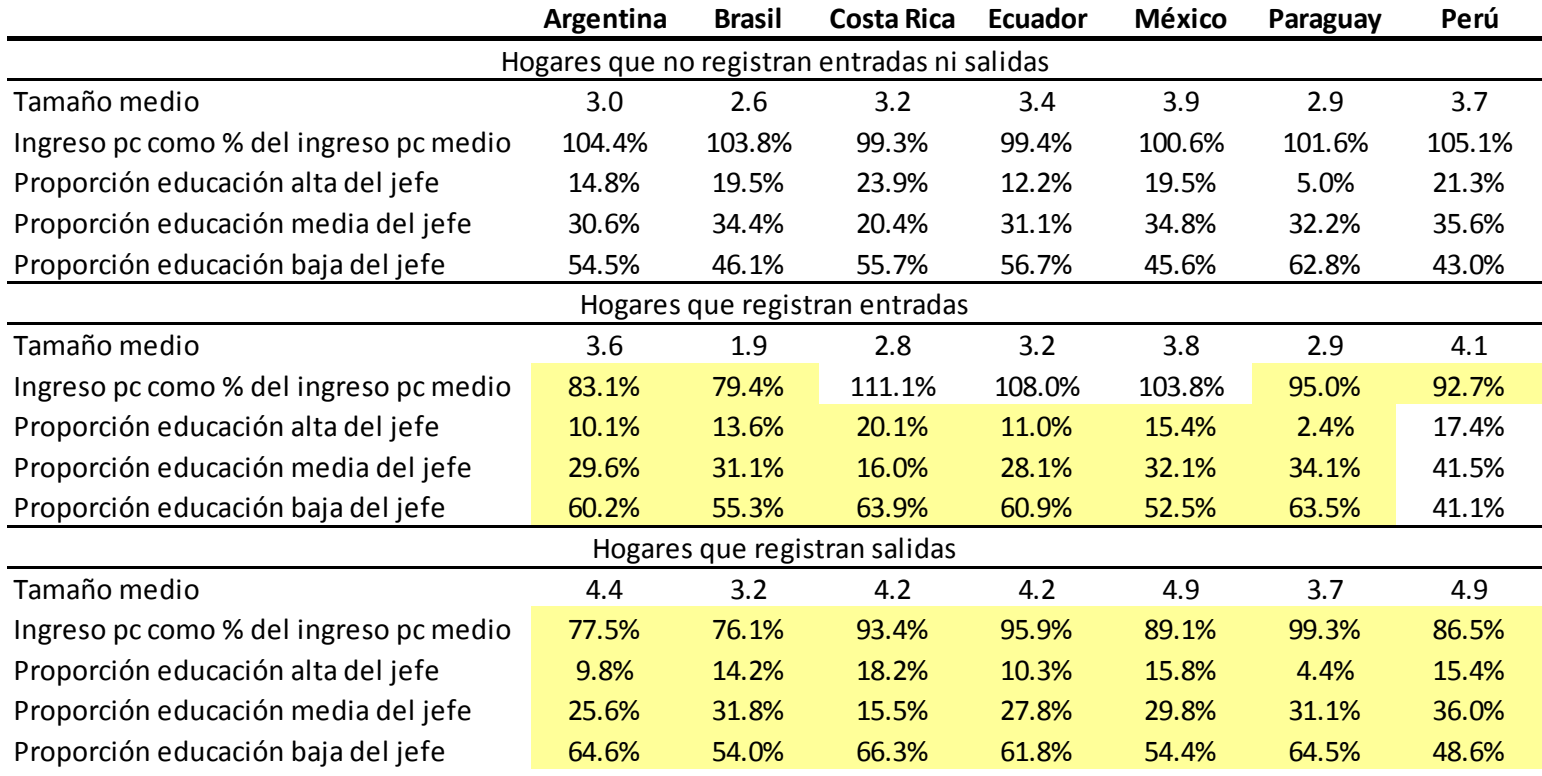

Fuente: Elaboración propia en base a encuestas de hogares (ver sección 3)

El Cuadro 2 presenta el tamaño medio, ingreso per cápita y nivel educativo del jefe de hogar para 3 grupos de hogares: aquellos que no registran entradas ni salidas, aquellos que registran entradas y aquellos que registran salidas (si bien estas últimas 
no son mutuamente excluyentes, los datos del Cuadro 1 indican que la intersección entre ellas es pequeña). En primer lugar, se observa que los hogares donde entran miembros no tienen ex ante un tamaño diferente del de los hogares que no registran movimientos; en cambio, las salidas de miembros sí ocurren típicamente en hogares más grandes, lo cual es razonable. Las salidas de miembros en hogares grandes podrían responder a una demanda por mayor espacio habitacional o bien a la formación de nuevos núcleos familiares, posiblemente a partir del matrimonio de individuos jóvenes. También es posible que a partir de cierto tamaño las economías de escala al interior del hogar se agoten o incluso se reviertan, lo cual proveería incentivos a que los individuos abandonen el hogar para conformar uno nuevo.

Por otra parte, no encontramos evidencia concluyente de que los hogares que registran entradas de miembros tengan peores condiciones de vida que aquellos que no sufren movimientos. El ingreso per cápita de los primeros es menor en algunos casos y mayor en otros, sin un patrón claro, aunque en todos los casos, excepto en Perú, se observa en estos un menor nivel educativo, lo que indicaría menor acumulación de capital humano, habitualmente correlacionado con la riqueza o el ingreso intertemporal del hogar. Un nivel de ingreso intertemporal bajo puede funcionar como incentivo a incorporar miembros al hogar con el fin de aprovechar economías de escala no explotadas al interior del mismo, lo que explicaría la correlación observada. Alternativamente, también es posible que el menor nivel educativo esté asociado a una mayor fertilidad.

En cambio, cuando se analiza los hogares que experimentan salidas de miembros, sí se obtiene un panorama más claro. En todos los casos, estos hogares tienen un ingreso per cápita medio menor y un perfil educativo peor que los hogares que no sufren movimientos o que los hogares que experimentan entradas. En otras palabras, existe cierto grado de correlación entre la salida de miembros de un hogar y características que afectan negativamente su bienestar. Esto podría ser consecuencia de movimientos migratorios originados en la necesidad de aumentar el ingreso total del hogar $^{26}$. Alternativamente, la causalidad podría operar en sentido inverso: el bajo nivel de capital humano o de ingreso podrían ser consecuencia de un determinado nivel de inestabilidad en el núcleo del hogar.

\footnotetext{
${ }^{26}$ En CEPAL (2003), se señala que "en los movimientos migratorios intrarregionales predominan los trabajadores con menor calificación. Por una parte, los que se limitan a las zonas de frontera y que se insertan en actividades agrícolas en muchos casos de carácter transitorio o estacional; por otra parte, se encuentran los trabajadores que se dirigen a las ciudades y cumplen una función complementaria a la migración interna, en que las actividades vinculadas con la construcción predominan entre los hombres y el servicio doméstico entre las mujeres".
} 
Cuadro 3. Características de los miembros que entran a hogares

\begin{tabular}{|c|c|c|c|c|c|c|c|}
\hline & Argentina & Brasil & Costa Rica & Ecuador & México & Paraguay & Perú \\
\hline \multicolumn{8}{|c|}{ Composición demográfica } \\
\hline & Mujer Varón & Mujer Varón & Mujer Varón & Mujer Varón & Mujer Varón & Mujer Varón & Mujer Varón \\
\hline Niño & $26.3 \% 25.9 \%$ & $9.7 \% \quad 9.6 \%$ & $24.2 \% \quad 27.2 \%$ & $29.7 \% \quad 30.0 \%$ & $23.5 \% \quad 23.4 \%$ & $10.9 \% \quad 15.3 \%$ & $20.5 \% 23.1 \%$ \\
\hline Joven & $7.9 \% \quad 6.8 \%$ & $11.0 \% \quad 11.8 \%$ & $9.3 \% \quad 7.8 \%$ & $7.5 \% \quad 7.2 \%$ & $9.9 \% \quad 8.5 \%$ & $10.0 \% \quad 6.1 \%$ & $9.5 \% \quad 9.3 \%$ \\
\hline Adulto $<45$ & $8.9 \% \quad 12.6 \%$ & $18.2 \% \quad 20.5 \%$ & $8.4 \% \quad 10.7 \%$ & $7.1 \% \quad 8.6 \%$ & $11.3 \% 11.7 \%$ & $12.8 \% \quad 26.3 \%$ & $11.9 \% 14.2 \%$ \\
\hline Adulto45-60 & $3.2 \% \quad 3.9 \%$ & $6.6 \% \quad 5.4 \%$ & $4.5 \% \quad 2.9 \%$ & $2.3 \% \quad 2.0 \%$ & $3.8 \% \quad 3.3 \%$ & $5.9 \% \quad 5.5 \%$ & $3.2 \% \quad 3.4 \%$ \\
\hline Adulto $>60$ & $3.0 \%$ & $5.1 \%$ & $3.5 \% \quad 1.6 \%$ & $4.0 \% \quad 1.6 \%$ & $1.7 \%$ & $4.6 \%$ & $2.6 \%$ \\
\hline Total & $49.3 \% \quad 50.7 \%$ & $50.5 \% \quad 49.5 \%$ & $49.9 \% \quad 50.1 \%$ & $50.6 \% \quad 49.4 \%$ & $51.5 \% \quad 48.5 \%$ & $44.2 \% \quad 55.8 \%$ & $47.6 \% \quad 52.4 \%$ \\
\hline \multicolumn{8}{|c|}{ Proporción de perceptores } \\
\hline $\begin{array}{l}\text { Proporción de ingresantes que } \\
\text { son perceptores }\end{array}$ & $35.2 \%$ & $54.1 \%$ & $37.4 \%$ & $27.9 \%$ & $27.1 \%$ & $73.8 \%$ & $45.9 \%$ \\
\hline $\begin{array}{l}\text { Proporción de hogares donde } \\
\text { entra un perceptor (como \% del } \\
\text { total) }\end{array}$ & $4.6 \%$ & $3.9 \%$ & $5.6 \%$ & $5.0 \%$ & $6.4 \%$ & $13.5 \%$ & $11.4 \%$ \\
\hline $\begin{array}{l}\text { Proporción de hogares donde } \\
\text { entra un perceptor (como \% de } \\
\text { los que registran una entrada) }\end{array}$ & $43.6 \%$ & $62.3 \%$ & $48.6 \%$ & $37.9 \%$ & $38.4 \%$ & $80.3 \%$ & $61.4 \%$ \\
\hline
\end{tabular}

Fuente: Elaboración propia en base a encuestas de hogares (ver sección 3)

El Cuadro 3 caracteriza a los miembros que entran a hogares a partir de dos dimensiones: composición demográfica (género y edad) y percepción de ingresos. Ciertos patrones aparecen como generales en la mayoría de los países analizados aunque existen algunas excepciones interesantes. En primer lugar, la proporción de hombres no difiere significativamente de la de mujeres en cinco de los países analizados. Las excepciones son Paraguay y Perú, donde el género masculino es un poco más frecuente. En segundo lugar, el rango etario de la mayoría de los miembros que ingresan los ubica en la categoría de niños en todos los casos a excepción de Brasil y Paraguay (donde, como explicamos anteriormente, limitaciones metodológicas del relevamiento impiden la captación de los de menor edad). Dejando de lado estos casos particulares, observamos que la proporción de niños entre los miembros ingresantes oscila entre $45 \%$ y $60 \%$, en consonancia con la hipótesis de que son los nacimientos los que explican buena parte de los movimientos demográficos. Las llegadas de niños mayores al año podrían atribuirse en parte a error de medición en los registros, aunque es claro que este fenómeno solo podría explicar un número limitado de casos. Los datos indican que también existe una proporción relevante de niños de edades mayores que ingresan a un hogar, posiblemente como producto de procesos de fusión y destrucción de hogares.

El siguiente grupo etario en importancia es el de los adultos jóvenes, con un peso de entre 20 y $25 \%$. Al interior de ese grupo sí se observa mayor frecuencia de varones por sobre mujeres. Recordando que la tasa de actividad es mayor en hombres que en mujeres, esto sugiere mayor proporción de ingreso de individuos ocupados que perciben ingresos. De hecho, la proporción de ingresantes perceptores correlaciona positivamente con la diferencia a favor de varones en la proporción de ingresantes de 
esta franja etaria, lo cual respalda la hipótesis. También es importante notar que, en el subconjunto de hogares que registra ingresos de miembros, la proporción que recibe al menos un perceptor nuevo es en general muy alta (entre 38 y $80 \%$ ). Por su parte, los jóvenes de entre 18 y 25 años tienen cierto peso en la distribución de miembros que ingresan aunque marcadamente menor al de las categorías anteriores. Finalmente, el ingreso de adultos mayores es muy poco frecuente.

\section{Cuadro 4. Características de los miembros que salen a hogares}

\begin{tabular}{|c|c|c|c|c|c|c|c|}
\hline & Argentina & Brasil & Costa Rica & Ecuador & México & Paraguay & Perú \\
\hline \multicolumn{8}{|c|}{ Composición demográfica } \\
\hline & Mujer Varón & Mujer Varón & Mujer Varón & Mujer Varón & Mujer Varón & Mujer Varón & Mujer Varón \\
\hline Niño & $12.1 \% \quad 12.6 \%$ & $\begin{array}{|ll|}8.3 \% & 7.9 \% \\
\end{array}$ & $19.6 \% \quad 23.4 \%$ & $23.9 \% \quad 25.0 \%$ & $17.3 \% \quad 15.7 \%$ & $11.6 \% \quad 13.7 \%$ & $16.0 \% \quad 13.2 \%$ \\
\hline Joven & $11.9 \% 10.8 \%$ & $12.9 \% \quad 15.0 \%$ & $13.2 \% \quad 9.8 \%$ & $9.4 \% \quad 10.3 \%$ & $12.7 \% \quad 12.0 \%$ & $7.7 \% \quad 9.0 \%$ & $11.2 \% 11.4 \%$ \\
\hline Adulto $<45$ & $12.9 \% \quad 19.3 \%$ & $18.5 \% \quad 22.0 \%$ & $9.8 \% \quad 12.2 \%$ & $9.7 \% \quad 11.2 \%$ & $13.4 \% \quad 15.3 \%$ & $9.1 \% \quad 22.0 \%$ & $14.8 \% 18.1 \%$ \\
\hline Adulto $45-60$ & $3.8 \% \quad 4.4 \%$ & $4.9 \% \quad 3.9 \%$ & $2.7 \% \quad 3.3 \%$ & $2.5 \% \quad 1.8 \%$ & $4.0 \% \quad 3.9 \%$ & $6.0 \% \quad 8.6 \%$ & $3.6 \% \quad 4.4 \%$ \\
\hline Adulto $>60$ & $6.4 \% \quad 5.7 \%$ & $4.6 \% \quad 1.9 \%$ & $3.7 \% \quad 2.2 \%$ & $4.1 \% \quad 2.1 \%$ & $3.1 \% \quad 2.5 \%$ & $6.6 \%$ & $3.4 \%$ \\
\hline Total & $47.1 \% \quad 52.9 \%$ & $49.3 \% \quad 50.7 \%$ & $49.1 \% \quad 50.9 \%$ & $49.6 \% \quad 50.4 \%$ & $50.5 \% \quad 49.5 \%$ & $40.2 \% \quad 59.9 \%$ & $49.1 \% \quad 51.0 \%$ \\
\hline \multicolumn{8}{|c|}{ Proporción de perceptores } \\
\hline $\begin{array}{l}\text { Proporción de salientes que son } \\
\text { perceptores }\end{array}$ & $54.4 \%$ & $58.0 \%$ & $45.4 \%$ & $35.1 \%$ & $35.9 \%$ & $73.5 \%$ & $57.0 \%$ \\
\hline $\begin{array}{l}\text { Proporción de hogares donde } \\
\text { sale un perceptor (como \% del } \\
\text { total) }\end{array}$ & $7.6 \%$ & $6.1 \%$ & $7.5 \%$ & $7.3 \%$ & $8.4 \%$ & $20.8 \%$ & $16.4 \%$ \\
\hline $\begin{array}{l}\text { Proporción de hogares donde } \\
\text { sale un perceptor (como \% de } \\
\text { los que registran una salida) }\end{array}$ & $72.7 \%$ & $65.8 \%$ & $62.4 \%$ & $51.9 \%$ & $45.5 \%$ & $82.0 \%$ & $80.4 \%$ \\
\hline
\end{tabular}

Fuente: Elaboración propia en base a encuestas de hogares (ver sección 3)

Para complementar el análisis anterior, el Cuadro 4 presenta información análoga para aquellos miembros que salen de hogares en la ventana de observación. Resulta más difícil caracterizar de manera general estos movimientos dado que no emergen patrones claros. Sí podemos afirmar que la composición por género es nuevamente equilibrada, a excepción de Argentina y Paraguay donde la proporción de varones es mayor entre los miembros salientes. Sin embargo, en lo que concierne a la composición por grupo etario, es difícil detectar generalidades. Niños, jóvenes y adultos jóvenes son las categorías más relevantes aunque el orden y la relación de proporciones entre ellas varían considerablemente de un país a otro. Los adultos jóvenes son la categoría más frecuente entre miembros salientes en todos los casos a excepción de Costa Rica y Ecuador; la proporción de estos casos ronda el 31\%, aunque alcanza el $41 \%$ en Brasil. Sin embargo, un hallazgo inesperado es la elevada frecuencia de salida de niños en todos los países analizados. La proporción de niños entre los miembros salientes oscila entre 16 y 49\%, siendo la categoría de mayor peso en Costa Rica y Ecuador, es decir, precisamente allí donde se dan menos salidas de adultos jóvenes. La salida de jóvenes tampoco es despreciable: comprende a una proporción de entre 17 y $28 \%$ de los casos. 
La salida de jóvenes o adultos jóvenes puede ser producto de movimientos migratorios orientados a acceder a oportunidades laborales particulares. Por otro lado, también puede responder a decisiones de los miembros de formar hogares nuevos, factiblemente a través de matrimonios. Ninguna de las dos posibilidades anteriores es incompatible con la salida de niños, que a su vez puede ser consecuencia de la disolución de hogares debida a divorcios o separaciones. Sin embargo, la elevada frecuencia de la salida de niños definitivamente contradice la intuición y sugiere considerar la posibilidad de que existan problemas de captación en estas encuestas. Por último, las salidas de adultos mayores de 45 tienen cierta frecuencia (tomadas conjuntamente representan entre un 11 y un $27 \%$ de los casos), parcialmente atribuible a defunciones para los casos de mayores de 60 .

Dado que las salidas involucran miembros de mayor edad que las entradas, es de esperar que también involucren más frecuentemente a perceptores de ingresos. De hecho, la proporción de salientes que percibe ingresos es siempre superior a la proporción de entrantes que percibe ingresos. En consecuencia, entre un 52 y un $82 \%$ de los hogares que registraron salidas de miembros sufrieron la pérdida de al menos un perceptor de ingresos. Estos datos deben ser puestos en el contexto que sugiere el análisis del Cuadro 2, donde observamos que las salidas son más frecuentes en hogares de ingreso y nivel educativo más bajos. La correlación entre salida de miembros y peores condiciones socioeconómicas, por un lado, y la elevada proporción de perceptores de ingresos entre los miembros salientes, por el otro, indican que este subconjunto de hogares probablemente sufre de una inestabilidad de ingresos elevada, con consecuencias negativas para su bienestar. Analizamos con mayor profundidad este punto en la subsección siguiente.

\subsection{Contribución de los movimientos demográficos a la movilidad de in-} gresos

En el segundo capítulo, se cuantifica el tamaño de la movilidad de ingresos para estos países y se utiliza la metodología de microsimulación para separar la contribución de sus diversos componentes. En este trabajo continuamos esa línea de análisis aplicando la misma metodología para cuantificar la contribución de los movimientos demográficos a la movilidad total observada. Para eso, imputamos ingresos a aquellos individuos que entran o salen en el segundo período de observación, de acuerdo a las siguientes reglas: 


$$
\begin{gathered}
y_{i 2}=y_{i 1} \cdot \frac{\bar{y}_{2}}{\bar{y}_{1}} \text { si } y_{i 1} \text { es observado pero } y_{i 2} \text { no (salida) } \\
y_{i 1}=y_{i 2} \cdot \frac{\bar{y}_{1}}{\bar{y}_{2}} \text { si } y_{i 2} \text { es observado pero } y_{i 1} \text { no (entrada) }
\end{gathered}
$$

El objetivo de este ejercicio consiste en computar el valor que adoptaría el indicador $m$ si los movimientos demográficos no existieran y cada individuo que entra 0 sale mantuviera el ingreso observado del período en que sí es relevado, corregido por el cambio medio en los ingresos entre períodos. Los resultados de este ejercicio se presentan en el Cuadro 5 junto con el cálculo anterior de movilidad para la muestra total y para algunas submuestras de interés. Debe tenerse en cuenta, como se detalló en la sección 3, que en Brasil y México solo el ingreso laboral es observado, aunque esta limitación no tiene gran incidencia en estos resultados.

\section{Cuadro 5. Movilidad de ingresos observada y microsimulación sin movimientos demográficos}

\begin{tabular}{lccccccc} 
& Argentina & Brasil* & Costa Rica & Ecuador & México* & Paraguay & Perú \\
\hline \multicolumn{7}{c}{ Movilidad observada } \\
\hline Total & 0.40 & 0.34 & 0.45 & 0.52 & 0.56 & 0.50 & 0.51 \\
Hogares que registran entradas & 0.54 & 0.58 & 0.61 & 0.59 & 0.65 & 0.65 & 0.62 \\
Hogares que registran salidas & 0.58 & 0.56 & 0.68 & 0.61 & 0.71 & 0.60 & 0.65 \\
Hogares que registran ambas & 0.56 & 0.57 & 0.64 & 0.62 & 0.67 & 0.60 & 0.62 \\
\hline \multicolumn{7}{c}{ Simulación } \\
\hline Movilidad no demográfica & 0.36 & 0.30 & 0.40 & 0.45 & 0.50 & 0.35 & 0.43 \\
Proporción de movilidad demográfica & $9.2 \%$ & $11.1 \%$ & $12.4 \%$ & $13.2 \%$ & $11.4 \%$ & $28.6 \%$ & $16.3 \%$ \\
* Ingreso laboral & & & & & &
\end{tabular}

Fuente: Elaboración propia en base a encuestas de hogares (ver sección 3)

En el primer panel del Cuadro 5 podemos observar el grado de inestabilidad de ingresos en tres submuestras de interés: hogares que registran entradas de miembros, hogares que registran salidas de miembros y hogares que registran ambas. Los hogares que registran salidas presentan la mayor inestabilidad de ingresos en todos los casos a excepción de Brasil y Paraguay, donde de todos modos esta es marcadamente mayor que en la muestra general. Se confirma de este modo la idea de que los hogares que sufren la pérdida de alguno de sus miembros están caracterizados por una volatilidad especialmente elevada en su flujo de ingresos, diferencia que es particularmente grande en Argentina, Brasil y Costa Rica, donde promedia el 50\%. Los hogares que experimentan una incorporación de nuevos miembros también presentan valores más altos que la muestra general, aunque en la mayoría de los casos la diferencia relativa es de menor magnitud. Queda claro entonces que los movimientos demográfi- 
cos constituyen una fuente relevante de variabilidad de los ingresos para al menos un subconjunto de los hogares de los países analizados ${ }^{27}$.

El segundo panel muestra los resultados del ejercicio de microsimulación. Naturalmente, la inestabilidad de ingresos resulta menor si se anulan los movimientos demográficos, pero la magnitud de esta reducción no es evidente a priori. De acuerdo al procedimiento realizado, podemos observar que esta resulta ser pequeña pero no despreciable. Argentina es el país donde menor es el peso de estos movimientos, ya que la reducción obtenida es de solo $9.2 \%$, mientras que el extremo opuesto es Paraguay con un $28.6 \%$. En los demás países, el cambio se ubica en la franja de entre $10 \mathrm{y}$ $20 \%$. Resulta claro que los movimientos demográficos no tienen la misma relevancia que las entradas y salidas de miembros del hogar al mercado de trabajo, sin embargo, sí resulta similar en varios casos al peso de las fluctuaciones en los ingresos no laborales de los hogares (ver segundo capítulo).

Una transformación adecuada de la variable de interés podría ser útil para enriquecer nuestra comprensión del problema: podemos emplear el ingreso per cápita del hogar en lugar del total para incorporar el hecho de que hogares con distintos tamaños tienen distintas necesidades de consumo. El Cuadro 6 presenta los resultados descriptivos anteriores calculados a partir del ingreso per cápita (ya sea observado o imputado). El principal hallazgo de este ejercicio consiste en la constatación de que la movilidad observada computada sobre el ingreso per cápita difiere en general muy poco de la computada a partir del ingreso total (menos del $5 \%$ en todos los casos a excepción de Paraguay, donde es ligeramente mayor a ese umbral).

Cuadro 6. Movilidad de ingresos observada y microsimulación sin movimientos demográficos (ingreso per cápita)

\begin{tabular}{|c|c|c|c|c|c|c|c|}
\hline & Argentina & Brasil* & Costa Rica & Ecuador & México* & Paraguay & Perú \\
\hline \multicolumn{8}{|c|}{ Movilidad observada } \\
\hline Total & 0.40 & 0.34 & 0.44 & 0.51 & 0.56 & 0.47 & 0.50 \\
\hline Hogares que registran entradas & 0.52 & 0.54 & 0.57 & 0.62 & 0.68 & 0.59 & 0.59 \\
\hline Hogares que registran salidas & 0.54 & 0.53 & 0.61 & 0.65 & 0.70 & 0.53 & 0.60 \\
\hline Hogares que registran ambas & 0.53 & 0.53 & 0.59 & 0.60 & 0.69 & 0.53 & 0.58 \\
\hline \multicolumn{8}{|c|}{ Simulación } \\
\hline Movilidad no demográfica & 0.36 & 0.30 & 0.40 & 0.45 & 0.50 & 0.35 & 0.43 \\
\hline Proporción de movilidad demográfica & $7.8 \%$ & $10.0 \%$ & $10.1 \%$ & $11.5 \%$ & $11.4 \%$ & $24.6 \%$ & $14.0 \%$ \\
\hline
\end{tabular}

Fuente: Elaboración propia en base a encuestas de hogares

${ }^{27}$ Computamos errores estándar bootstrap de los estadísticos presentados. Las diferencias entre submuestras no siempre son estadísticamente significativas, aunque sí lo son las diferencias entre cualquiera de las submuestras y la muestra general. 
En segundo lugar, la mayor inestabilidad del ingreso en hogares que experimentan cambios demográficos se mantiene, aunque la magnitud de las diferencias se reduce ligeramente, lo cual es razonable en la medida en que una parte del impacto sobre el ingreso es amortiguado por el cambio en la cantidad de miembros del hogar. También encontramos, en general, los valores de volatilidad más altos en los hogares que sufren salidas de miembros, con las mismas excepciones que antes (Brasil y Paraguay). El peso de la movilidad de origen demográfico naturalmente se reduce en todos los países, aunque en magnitudes pequeñas.

Que la movilidad calculada a partir del ingreso total y la calculada a partir del ingreso per cápita sean muy similares, incluso en hogares que registran salidas y entradas de miembros, es un resultado central que amerita un análisis más profundo. De acuerdo a lo explicado en la primera parte de la sección anterior, sabemos que un porcentaje relevante de miembros entrantes y salientes son perceptores de ingresos, por lo tanto no es extraño que el ingreso total y el ingreso per cápita presenten movimientos aproximadamente similares. A su vez, esto es consistente con la hipótesis de que los hogares buscan suavizar el flujo de ingreso per cápita en el tiempo, ya que los movimientos demográficos podrían estar condicionados por este objetivo. Sin embargo, también es frecuente el ingreso o salida de miembros que no perciben ingresos, lo cual naturalmente tiene efectos sobre el ingreso del hogar. Por ejemplo, el ingreso de un nuevo miembro que no percibe ingresos al hogar equivale, ceteris paribus, a una reducción en el ingreso per cápita del mismo. Sin embargo, si esto incentivara a otros miembros a aumentar sus ingresos por alguna vía, el ingreso per cápita podría reducirse en menor medida, mantenerse constante o incluso aumentar. En otras palabras, es posible que existan estrategias al interior del hogar que apunten a compensar el efecto de los movimientos demográficos sobre el ingreso total.

Dado que típicamente los individuos no tienen mucho control sobre el flujo de ingresos no laborales que reciben, es natural pensar que las estrategias a las que nos referimos consisten en entrar o salir del mercado de trabajo, cambiar de un empleo a otro o modificar la cantidad de horas trabajadas. En otras palabras, conjeturamos que el ingreso laboral del hogar puede ajustar ante cambios en la composición del mismo. En la siguiente sección, exploramos a fondo esta hipótesis y proponemos diversos ejercicios de estimación que proveen evidencia que la respalda en uno de los países de la muestra. 


\section{Estrategias del hogar}

En esta sección, proveemos evidencia de la existencia de estrategias como las descriptas anteriormente, para el caso de Argentina. Por lo discutido, una parte relevante de los movimientos demográficos podrían ser de naturaleza endógena, en el sentido de que perseguirían un objetivo vinculado a la satisfacción de necesidades de consumo de miembros del hogar. Esto impide el análisis de estrategias ya que dificulta la determinación de qué conducta puede ser interpretada como una reacción. Sin embargo, es posible conjeturar que algunos movimientos demográficos son exógenos en el sentido de que no responden a necesidades materiales sino a necesidades de otro tipo (emocionales, psicológicas, etcétera) o bien son accidentales.

La llegada de un niño al hogar ${ }^{28}$ podría integrar este último grupo, precisamente por tratarse de un movimiento que no necesariamente es consecuencia de decisiones de los miembros del hogar y que puede responder a necesidades subjetivas no vinculadas a los ingresos. La hipótesis de la que partimos es que la llegada de un niño al hogar provee incentivos a aumentar la oferta de trabajo en los miembros del hogar que están en edad activa. Este ajuste puede darse en el margen extensivo, en el margen intensivo o en ambos, aunque centraremos la discusión sobre el margen extensivo por tratarse de aquel que ofrece resultados más interesantes. Para testear esta hipótesis, realizamos diversos ejercicios de estimación de un modelo donde la variable independiente es una dummy que indica la llegada de un niño al hogar en un período y la variable dependiente es una dummy que indica el ingreso al empleo de algún miembro del hogar previamente no ocupado. Resulta de gran importancia distinguir el género de este último ya que, como veremos, los comportamientos difieren notablemente entre varones y mujeres.

Un panel de dos observaciones plantea ciertas limitaciones para un análisis de este tipo, en particular porque impide aplicar transformaciones que permitan aislar la incidencia de heterogeneidades inobservables entre hogares. Por ese motivo, explotamos más intensamente el esquema rotativo particular de la encuesta argentina y construimos paneles de cuatro observaciones para todo el período 2003-2015 en ese país. En esa base, construimos las variables de interés y también variables de control de uso habitual en la literatura: dummies que indican el nivel educativo del jefe del hogar, edad del jefe del hogar, dummies temporales (por año y por trimestre), dum-

\footnotetext{
${ }^{28}$ Las encuestas de hogares utilizadas no permiten distinguir si estas llegadas son fruto de nacimientos o de otros movimientos. Si bien consideramos la primera posibilidad como mucho más factible, no se trata de un punto relevante para los fines del análisis que aquí emprendemos.
} 
mies regionales y una dummy que indica si el hogar ya contaba con niños antes de la llegada del nuevo integrante.

Asumimos la existencia de efectos fijos invariantes en el tiempo y potencialmente correlacionados con la variable de interés, como es habitual en la literatura. A continuación, procedemos a estimar la regresión de interés mediante tres estimadores de uso habitual: Mínimos Cuadrados Ordinarios (MCO), Efectos Aleatorios (EA) y Efectos Fijos (EF, implementado a través del "within estimator", de uso habitual). Recordemos que la diferencia fundamental radica en que solo el tercero controla por heterogeneidades inobservables mientras que los primeros dos no. Los resultados, para distintas variables dependientes, aparecen resumidos en el Cuadro 7.

\section{Cuadro 7. Estrategias del hogar frente a la llegada de un niño: entradas}

\begin{tabular}{lccc}
\multicolumn{1}{c}{ Variable dependiente } & Media muestral & Estimador & Resultado \\
\hline Dummy al menos una entrada al empleo & & $\mathrm{MCO}$ & $0.037^{* * *}$ \\
Dummy al menos una entrada al empleo & 0.0860 & $\mathrm{EA}$ & $0.035^{* * *}$ \\
Dummy al menos una entrada al empleo & & $\mathrm{EF}$ & 0.009 \\
\hline Dummy al menos un hombre entra al empleo & & $\mathrm{MCO}$ & $0.027^{* * *}$ \\
Dummy al menos un hombre entra al empleo & 0.0403 & $\mathrm{EA}$ & $0.026^{* * *}$ \\
Dummy al menos un hombre entra al empleo & & $\mathrm{EF}$ & $0.013^{* * *}$ \\
\hline Dummy al menos una mujer entra al empleo & & $\mathrm{MCO}$ & $0.016^{* * *}$ \\
Dummy al menos una mujer entra al empleo & 0.0505 & $\mathrm{EA}$ & $0.015^{* * *}$ \\
Dummy al menos una mujer entra al empleo & & $\mathrm{EF}$ & -0.002
\end{tabular}

Fuente: Elaboración propia

El primer panel presenta los resultados de la regresión inicialmente propuesta. La estimación por MCO o por EA arroja un resultado estadísticamente significativo y de tamaño relevante (casi la mitad de la media muestral observada), lo que indica que efectivamente la llegada de un niño al hogar produce un aumento importante en la probabilidad de que un miembro no ocupado del mismo entre al mercado de trabajo. Sin embargo, cuando se aplica el estimador de EF para eliminar el posible efecto de heterogeneidades inobservables, este efecto desaparece por completo.

Si se acepta la hipótesis de exogeneidad de la llegada de un niño al hogar, los resultados obtenidos por EF pueden ser interpretados en términos causales. En el caso contrario, no es posible hablar de causalidad sino de asociación estadística, aun en el estimador de EF. Sin embargo, es importante señalar que el hecho de que el efecto no sea causal no implica que de hecho no exista la compensación explicada entre el movimiento demográfico y el del ingreso total del hogar; sí indica que no es posible atribuir a esta una interpretación de tipo causal. En el análisis sucesivo, man- 
tendremos el supuesto de exogeneidad; si este no fuera considerado adecuado, los resultados pueden ser interpretados en términos de correlación.

Es un hallazgo habitual en la literatura que las decisiones de oferta laboral varían considerablemente entre varones y mujeres, en particular en lo que respecta a la influencia de la cantidad de hijos. Para analizar esta posibilidad en nuestro modelo, los dos paneles inferiores del Cuadro 7 permiten descomponer el efecto anterior en lo que ocurre con varones y mujeres por separado. Los resultados son marcadamente diferentes. Para el caso de miembros de sexo masculino, existe un efecto causal de 1,3 puntos porcentuales (alrededor de un tercio de la media observada) sobre la probabilidad de entrar al mercado de trabajo como consecuencia de la llegada de un niño al hogar. Por el contrario, en los miembros de sexo femenino no se observa un efecto causal, mientras que el efecto no causal obtenido por MCO y EA es mucho más pequeño en tamaño.

Estos resultados indican que la llegada de niños al hogar motiva el ingreso de miembros varones al mercado de trabajo pero no así de miembros mujeres. Este hallazgo es consistente con la abundante literatura que documenta el mayor peso del trabajo de cuidado (o del trabajo no remunerado en el hogar en general) en las mujeres con respecto a los varones ${ }^{29}$. Asimismo, si tenemos en cuenta que existe una brecha de ingresos relevante entre los salarios de hombres y de mujeres, la entrada de varones al empleo es una estrategia racional en relación al objetivo de obtener ingresos que compensen la presencia de un nuevo miembro. De hecho, precisamente por estos motivos, es posible que las mujeres tengan incentivos a retirarse del mercado de trabajo ante la llegada de niños al hogar o bien sufran de restricciones de participación, de modo que el mecanismo operaría en sentido inverso. Para investigar esta posibilidad con mayor profundidad, reproducimos el ejercicio anterior pero invirtiendo el sentido de la variable dependiente: ahora utilizamos una dummy que indica la salida del empleo por parte de un miembro del hogar.

\footnotetext{
${ }^{29}$ Ver, por ejemplo, Esquivel (2009).
} 


\section{Cuadro 8. Estrategias del hogar frente a la llegada de un niño: salidas}

\begin{tabular}{lccc}
\multicolumn{1}{c}{ Variable dependiente } & Media muestral & Estimador & Resultado \\
\hline Dummy al menos una salida del empleo & & MCO & $0.057^{* * *}$ \\
Dummy al menos una salida del empleo & 0.0837 & EA & $0.055^{* * *}$ \\
Dummy al menos una salida del empleo & & EF & $0.019^{* * *}$ \\
\hline Dummy al menos un hombre sale del empleo & & MCO & $0.014^{* * *}$ \\
Dummy al menos un hombre sale del empleo & 0.0370 & EA & $0.013^{* * *}$ \\
Dummy al menos un hombre sale del empleo & & EF & -0.002 \\
\hline Dummy al menos una mujer sale del empleo & & MCO & $0.045^{* * *}$ \\
Dummy al menos una mujer sale del empleo & 0.0509 & EA & $0.044^{* * *}$ \\
Dummy al menos una mujer sale del empleo & & EF & $0.019^{* * *}$
\end{tabular}

Fuente: Elaboración propia

El Cuadro 8 presenta los resultados de estas nuevas estimaciones. A diferencia del ejercicio anterior, aquí sí encontramos evidencia de mayor probabilidad de salida del mercado de trabajo por parte de algún miembro del hogar causada por la llegada de un niño al hogar, luego de controlar por heterogeneidades inobservables. El tamaño de este efecto es de 1,9 puntos porcentuales, casi la cuarta parte de la media observada, de modo que se trata de un aumento considerable. Como se ve, las decisiones de oferta de trabajo al interior del hogar son sensibles a movimientos demográficos en más de un sentido.

Nuevamente el análisis se enriquece cuando se lo divide por género. En varones, el efecto de la llegada de niños sobre la salida de miembros existe y tiene un tamaño relevante cuando se lo estima por MCO o EA, pero desaparece cuando se lo estima por EF. En otras palabras, se trata de otro caso de un efecto no causal. No podemos afirmar que los varones tengan ceteris paribus mayor probabilidad de abandonar sus puestos de trabajo debido a la llegada de niños al hogar, aunque ese comportamiento se observa en muchos casos luego de controlar por otros factores observables. En cambio, para las mujeres, sí se obtiene un efecto causal por EF. De hecho, el tamaño de este efecto es casi idéntico al obtenido en la regresión general, pero dado que la media observada es menor para mujeres, su peso relativo se vuelve mayor (ligeramente por encima de un tercio).

Un ejercicio interesante consiste en repetir los ejercicios anteriores a nivel de individuos en lugar de hogares. En esta nueva especificación, la unidad observada es el individuo, la variable dependiente es nuevamente una dummy de entrada al o salida del empleo y la variable independiente es una dummy que registra la llegada de un niño al hogar del que forma parte ese individuo. El Cuadro 9 presenta los resultados de este ejercicio. 
Cuadro 9. Estrategias del hogar frente a la llegada de un niño: entradas y salidas (individuos)

\begin{tabular}{lcccccc} 
& \multicolumn{3}{c}{ Hombres } & \multicolumn{3}{c}{ Mujeres } \\
\cline { 2 - 7 } Variable dependiente & Media Estimador & Resultado & Media & Estimador & Resultado \\
\hline Dummy entrada al empleo & & MCO & $0.013^{* * *}$ & & MCO & -0.002 \\
Dummy entrada al empleo & 0.0542 & EA & $0.013^{* * *}$ & 0.0643 & EA & -0.002 \\
Dummy entrada al empleo & & EF & $0.014^{* * *}$ & & EF & 0.000 \\
\hline Dummy salida del empleo & \multirow{3}{*}{0 MCO } & 0.004 & & MCO & $0.020^{* * *}$ \\
Dummy salida del empleo & 0.0477 & EA & 0.004 & 0.0634 & EA & $0.020^{* * *}$ \\
Dummy salida del empleo & & EF & 0.001 & & EF & $0.013^{* * *}$
\end{tabular}

Fuente: Elaboración propia

Los resultados son consistentes con los anteriores, e incluso algo más claros. Solo el efecto entrada es estadísticamente significativo en los varones (curiosamente, su tamaño es aproximadamente similar entre estimadores), mientras que solo el efecto salida es estadísticamente significativo en mujeres. Los tamaños de estos efectos se ubican en torno a un cuarto de la media observada, análogamente a lo obtenido en las regresiones realizadas a nivel de hogares.

Las decisiones de participación en el mercado de trabajo reconocen diversos determinantes, además del ingreso monetario. Como señalamos anteriormente, la carga de trabajo no remunerado dentro del hogar afecta considerablemente a la propensión de un individuo a trabajar de manera remunerada fuera del mismo. Por otra parte, podríamos recurrir al capital humano como un proxy del ingreso intertemporal o riqueza del hogar, que podrían ser determinantes incluso más fuertes que el ingreso corriente. Diversas hipótesis no necesariamente excluyentes entre sí pueden ser planteadas al respecto. Individuos con mayor capital humano acumulado pueden tener mayores incentivos a aceptar puestos de trabajo a un salario dado, por ejemplo para evitar que ese capital humano adquirido se deprecie, o bien porque este les permite aspirar a salarios mayores en el futuro. También es posible que individuos con mayor capital humano deriven utilidad de realizar tareas remuneradas fuera del hogar, lo que aumentaría sus incentivos. A su vez, hogares intertemporalmente más ricos tendrían mayor facilidad para tercerizar el trabajo no remunerado dentro del hogar. Sin embargo, también es razonable pensar que los individuos que viven en hogares intertemporalmente más pobres son los que mayores incentivos tendrían a aceptar un puesto de trabajo debido a la mayor volatilidad en su flujo de ingresos ${ }^{30}$ y a las mayores limitaciones para acceder al mercado de crédito. Con el fin de explorar estas hipótesis y comprender con mayor detalle la naturaleza del comportamiento que observamos,

${ }^{30}$ Documentada en el segundo capítulo. 
dividimos las estimaciones por nivel educativo y presentamos los resultados en el Cuadro 10.

Cuadro 10. Estrategias del hogar frente a la llegada de un niño, por nivel educativo

\begin{tabular}{clcc}
$\begin{array}{c}\text { Unidad } \\
\text { observacional }\end{array}$ & \multicolumn{1}{c}{ Variable dependiente } & $\begin{array}{c}\text { Nivel educativo } \\
\text { bajo }\end{array}$ & $\begin{array}{c}\text { Nivel educativo } \\
\text { alto }\end{array}$ \\
\hline Hogares & Dummy al menos una entrada al empleo & $0.021^{* * *}$ & -0.021 \\
Hogares & Dummy al menos una salida del empleo & $0.016^{* *}$ & $0.040^{* * *}$ \\
\hline Individuos & Dummy hombre entra al empleo & $0.014^{* * *}$ & 0.003 \\
Individuos & Dummy hombre sale del empleo & 0.006 & $-0.020^{* *}$ \\
\hline Individuos & Dummy mujer entra al empleo & -0.003 & 0.008 \\
Individuos & Dummy mujer sale del empleo & $0.013^{* * *}$ & $0.018^{*}$
\end{tabular}

Fuente: Elaboración propia

A nivel de hogares, el efecto entrada solo aparece en los hogares con menor nivel educativo, lo que es consistente con la idea de que estos hogares son los que experimentan una mayor necesidad de compensar la llegada del nuevo miembro con mayores ingresos. En cambio, el efecto salida se observa en ambos extremos de la distribución de capital humano, aunque su tamaño es sensiblemente mayor en los hogares de nivel educativo elevado, lo que podría indicar que estos hogares privilegian el cuidado de sus hijos o el trabajo dentro del hogar en mayor medida que los hogares donde el nivel de capital humano acumulado es bajo.

Las regresiones realizadas a nivel individual, y separadas por género, apuntan en el mismo sentido. Solo los varones de menor nivel educativo experimentan un aumento en su probabilidad de entrar a un empleo como consecuencia de la llegada de un niño, aunque los de nivel educativo alto sí exhiben una reducción en su tasa de salida. En cambio, en las mujeres nuevamente podemos ver un efecto salida en ambas franjas educativas, con tamaños aproximadamente similares, aunque con menor variabilidad entre las de menor nivel educativo. Que el efecto salida sea relativamente independiente del nivel de capital humano del hogar puede sugerir que cierta cuota de presencia femenina en el cuidado de niños pequeños es habitual, factiblemente debido a normas sociales generalizadas ${ }^{31}$. Sin embargo, estas conclusiones deben ser tomadas con cautela ya que no siempre es posible afirmar que la diferencia entre los coeficientes por nivel educativo sea estadísticamente diferente de cero con 95\% de confianza.

\footnotetext{
${ }^{31}$ Para una discusión exhaustiva sobre el vínculo entre participación laboral femenina y fertilidad, ver Busso y Romero Fonseca (2015).
} 
Tomados de conjunto, los ejercicios de estimación realizados indican que la llegada de niños al hogar lleva al ingreso de varones y a la salida de mujeres del mercado de trabajo. Las magnitudes de estos efectos no son muy distintas en términos absolutos ni en términos relativos, de modo que es posible que la cantidad de miembros ocupados a nivel general no se altere sensiblemente. Sin embargo, al nivel del hogar, sí es de esperar que el efecto sobre el ingreso laboral sea considerable, habida cuenta del diferencial existente entre los salarios de varones y de mujeres. De este modo, la reducción del ingreso per cápita experimentada por el ingreso de un niño se vería compensada (al menos parcialmente) por un aumento en el ingreso laboral del hogar, reduciendo así la inestabilidad de ingresos a la que el hogar se encuentra expuesto.

Para transmitir una idea de la relevancia de estas decisiones de participación laboral en la determinación del nivel de inestabilidad de ingresos observado, podemos recurrir nuevamente a la estrategia de microsimulación. En la submuestra de hogares que experimentan la llegada de un niño, imputamos el ingreso que el hogar recibiría si ese movimiento demográfico no generara cambios en las decisiones de participación laboral de otros miembros del hogar. Resulta de particular interés indagar lo que ocurre en hogares donde la llegada del nuevo miembro coincide con una reducción en el ingreso total del hogar, para los que encontramos efectos relevantes. El Cuadro 11 presenta los resultados de estos ejercicios.

Cuadro 11. Estrategias del hogar frente a la llegada de un niño, por nivel educativo

\begin{tabular}{lcc} 
& $\begin{array}{c}\text { Hogares donde } \\
\text { entran niños }\end{array}$ & $\begin{array}{c}\text { Solo aquellos donde } \\
\text { cae el ingreso }\end{array}$ \\
\hline & Movilidad observada \\
\hline Ingreso total & 0.48 & 0.43 \\
Ingreso per cápita & 0.51 & 0.72 \\
\hline \multicolumn{3}{c}{ Movilidad simulada: no hay entradas } \\
\hline Ingreso total & 0.46 & 0.46 \\
Ingreso per cápita & 0.51 & 0.75 \\
\hline \multicolumn{4}{c}{ Movilidad simulada: no hay salidas } \\
\hline Ingreso total & 0.47 & 0.36 \\
Ingreso per cápita & 0.47 & 0.61
\end{tabular}

Fuente: Elaboración propia

El primer panel muestra que la movilidad observada en el ingreso per cápita es particularmente elevada en hogares que experimentan la llegada de un niño y una caída en el ingreso total al mismo tiempo. Estos hogares se encuentran en una situación particularmente vulnerable en la medida en que sus necesidades aumentan a la 
vez que sus recursos se reducen. En el segundo panel, simulamos la no ocurrencia de entradas en miembros varones. El resultado de este ejercicio es un aumento pequeño pero relevante en la movilidad de ingresos en los hogares que experimentan reducciones (aunque a nivel general de la submuestra la movilidad se mantiene constante). Por otro lado, el segundo panel muestra los resultados de simular la no ocurrencia de salidas en miembros mujeres. Allí observamos una importante reducción en la movilidad, tanto para el ingreso total como para el ingreso per cápita, especialmente en los hogares que sufren reducciones de ingreso.

Es claro que las decisiones de participación laboral son un determinante fundamental de la movilidad de ingresos observada, donde las estrategias de los hogares cumplen un papel relevante. Las llegadas de niños disparan tanto estrategias que compensan su impacto en el ingreso (entrada de varones adultos al mercado de trabajo) como otras que lo amplifican (salida de mujeres adultas del mercado de trabajo). Resulta claro que existe cierto grado de cancelación entre efectos aunque la similitud entre la movilidad computada sobre el ingreso total y la computada sobre el ingreso per cápita a nivel general de la submuestra sugiere que el efecto neto podría ser ligeramente compensador (algo que también es consistente con el hecho de que los salarios de varones sean en promedio superiores a los de mujeres).

\section{Conclusiones}

Este trabajo analiza el tamaño y las características de los movimientos demográficos en los hogares de siete países latinoamericanos para el período 2003-2015. Como explica el grueso de la literatura especializada, estos movimientos pueden ser de gran importancia en la determinación del sendero temporal de ingresos de los hogares. De acuerdo a la evidencia presentada aquí, es posible afirmar que los cambios de tamaño y composición de los hogares latinoamericanos son de magnitud y frecuencia pequeña pero relevante. Ejercicios de microsimulación indican que su contribución a la inestabilidad observada en los ingresos de los hogares no es despreciable.

La llegada de niños al hogar es uno de los movimientos de mayor frecuencia y sus efectos sobre el ingreso per cápita del hogar son claramente negativos. En este trabajo proveemos evidencia de la existencia de estrategias al interior del hogar con diversos fines, entre los que se encuentra la compensación de este efecto, de modo tal de reducir la volatilidad en el flujo de ingresos. En particular, nuestras estimaciones para Argentina indican que la llegada de niños tiene un efecto positivo tanto sobre la entrada de varones al mercado de trabajo como sobre la salida de mujeres del mismo. 
Estos efectos pueden interpretarse tanto en términos de oferta laboral como de distribución del trabajo de cuidado al interior del hogar. Pero, fundamentalmente, pueden tener un efecto de reducción de la volatilidad del ingreso del hogar. De este modo, encontramos evidencia de un determinante clave de la movilidad de ingresos documentada y analizada en la literatura.

\section{Bibliografía}

Alves, N., \& Martins, C. (2014). Household income mobility in the European Union and in Portugal: an analysis of labor market and demographic events. Economic Bulletin and Financial Stability Report Articles, 53-63.

Bartels, C., \& Bonke, T. (2013). Can households and welfare states mitigate rising earnings instability? The review of income and wealth 59 (2), 250-282.

Beccaria, L., Maurizio, R., Trombetta, M., \& Vazquez, G. (2015). Income instability during a period of economic growth and improving social and labor conditions: Latin America in the 2000s. 2015 RIDGE December Forum. La Plata.

Busso, M., \& Romero Fonseca, D. (2015). Determinants of female labor force participation. En L. Gasparini, \& M. Marchionni, Bridging gender gaps? The rise and deceleration of female labor force participation in Latin America. La Plata: CEDLASUniversidad Nacional de La Plata.

Chiappori, P.-A. (1992). Collective labor supply and welfare. Journal of Political Economy 100 (3), 437-467.

Duncan, G., \& Morgan, J. (1981). Persistence and change in economic status and the role of changing family composition. En M. Hill, D. Hill, \& J. Morgan, Five thousand American families - Patterns of economic progress (págs. 1-45). Ann Arbor: Institute for Social Research.

Esquivel, V. (2009). Uso del tiempo en la Ciudad de Buenos Aires. Los Polvorines: Universidad Nacional de General Sarmiento.

Fields, G., \& Ok, E. (1999). Measuring Movement of Incomes. Economica 66, 455-471.

Fritzell, J. (1990). The dynamics of income distribution: Economic mobility in Sweden in comparison with the United States. Social Science Research 19, 17-46.

Gittleman, M., \& Joyce, M. (1999). Have familiy income mobility patterns changed? Demography 36 (3), 299-314.

Jarvis, S., \& Jenkins, S. (1999). Marital splits and income changes: evidences for Britain. Population Studies 53 (2), 237-254. 